\title{
Equipment and methods for measuring reflectance of concentrating solar reflector materials
}

\author{
Aránzazu Fernández-García ${ }^{\mathrm{a}, 1}$, Florian Sutter ${ }^{\mathrm{b}}$, Lucía Martínez-Arcos ${ }^{\mathrm{a}}$, Christopher \\ Sansom $^{\mathrm{c}}$, Fabian Wolfertstetter ${ }^{\mathrm{b}}$, Christine Delord $^{\mathrm{d}}$, \\ ${ }^{a}$ CIEMAT-PSA. Senés Road, km. 4.5 B.O. Box 22, E04250, Tabernas, Almería, \\ Spain. \\ ${ }^{\mathrm{b}}$ DLR German Aerospace Center, Institute of Solar Research, PSA, Senés Road, \\ Km. 4.5, P.O. Box 44, E04200, Tabernas, Almería, Spain. \\ ${ }^{c}$ Global CSP Laboratory, Cranfield University, Bedfordshire MK43 0AL, \\ United Kingdom. \\ ${ }^{\mathrm{d}}$ CEA LITEN, National Institute of Solar Energy INES, 73377 Le Bourget-du- \\ Lac, France.
}

\begin{abstract}
The proper optical characterization of solar reflector materials is a challenging task. Although several commercial instruments exist to measure reflectance, they have been developed for other applications and often do not meet all the specific requirements demanded by the solar thermal industry. In particular, the characterization of solar reflectors involve the complete solar spectral wavelength range, an incidence angle range from near normal to $70^{\circ}$ and most importantly a very narrow acceptance angle range from near specular to $20 \mathrm{mrad}$. The accurate measurement of reflectance as a function of all the previously mentioned parameters has not been commercially implemented. This paper reviews the different alternatives to measure reflector materials, describes reflectance models used to approximate the missing information and presents current research work on prototype reflectometers to fill the gap.
\end{abstract}

Keywords: solar reflector, concentrating solar technology, reflectance measurement, spectrophotometer, reflectometer

\footnotetext{
${ }^{1}$ Corresponding author: Aránzazu Fernández-García. E-mail address: arantxa.fernandez@psa.es. Phone:+34 950387800. Fax:+34 950365015
} 


\section{Nomenclature}

Abbreviations

$(\mathrm{SR})^{2} \quad$ Space Resolved Specular Reflectometer

ARTA Absolute Reflectance and Transmittance Analyzer

BRDF bidirectional reflectance distribution function

CMOS complementary metal-oxide-semiconductor

CPV concentrating photovoltaics

CSP concentrating solar power

D\&S Devices \& Services

DNI direct normal irradiance

EMA Equivalent Model Algorithm

IEA International Energy Agency

ISE Institute for Solar Energy Systems

LED light-emitting diodes

MIRA Mirror Reflectance Function Analyzer

MWR Multiple Wavelength Reflectometer

NIR near infrared

OPAC Optical \& Aging Characterization

$\mathrm{Pab} \quad \mathrm{Pab}$ advanced technologies Ltd (pab)

PE Perkin Elmer

PMT photomultiplier

PSA Plataforma Solar de Almería

S2R Spectral Specular Reflectometer

SMQ Solar Mirror Qualification

SMS Schmitt Measurement Systems

STE solar thermal electricity 
TraCS Tracking Cleanliness Sensor

URA universal reflectance accessory

UV ultraviolet

Vis visible

VLABS Very-low-angle beam spread

Greek symbols

$\begin{array}{ll}\sigma & \text { standard deviation } \\ \sigma_{\varphi} & \text { equivalent roughness } \\ \alpha & \text { absorptance } \\ \beta & \text { incident angle from the laser beam to the reference mirror (University of } \\ & \text { Malaysia set-up) } \\ \Delta \rho & \text { reflectance difference } \\ \theta & \text { reflected angle from the reference mirror to the photo detector } \\ \theta_{i} & \text { (University of Malaysia set-up) } \\ \lambda & \text { direction of the incident radiation } \\ \xi & \text { wavelength } \\ \chi & \text { cleanliness } \\ & \text { reflectance or amplitude of a reflectance Gaussian distribution } \\ & \text { transmittance } \\ & \text { acceptance angle } \\ & \text { angle }\end{array}$

Roman symbols

a major half axis of the ellipse

$A_{1}, A_{2} \quad$ amplitude coefficients 


$\begin{array}{ll}a_{1}, a_{2}, a_{3} & \text { amplitude coefficients } \\ b & \text { offset between reflection terms } \\ c & \text { minor half axis of the ellipse } \\ C_{\text {clean }} & \text { calibration constant for TraCS system } \\ f & \text { focal length } \\ F 1, F 2 & \text { focal points of the ellipse } \\ K & \text { relative weight of two Gaussians } \\ t & \text { time } \\ T_{\text {clean }} & \text { time span } \\ T_{s} & \text { surface temperature }\end{array}$

\section{Subscripts}

$\begin{array}{ll}h & \text { hemispherical } \\ S & \text { solar } \\ \lambda & \text { spectral }\end{array}$

\section{Introduction}

The development of renewable energy has increased over the past few years due to the high environmental cost of fossil fuels and our great dependence on them [1]. Solar energy is considered one of the most promising alternative sources of energy for avoiding the dependency on fossil energy resources [2]. In the last 30 years, $26 \%$ of the global research effort has been related to the use of solar energy [3]. Among solar technologies, solar thermal electricity (STE) from concentrating solar power (CSP) plants is set to play a decisive role in the renewable energy mix [4]. The two main systems of concentrating solar collectors, line-focusing (parabolic-trough collectors and Fresnel collectors) and point-focusing (solar towers, parabolic dishes and solar furnaces), have in common that the sunlight is focused onto a receiver by mirrored reflectors to increase the enthalpy of the heat transfer fluid flowing inside that receiver. Parabolic-trough technology is the most proven large-scale solar thermal power technology that is available today [4]-[6]. 
The reflectance of the concentrating reflectors (interchangeably called mirrors) has a direct impact on the overall efficiency of these solar thermal systems [7].Its accurate assessment requires appropriate testing methods and measurement tools. This makes the measurement of the solar-weighted specular reflectance (which is the parameter that correctly quantifies the reflective quality of a solar reflector [8]) an important concern for solar reflector evaluation. However, currently there is no commercial instrument available to directly measure this optical parameter effectively [9], accomplishing all of the features required by a hypothetical ideal instrument. These requirements have been specified in [10] and include -among others- the following points:

- The measurement over the complete solar spectral wavelength range, but at least between $\lambda=280$ and $\lambda=2500 \mathrm{~nm}$. The remaining contribution to the direct irradiance in the spectral range of $2500-4000 \mathrm{~nm}$ can be calculated from the standard spectrum [11] to be around $2.5 \%$.

- Precise, selectable acceptance apertures or a range of acceptance angles appropriate to measure the specular reflectance as a function of $\varphi$.

- Measurement at various incidence angles ranging from near normal to at least $50^{\circ}$ or an innovative approach to obtain the specular reflectance as a function of $\theta$.

- Adjustment options to account for different mirror thicknesses and surface curvatures.

- Measurement spot size as large as possible.

- Non-contact measurement.

- High precision and repeatability.

- No influence by external stray light.

Reflectance measurements serve to qualify reflectors in mint condition, to evaluate their cleanliness due to soiling, or to quantify their vulnerability to ageing effects during exposure to the environment.

An evaluation formula presented by Pettit [12] has been widely used in the past. Although this approximation is appropriate for reflectors with high specularity in the whole solar spectrum, new research has demonstrated that for some innovative reflector materials a valid and adequate procedure is still missing. Research work of the last few years regarding the reflectance measurement procedure [13]-[15] and instruments [16]-[18] to 
assess solar reflector materials has advanced significantly.

It deserves to be mentioned the activities ongoing in several working groups during the last decade to stablish a proper protocol to measure the reflectance of concentrating solar reflector materials. A group of experts in the field of optical characterization of solar reflectors has been working since 2009 as members of the SolarPACES Organization (which belongs to the International Energy Agency, IEA) to create a reflectance measurement guideline [9], [15]. Several versions of the guideline have been already published [10]. Under the framework of the Spanish standardization body AENOR, the sub-committee AEN/CTN 206/SC "Thermoelectric solar energy systems" is working on topics related to the concentrating solar thermal power plants since 2010 [19]-[21]. Several standards have been published or are in preparation, including one for the reflectors characterization and durability assessment. At international level, within the IEC TC 117 committee "Solar thermal electric plants" created in 2012, a project team is also focus on this subject [19]-[21]. The three working groups are linked among them to avoid duplicating the efforts and obtaining contradictory results.

Besides the characterization of reflector materials, research activities on the fluctuating reflectance losses due to soiling, i.e. the accumulation of dust and dirt on mirror surfaces when exposed to the environment, have increased significantly [22]. As soiling is quantified by monitoring the reflectance of mirrors over time, the here presented methods play an important role in this field of research. Applications of soiling research can be found in resource assessment studies and the optimization of cleaning cycles in running power plants. As CSP projects are located more closely to dusty environments like sand deserts [23], growing attention is given to the issue of soiling and thus reflectance measurement methods.

This paper presents a review of the techniques employed to assess the optical properties of solar reflectors, as a contribution to define the correct characterization protocol. In the first part, the models developed to calculate the representative optical parameters related to reflectance (both based on theoretical statements or experimental parameters) are presented. Secondly, commercial instruments used to optically characterize solar reflectors in laboratory and outdoors are reviewed. Finally, the known prototypes currently under development are described. Glossmeters use the specular reflection as a photometric value (the radiometric reflectance value weighted with the visual sensitivity function of the human eye) for the evaluation of gloss in relation to a black polished 
reference at defined incidence angles. As their capabilities are not suitable for evaluating the specular reflectance of solar mirror materials, they are not included in this work. Nomenclature and reflectance definitions used in this paper are in accordance with existing standards [25], [26], with some slight improvements which will be fed into the standardization committees.

\section{Reflectance models}

Measuring the solar-weighted specular reflectance of a mirror requires instruments capable of measuring cumulative specular reflectance values over the whole solar spectrum. While some laboratory devices have been developed for this objective, no portable equipment to be used in the solar fields is available with the appropriate features. Over the years, models have been proposed to approach the solar-weighted specular reflectance by a combination of measurements with portable and laboratory devices. This section includes the most notable of such models, as reported in the literature.

\subsection{Solar-weighted specular reflectance approach, by R.B. Pettit}

In 1982, R.B. Pettit proposed a reflectance model in case the solar-weighted specular reflectance cannot be measured with a laboratory instrument [12]. Pettit's model is based on the equation (1):

$$
\rho_{s, \varphi}\left(\left[\lambda_{a}, \lambda_{b}\right], \theta_{i}, \varphi, T_{s}\right)=\rho_{s, h}\left(\left[\lambda_{a}, \lambda_{b}\right], \theta_{i}, h, T_{s}\right) \cdot \frac{\rho_{\lambda, \varphi}\left(\lambda_{c}, \theta_{i}, \varphi, T_{s}\right)}{\rho_{\lambda, \varphi}\left(\lambda_{c}, \theta_{i}, h, T_{s}\right)}
$$

where $\rho$ is the reflectance, the subscript $s$ means solar weighted, the subscript $\varphi$ means specular, $\lambda$ is the wavelength (measured from $\lambda_{a}$ to $\lambda_{b}$, inclusive), $\theta_{i}$ is the incidence angle, $\varphi$ is the acceptance angle (defined as the angle between the specular direction and the direction of the admissible dispersion on the surface for the specific application as well as the angle associated to the detector aperture of the measurement instrument), $T_{s}$ is the surface temperature, $\rho_{s, \varphi}\left(\left[\lambda_{a}, \lambda_{b}\right], \theta_{i}, \varphi, T_{s}\right)$ is the solar-weighted specular reflectance, $\rho_{s, h}\left(\left[\lambda_{a}, \lambda_{b}\right], \theta_{i}, h, T_{s}\right)$ is the solar-weighted hemispherical reflectance (which is indicated in the nomenclature by substituting the $\varphi$ angle by the symbol $h), \rho_{\lambda, \varphi}\left(\lambda_{c}, \theta_{i}, \varphi, T_{s}\right)$ is the 
monochromatic specular reflectance at a certain wavelength, $\lambda_{c}$ (with $\lambda_{c} \in\left[\lambda_{a}, \lambda_{b}\right]$ ), and $\rho_{\lambda, h}\left(\lambda_{c}, \theta_{i}, h, T_{s}\right)$ is the monochromatic hemispherical reflectance at the same $\lambda_{c}$ (see Figure $1)$. The value of $\rho_{s, h}\left(\left[\lambda_{a}, \lambda_{b}\right], \theta_{i}, h, T_{s}\right)$ is calculated from the measurement of the hemispherical reflectance spectrum at a number of wavelengths $\lambda$ regularly distributed over the whole solar spectrum (typically measured with a laboratory spectrophotometer). $\rho_{s, h}\left(\left[\lambda_{a}, \lambda_{b}\right], \theta_{i}, h, T_{s}\right)$ is then derived according to the solar weighting calculation described in [27] or [28], and typically using the solar spectrum from [11]. The quantity $\rho_{\lambda, \varphi}\left(\lambda_{c}, \theta_{i}, \varphi, T_{s}\right)$ is typically measured with a portable reflectometer, at a unique $\lambda_{c}$. The quantity $\rho_{\lambda, h}\left(\lambda_{c}, \theta_{i}, h, T_{s}\right)$ is also taken from the hemispherical reflectance spectrum, at the same $\lambda_{c}$ as that used for the measurement of $\rho_{\lambda, \varphi}\left(\lambda_{c}, \theta_{i}, \varphi, T_{s}\right)$. In consideration of the scope of this work, the influence of $T_{s}$ is omitted.

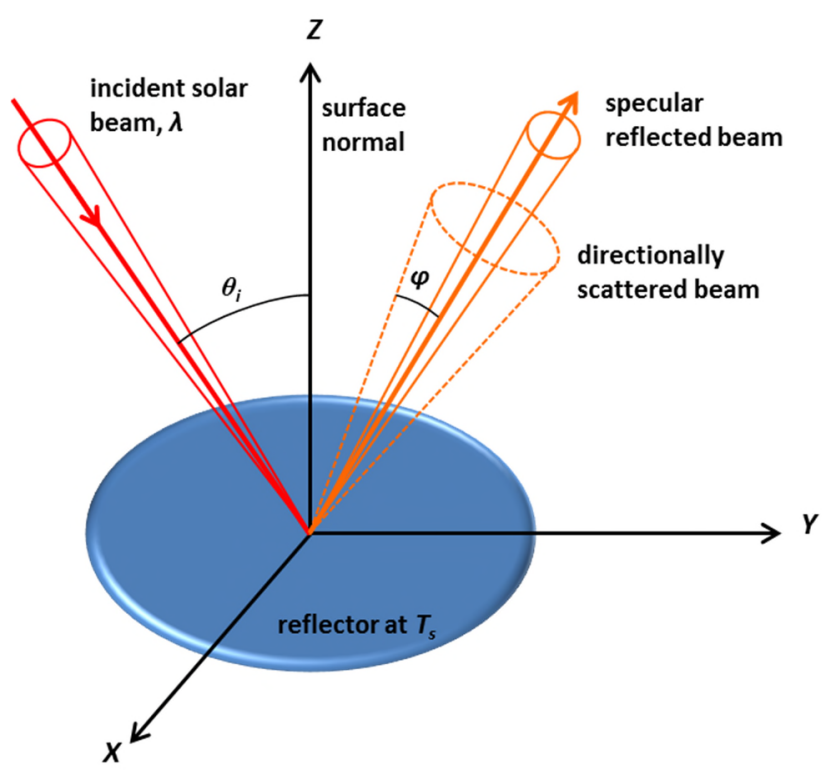

Figure 1. Scheme of the solar specular reflectance.

In this model, the solar-weighted specular reflectance is obtained from the solar-weighted hemispherical reflectance (which can be accurately measured with commercial instruments) by applying the ratio of specular to hemispherical reflectance at a certain $\lambda_{c}$, which provides the relationship between both magnitudes. Hence, the Pettit approach is based on two assumptions:

- Firstly, it is assumed that the ratio between specular and hemispherical reflectance is wavelength independent. 
- As the first assumption is known to be false, especially in the presence of dust accumulation or surface degradation, the second assumption is that this approximation leads to a small error when compared to the reflectance losses.

Because of these two assumptions, this approach is only valid for highly specular reflectors. For example, this model can be used for high quality silvered-glass reflectors in new condition, that is, without any soiling or degradation (corrosion spots, scratches, delamination, stains, etc). To have confidence in using this model one can check its validity for a certain mirror by comparing hemispherical and specular reflectance results for several $\lambda$ and $\varphi$.

\subsection{Spectral specular reflectance model with one Gaussian, by R.B. Pettit}

Another approach proposed by Pettit in 1977 [29], is to assume that a mirror would scatter the beam around the specular direction according to a normal distribution of the form in equation (2):

$$
\rho_{\lambda, \varphi}\left(\lambda, \theta_{i}, \varphi\right) \propto \rho \exp \left[\frac{-\varphi^{2}}{2 \sigma^{2}}\right]
$$

where $\rho$ in this case means the amplitude of the reflectance Gaussian distribution and $\sigma$ is the standard deviation of the distribution. In terms of roughness, this approach is based on the assumption that the average height and slope distributions can be characterized by a normal distribution.

This model was validated on the silvered polymer mirror 3M 5400 Scotchcal at $\lambda=500 \mathrm{~nm}$ and for $\varphi$ from 1 to $13 \mathrm{mrad}$. The instrument used for the experimental measurements was a bi-directional reflectometer which determines the absolute specular reflectance of flat mirrors at discrete $\lambda$ over the range $400-900 \mathrm{~nm}$. The curve resulting from the model fitted the experimental data with parameters $\rho(500 \mathrm{~nm})=0.86$ and $\sigma=1.9 \mathrm{mrad}$. 


\subsection{Spectral specular reflectance model with two Gaussians, by R.B. Pettit}

While the previously explained approach of a single Gaussian perfectly describes some of the materials examined, it is not sufficient for all materials. A more generalist approach was developed by Pettit, assuming that any scattering mechanism might be described by a Gaussian law, and that most of the materials are characterized by a narrow central beam and a broad background reflectance curve [29].

This second approach of Pettit assumes that the sum of two Gaussians, a first one characteristic of the sharp central beam and a second one characteristic of the background reflectance, can describe any reflector material or soiling condition. For example, a laminated plastic film can be described by a normal distribution characteristic of the intrinsic properties of the metallized plastic film, plus a second distribution characteristic of the bounding interface. The reflectance profile can then be defined as in equation (3):

$$
\rho_{\lambda, \varphi}\left(\lambda, \theta_{i}, \varphi\right) \propto \rho_{1} \exp \left[\frac{-\varphi^{2}}{2 \sigma_{1}^{2}}\right]+\rho_{2} \exp \left[\frac{-\varphi^{2}}{2{\sigma_{2}}^{2}}\right]
$$

With the constraint that $\rho_{\lambda, h}\left(\lambda, \theta_{i}, h\right)=\rho_{1}+\rho_{2}$, and with $\sigma_{1}$ and $\sigma_{2}$ characteristic of the highly specular and intense beam and of the broader beam of lower intensity, respectively. For example, experimental data of a roll-polished anodized aluminum sheet at $\lambda=505 \mathrm{~nm}$ (also measured with the bi-directional reflectometer mentioned in the previous section) was well described by a first normal distribution, with $\rho_{l}=0.56 \sigma_{l}=0.42 \mathrm{mrad}$, and by a second distribution characteristic of the scattering due to the rolling marks, with $\rho_{2}=0.33$ and $\sigma_{2}=10.1 \mathrm{mrad}$.

Instead of explaining the solar reflected beam as the sum of two reflected beams, it can be also described as the $\rho_{\lambda, h}\left(\lambda, \theta_{i}, h\right)$ minus the light scattered outside of the angle $\varphi$. This approach was also proposed by R.B. Pettit et al. in 1983 [30]. The light scattered outside the angle $\varphi$ is represented as two Gaussians dependent on the half-width $\sigma$. Similarly with the previous approach, one of the Gaussians is of high intensity and highly specular (low $\sigma$ ), while the second Gaussian is of low intensity and broad dispersion (high $\sigma$ ). The 
quantity $\rho_{\lambda, \varphi}\left(\lambda, \theta_{i}, \varphi\right)$ is therefore described by equation (4) where $K$ is representative of the relative weight of the two Gaussians.

$$
\rho_{\lambda, \varphi}\left(\lambda, \theta_{i}, \varphi\right)=\rho_{\lambda, h}\left(\lambda, \theta_{i}, \mathrm{~h}\right)\left\{1-K \exp \left[\frac{-\left(\frac{\varphi}{2}\right)^{2}}{2 \sigma_{1}{ }^{2}}\right]-(1-K) \exp \left[\frac{-\left(\frac{\varphi}{2}\right)^{2}}{2 \sigma_{2}{ }^{2}}\right]\right\}
$$

This approach was applied to a polymer based mirror, experimentally characterized with the portable reflectometer 15R from Devices \& Services (D\&S) (see section 3.2.1) by Gee et al. in 2010 [8]. According to the results obtained, a very good approximation of the experimental data was achieved, with $K=0.97$. The first exponential is representative of the peak of high intensity and high specularity, with $\sigma=1.7 \mathrm{mrad}$, and the second exponential is representative of the broader peak, with $\sigma=20.0 \mathrm{mrad}$. When experimental data were fitted by using a unique Gaussian approximation, a poorer fit was achieved, with $\sigma=2.0 \mathrm{mrad}$.

\subsection{Spectral specular reflectance model with two Gaussians, by Heimsath et al.}

In 2010, new experiments with a goniophotometric setup were carried out at the Fraunhofer Institute for Solar Energy Systems (ISE) in Germany and a novel approach was proposed by Heimsath et al. [31]. In their approach, there is a distinction between front surface mirrors, such as aluminum or polymer based mirrors, and second surface mirrors, such as glass. Front surface mirrors present a higher scattering of the reflected beam compared to glass mirrors.

As in [29], they distinguish two Gaussians in the specular reflectance of front surfaces at small and moderate scattering angles. They additionally note an exponential distribution for large scattering angles. The proposed equation is therefore as in equation (5):

$$
\rho_{\lambda, \varphi}\left(\lambda, \theta_{i}, \varphi\right)=a_{1} \exp \left(\frac{-\varphi^{2}}{2 \sigma_{1}^{2}}\right)+a_{2} \exp \left(\frac{-\varphi^{2}}{2 \sigma_{2}^{2}}\right)+a_{3} \exp \left(\frac{-|\varphi|}{\chi}\right)
$$


where $a_{1}, a_{2}$ and $a_{3}$ are the amplitudes of the Gaussian terms, $\sigma_{1}$ and $\sigma_{2}$ are the standard deviations of the Gaussian terms, and $\chi$ a parameter for the observed exponential decrease of the wide scattering angle.

The model function for glass mirrors includes three terms, the first one for the glass surface reflectance to the air, a second one for the reflecting layer, and a third term for the second reflection due to absorption in the glass layer. Further reflections are neglected. Each reflection is represented by a Gaussian function. The three reflections are separated by an offset depending on the glass thickness and on the incidence angle (see equation 6).

$$
\rho_{\lambda, \varphi}\left(\lambda, \theta_{i}, \varphi\right)=a_{1} \exp \left(\frac{-\varphi^{2}}{2 \sigma^{2}}\right)+a_{2} \exp \left(\frac{-(\varphi+b)^{2}}{2 \sigma^{2}}\right)+a_{3} \exp \left(\frac{-(\varphi+2 b)^{2}}{2 \sigma^{2}}\right)
$$

with $b$ being the offset between reflection terms. Coefficients of equations (5) and (6) were obtained with the Fraunhofer ISE experimental set up (see section 4.6) for several reflector types.

\subsection{Off-normal solar reflectance model, by Montecchi}

This model was proposed by M. Montecchi in 2013 [17]. It is a combination of a model named the Equivalent Model Algorithm (EMA), and the well-known relation called Total Integrated Scatter (TIS).

The EMA model was initially developed for architectural glazing, and is not suitable in its most basic form for modelling the reflectance of solar mirrors. It is based on refractive index calculations and reflector layers analysis, which perfectly reproduces the experimental measurements at near-normal incidence and predicts off-normal incidence features with good accuracy. By definition, the value at $0^{\circ}$ is equal to the measurement and value at $90^{\circ}$, and is equal to $100 \%$.

The TIS relationship obtained by Beckman and Spizzichino in 1963 [32] was slightly rearranged by Montecchi to consider the $\varphi$ specific to the specular component. The TIS relationship is the expression of the ratio between the specular and the hemispherical 
components as a function of $\lambda, \theta_{i}$ and the equivalent-roughness, $\sigma_{\varphi}$, as indicated in equation (7).

$$
\frac{\rho_{\lambda, \varphi}\left(\lambda, \theta_{i}, \varphi\right)}{\rho_{\lambda, h}\left(\lambda, \theta_{i}, \mathrm{~h}\right)}=\exp \left[-\left(\frac{4 \pi \sigma_{\varphi} \cos \theta}{\lambda}\right)^{2}\right]
$$

The quantity $\sigma_{\varphi}$ is a heuristic parameter and is not a physical characteristic of the surface. From experimental data points of equivalent roughness on laminated specimens, the best equation to express this parameter is equation (8).

$$
\sigma_{\varphi}=A_{1} \exp \left[-\left(\frac{\varphi}{\sigma_{1}}\right)^{2}\right]+A_{2} \exp \left[-\left(\frac{\varphi}{\sigma_{2}}\right)^{2}\right]
$$

where $A_{1}$ and $A_{2}$ are the amplitude coefficients. TIS was measured with the ENEA experimental setup to obtain coefficients $A$ and $\sigma$ (see section 4.2).

\subsection{Summary of reflectance models}

A summary of the reflectance models described in this section is presented in Table 1 .

\section{Table 1}

Main characteristics of the reflectance models.

\begin{tabular}{|c|c|c|c|c|c|}
\hline Authors & $\begin{array}{c}\text { Reflectance } \\
\text { type }\end{array}$ & Year & Model principle & $\begin{array}{c}\text { Materials suited to the } \\
\text { model }\end{array}$ & $\begin{array}{c}\text { Refe- } \\
\text { rences }\end{array}$ \\
\hline
\end{tabular}




\begin{tabular}{|c|c|c|c|c|c|}
\hline R.B. Pettit & $\begin{array}{l}\text { Solar- } \\
\text { weighted } \\
\text { specular } \\
\text { reflectance }\end{array}$ & 1982 & $\begin{array}{c}\text { The solar-weighted specular } \\
\text { reflectance is obtained from the } \\
\text { solar-weighted hemispherical } \\
\text { reflectance by applying the ratio of } \\
\text { specular to hemispherical reflectance } \\
\text { at a } \lambda\end{array}$ & $\begin{array}{l}\text { Highly specular } \\
\text { reflectors, where the } \\
\text { ratio between specular } \\
\text { and hemispherical } \\
\text { reflectance is } \lambda \\
\text { independent } \\
\end{array}$ & {$[12]$} \\
\hline R.B. Pettit & $\begin{array}{l}\text { Spectral } \\
\text { specular } \\
\text { reflectance }\end{array}$ & 1977 & $\begin{array}{l}\text { Mirrors scatter the beam around the } \\
\text { specular direction according to a } \\
\text { normal distribution (Gaussian) }\end{array}$ & Only some materials & [29] \\
\hline R.B. Pettit & $\begin{array}{l}\text { Spectral } \\
\text { specular } \\
\text { reflectance }\end{array}$ & 1977 & $\begin{array}{l}\text { Reflectance is described by the sum } \\
\text { of two Gaussians, one for the sharp } \\
\text { central beam and another for } \\
\text { background reflectance }\end{array}$ & $\begin{array}{l}\text { Any reflector material or } \\
\text { soiling condition }\end{array}$ & [29] \\
\hline R.B. Pettit & $\begin{array}{l}\text { Spectral } \\
\text { specular } \\
\text { reflectance }\end{array}$ & 1983 & $\begin{array}{c}\text { Reflectance can be also described as } \\
\text { the hemispherical component minus } \\
\text { the light scattered outside of the } \\
\text { angle } \varphi \text {, represented as two } \\
\text { Gaussians }\end{array}$ & $\begin{array}{l}\text { Any reflector material or } \\
\text { soiling condition }\end{array}$ & {$[30]$} \\
\hline $\begin{array}{l}\text { A. } \\
\text { Heimsath } \\
\text { et al }\end{array}$ & $\begin{array}{l}\text { Spectral } \\
\text { specular } \\
\text { reflectance }\end{array}$ & 2010 & $\begin{array}{l}\text { Reflectance is described by two } \\
\text { Gaussians at small and moderate } \\
\text { scattering angles plus. an exponential } \\
\text { distribution for large scattering } \\
\text { angles }\end{array}$ & Front surface reflectors & [31] \\
\hline $\begin{array}{l}\text { A. } \\
\text { Heimsath } \\
\text { et al }\end{array}$ & $\begin{array}{l}\text { Spectral } \\
\text { specular } \\
\text { reflectance }\end{array}$ & 2010 & $\begin{array}{l}\text { Reflectance is described by three } \\
\text { Gaussians, one for the glass-air layer, } \\
\text { one for the reflecting layer, and one } \\
\text { for the second reflection due to } \\
\text { absorption in the glass layer }\end{array}$ & Glass reflectors & [31] \\
\hline $\begin{array}{c}\text { M. } \\
\text { Montecchi }\end{array}$ & $\begin{array}{l}\text { Spectral } \\
\text { specular } \\
\text { reflectance }\end{array}$ & 2013 & $\begin{array}{l}\text { The ratio between hemispherical and } \\
\text { specular spectral reflectance is an } \\
\text { exponential function of } \lambda, \theta_{i} \text { and the } \\
\text { equivalent-roughness, } \sigma_{\varphi}\end{array}$ & Any reflector material & [17] \\
\hline
\end{tabular}

\section{Commercial instruments}

In what follows we describe the instruments used to measure reflectance that are commercially available. Section 4 then gives an insight to academic instrument developments. The commercial instruments available to measure reflectance of solar mirrors are divided in this section into laboratory scale spectrophotometers and (mostly) portable reflectometers.

\subsection{Spectrophotometers}

A spectrophotometer is a photometer (a device for measuring light intensity) that can measure intensity as a function of the light source wavelength $\lambda$. They are commonly used for a wide range of applications to measure transmittance, $\tau$, absorptance, $\alpha$, and $\rho$ of solutions and opaque materials.

The main advantage of a spectrophotometer for solar applications is the fact that the reflectance can be measured over the entire solar spectral range. These instruments typically use one or dual light sources and a monochromator to scan the near ultraviolet 
(UV), visible (Vis) and near infrared (NIR) spectrum in desired $\lambda$ intervals. Although the first commercial spectrophotometers to measure in the NIR range were marketed around the forties of last century, the devices to measure in the whole solar range were available a few decades later. The main disadvantages are that they are not portable, so they can only be used in laboratories, and they do not offer a beam adjustment, adaption to mirror curvature, adjustment of the acceptance angle to measure the mirrors specularity, nor are they applicable to different mirror thicknesses for back-silvered glass. The sample is illuminated with monochromatic light and the reflected flux is captured with the appropriate accessory by one or several detectors. The result is the reflectance as a discrete function of $\lambda$.

Both specular and hemispherical reflectance can be measured with spectrophotometers depending on the accessory used. Integrating spheres are widely employed to measure hemispherical reflectance accurately. However, the available accessories for measuring specular reflectance with a spectrophotometer are still under evaluation for solar concentrating reflectors.

\subsubsection{Lambda 950/1050 by Perkin Elmer}

The Perkin Elmer (PE) scanning spectrophotometer models Lambda 950 and 1050 are UV/Vis/NIR double beam and double monochromator instruments with two light sources, a deuterium lamp for the UV range and a halogen lamp for the Vis/NIR range (see PE lambda 1050 in Figure 2) [33]. The beam source has a spectral range from 175 to $3300 \mathrm{~nm}, \theta_{i}=8^{\circ}$ and about $17 \times 9 \mathrm{~mm}^{2}$ size. The beam is divided by a chopper into a sample and reference beam (see Figure 3). The double beam alignment increases the measurement accuracy, permitting to reduce errors due to lamp intensity variations. The detection system in both models is composed of a photomultiplier for the UV/Vis range and a Peltier controlled PbS (Lead (II) Sulfide) detector for the NIR range. However, the model Lambda 1050 incorporates a third InGaAs (Indium Gallium Arsenide) detector for the NIR range, which provides a better level of sensitivity, resolution and scanning speed. The resolution in both models is $0.05 \mathrm{~nm}$ in the UV+Vis range and $0.2 \mathrm{~nm}$ in the NIR range. In addition, the Lambda 1050 includes an extra mirror in the light source compartment to achieve a higher radiation flux. Beam attenuators are 0.1 and $1 \%$ in the Lambda 1050 and 1 and $10 \%$ in the Lambda 950. Operating temperature of the instruments and its accessories is from 10 to $35^{\circ} \mathrm{C}$. 
Wavelength calibration must be done regularly because of possible drift in motor positions and lamps monitoring is recommended every month to check their aging. In addition, maintenance and calibration tasks should be done yearly by PR technical service.

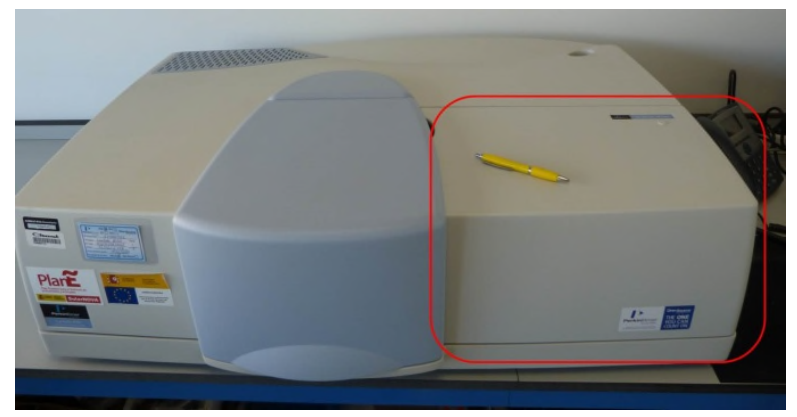

Figure 2. Picture of the spectrophotometer Lambda 1050 by PE. The red square indicates the detector compartment, which is interchangeable with different accessories.

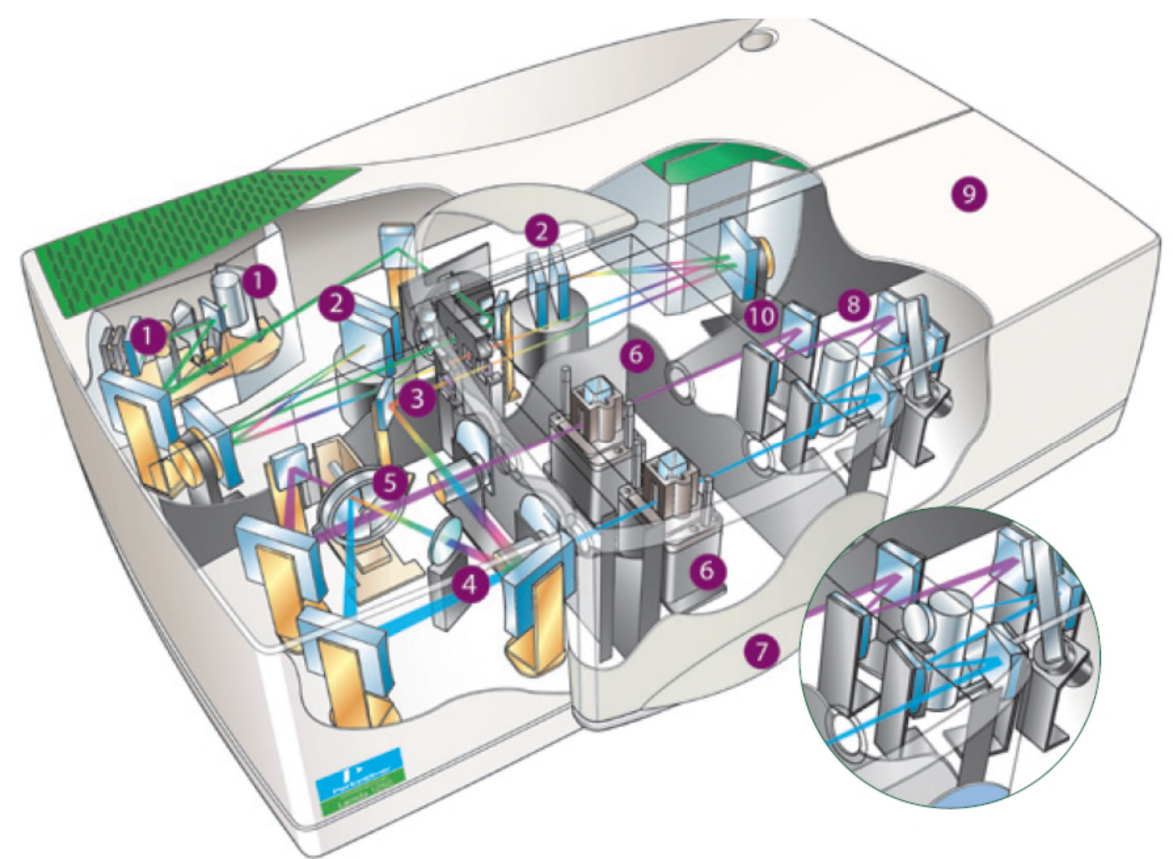

Figure 3. Scheme of the spectrophotometer Lambda 1050 by PE [33]. (1): Deuterium and tungsten halogen light sources. (2): Double holographic grating monochromators. (3): Common beam mask. (4): Common beam depolarizer. (5): Chopper. (6): sampler and reference beam attenuators. (7): sample compartment. (8) and (10): high-sensitivity photomultipliers and Peltier-controlled PbS detectors. (9): second sampling area. 
The detector compartment (the red square in Figure 2 and numbers 8-10 in Figure 3) is fully interchangeable with other sampling modules and can be quickly replaced by a different module accessory, as described in the following sections.

\section{a) Integrating sphere}

Integrating sphere reflectance accessories offer a simple method to extend the measurement capabilities of a UV-VIS-NIR spectrophotometer (see Figure 4 left). By adding a sphere reflectance accessory to a spectrophotometer, its capabilities are expanded from traditional transmittance measurements of liquid samples and nonscattering solids to reflectance or absorptance measurements of reflecting or opaque solids, such as solar absorbers or reflectors [34]. In an integrating sphere, thanks to the Lambertian reflectance inner surface and the geometrical sphere shape, the incident light is, in theory, spread evenly and without angular distribution over the entire surface of the sphere [35]. Consequently, the entire wall displays a constant luminance which is measured by a detector also placed in the wall. The sphere design must ensure that the detector is not illuminated directly by the incident light or the first reflection of the sample. To avoid that problem, baffles that shield the detectors are incorporated into PE integrating spheres [36]. In reflectance measurements, the sample is placed at a port opening opposite the entrance port. The incident flux is reflected by the sample and the total hemispherical reflectance is collected by the detector (see Figure 4 right).

The first rule of thumb for integrating spheres is that no more than $5 \%$ of the sphere surface area shall be consumed by port openings [37]. Openings for the introduction of the incidence beam should be kept as small as possible so that any scattered light after the first reflection on the sample is not lost through these openings. The port fraction of the $150 \mathrm{~mm}$ diameter integrating sphere used in PE lambda instruments is $2.5 \%$ [34]. This standard $150 \mathrm{~mm}$ sphere is the only one that will give accurate and comparable spectra between different instrument/sphere models [36]. An integrating sphere with a smaller size (typically $60 \mathrm{~mm}$ ) generally provides a better signal due to less attenuation, but it is often unable to meet the strict port fraction requirements [34].

The inner coating material is extremely important for the efficiency of the sphere. For instance, a $0.5 \%$ change in the reflectance of the sphere coating yields a $5 \%$ change in the sphere efficiency for a coating reflectance of approximately $90 \%$ [38]. 
Typically, integrating spheres are able to measure spectrally in the range of $\lambda=[200,2500] \mathrm{nm}$ but the recommended range in [10] is reduced to $\lambda=[280,2500] \mathrm{nm}$, with $5 \mathrm{~nm}$ steps, to be consistent with the solar spectrum from [11]. In some instruments significant cost savings can be made by avoiding the use of an extra UV-lamp and starting the measurements at $300 \mathrm{~nm}$. This is allowed since the UV and NIR tails have a low impact on the final average value [10]. The resulting range $(\lambda=[300,2500] \mathrm{nm})$ is in agreement with [39]. This type of spectrophotometer has been extensively used by several research institutions for the hemispherical reflectance measurements of solar reflectors for concentrating applications [40]-[43].

Following integrating sphere manufacturer's instructions, a material similar to the sample to be measured must be installed in the reference port. Concerning the calibration of the integrating sphere, although the instrument software has the capability to perform it automatically, a manual calibration is hardly recommended. The manual calibration is done by measuring first the zeroline, $\rho_{\text {zeroline, }}$ which consists on removing any sample from the measuring port. The second step consists on putting the calibrated standard on the measuring port and measuring it as the baseline, $\rho_{\text {baseline. }}$ The calibrated standard is a reference mirror of known reflectance, $\rho_{\text {reference, }}$ that should be calibrated by an external accredited laboratory. Finally, the sample to be measured is situated in the measurement port and the measurement $\rho_{\text {sample }}$ is obtained. The corrected reflectance of the sample, $\rho_{\text {sample, }}$ corrected, is obtained by applying the equation (9). It is recommended to check the baseline several times during a working day to detect possible drifts.

$$
\rho_{\text {sample,corrected }}=\frac{\rho_{\text {sample }}-\rho_{\text {zeroline }}}{\rho_{\text {baseline }}-\rho_{\text {zeroline }}} \cdot \rho_{\text {reference }}
$$

Most spheres have the ability to measure diffuse only reflectance by allowing the specular component to exit the sphere via an open specular exclusion port. It is not advisable to use the specular exclusion port to measure the diffuse reflectance and then calculate the specular reflectance by subtracting the diffuse reflectance from the hemispherical reflectance. The exclusion port is usually too large, thus the corresponding $\varphi$ obtained (around $116 \mathrm{mrad}$ [15]) is not representative of performance for solar concentrating applications [29]. Also, the incident light is not collimated which makes it difficult to determine $\varphi$. 

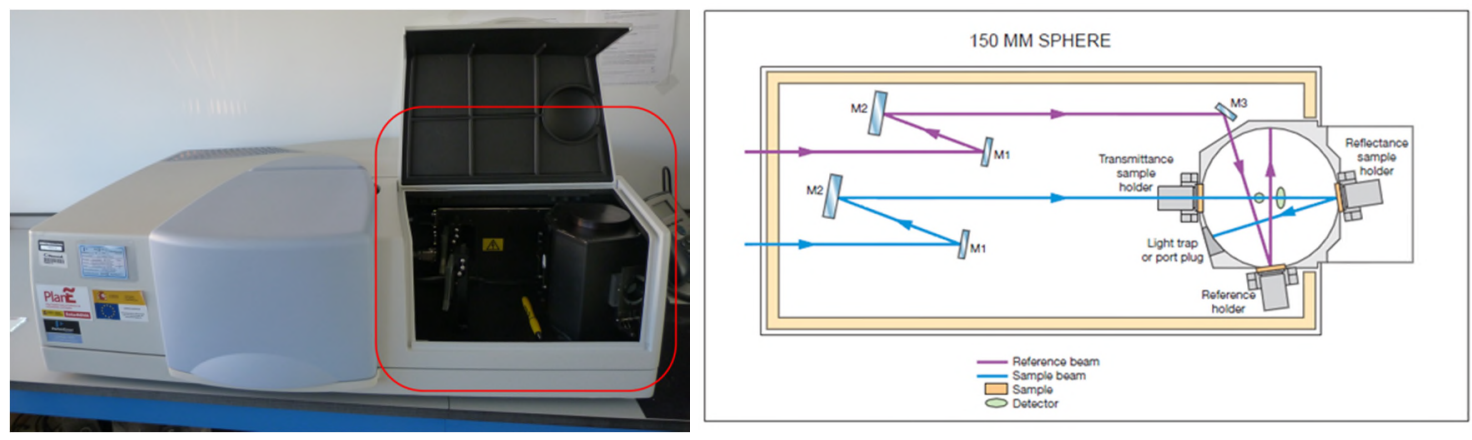

Figure 4. Left: Picture of the spectrophotometer Lambda 1050 by PE with the Integrating Sphere accessory. The red square indicates the Integrating Sphere accessory, which is interchanged with the detector compartment (see Figure 2). Right: Scheme of the optical design of $150 \mathrm{~mm}$ integrating sphere [44].

A round robin test was performed in 2010 between three research laboratories (DLR, CIEMAT, and NREL), within the framework of SolarPACES Task III activities, with samples that represent all of the commercial solar reflectors currently available for CSP applications [45]. Using the same instruments with the same properties and the same measurement procedure should lead to similar results when a reflector is measured at different laboratories by different operators. Each laboratory received a set of samples for the first round of measurements; the sets were then sent to the next laboratory, where they were measured and so on, resulting in three rounds. For the measurement of hemispherical reflectance, $\rho_{s, h}\left([250,2500] \mathrm{nm}, 8^{\circ}, h\right)$, PE Lambda series spectrophotometers were used. CIEMAT used a new Lambda 1050 with a $150 \mathrm{~mm}$ integrating sphere, DLR used a Lambda 950 with a $150 \mathrm{~mm}$ sphere, and NREL used the older Lambda 9 and Lambda 900 equipped with $60 \mathrm{~mm}$ spheres. Nine different types of solar mirrors were provided by six different manufacturers for the test. All samples had clean, smooth surfaces without scratches or soiling at the beginning of the test.

Surprisingly, the deviation of the hemispherical measurements was high between the laboratories, although the measurements within the laboratories were very repeatable. The standard deviation of the hemispherical reflectance (in reflectance units, that is, from 0 to 1) did not exceed $\sigma=0.002$ for all material types when the CIEMAT and DLR measurements were compared, but the NREL results were higher. This can be explained by the NREL spectrophotometers' use of smaller integrating spheres-60 $\mathrm{mm}$ vs. $150 \mathrm{~mm}$ - and the age of the NREL reference reflectors. DLR and CIEMAT had bought 
identical reference reflectors within the last two years from European laboratories, whereas NREL used significantly older reference standards that had not been recalibrated for a number of years because calibration services had been unavailable. This led to higher reflectance values; the same as would be the case if dirty reference standards were used. The measurements of $2^{\text {nd }}$ surface silvered glass reflectors would be expected to have the best repeatability because of their homogeneity. The results reveal the opposite, indicating the importance of the correct reference standard. The $3 \mathrm{~mm}$ and $4 \mathrm{~mm}$ silveredglass reflectors had the greatest standard deviation $(\sigma=0.007)$ because NREL used $1 \mathrm{~mm}$ reference standards and DLR and CIEMAT used $4 \mathrm{~mm}$ standards. The thin-glass standard deviation is also high $(\sigma=0.007)$ because only NREL had the $1 \mathrm{~mm}$ reference standards with similar properties to the samples, while DLR and CIEMAT used $1^{\text {st }}$ surface aluminum standards. The aluminum samples measured against $1^{\text {st }}$ surface aluminum reference standards thus show the smallest average divergence of $\sigma=0.006$. This results in a general averaged divergence of $\sigma=0.007$. In summary, the results showed differences in hemispherical reflectance of 0.007 between the laboratories. These differences indicate the importance of minimum instrument requirements and standardized procedures. Improved instruments and reference standards are needed to reach the necessary accuracy for cost and efficiency calculations.

According to the conclusions highlighted in this work, the SolarPACES reflectance guideline was updated, concluding in version V2.5 [10]. A second round robin test was launched at the beginning of 2013 [9], to check the suitability of the protocol to measure hemispherical reflectance described in the SolarPACES reflectance guideline. Six identical kits, each one consisting of ten specimens collected from eight cooperating producers, were distributed to six institutes, acting as evaluators: ENEA, CEA, CENER, CIEMAT, DLR, Fraunhofer-ISE, and NREL. Each research institute used a high quality spectrophotometer, with a light source at near normal incidence and equipped with an integrating sphere with diameter not less than $150 \mathrm{~mm}$. For each specimen, the reflectance spectrum was measured in the range $\lambda=[300-2500 \mathrm{~nm}]$. Then, the solar reflectance was computed by applying the standard ASTM E903 [27] and using the spectrum in the standard ASTM G-173-03 [11]. The maximum difference between the results obtained from two different evaluators was 0.014 . The deviation of the results achieved by each evaluator from the mean, which is assumed to be the true value, is smaller than \pm 0.007 . Therefore, the agreement between all participants was very good, even for the innovative 
mirrors. The institution in charge of the data treatment (assessor) was also one of the participants. This approach has the methodic drawback that the assessing institute has access to the results of the rest of the partners beforehand, so they are able to check the consistency of their own measurements in advance. Nevertheless the participants of the Round Robin test agreed that it is more important to include as many partners as possible and for this reason the assessor was also accepted as a participant. The University of Zaragoza made contact with the Task-III group after the rest of the partners already performed their measurements. Their results were added afterwards in order to compare the results of an additional institute.

\section{b) Universal Reflectance Accessory (URA)}

The URA is a variable angle specular reflectance measuring module that loads directly into the detector compartment of the PE lambda spectrometers (see Figure 5 and Figure 6) [46], [47]. The URA can be used to collect absolute or relative reflectance measurements with $\theta_{i}=[8,65]^{\circ}$ and $\lambda=[190,3100] \mathrm{nm}$. Samples are placed on the horizontal sample plate and can range in size from $8 \mathrm{~mm}$ to $150 \mathrm{~mm}$. Samples with sizes between $3 \mathrm{~mm}$ and $8 \mathrm{~mm}$ could be measured using a custom-made sample holder.

Due to the complexity of the optical path inside this accessory, which also depends on the $\theta_{i}$ selected, a $\varphi$ is not clearly defined [48]. This value may ensure stable readings but it is too large for CSP applications [29]. Also, problems might arise for imperfectly flat mirrors, because the beam alignment cannot be adjusted. Typically, second-surface samples and different shapes are not supported, especially at measurements of higher incidence angles.

Once fitted into the spectrometer, the URA can be fully calibrated using the software (both the zeroline -or 0\%- and the baseline -or 100\%-). This allows to eliminate the need to make manual adjustment to the optics or the sample. 


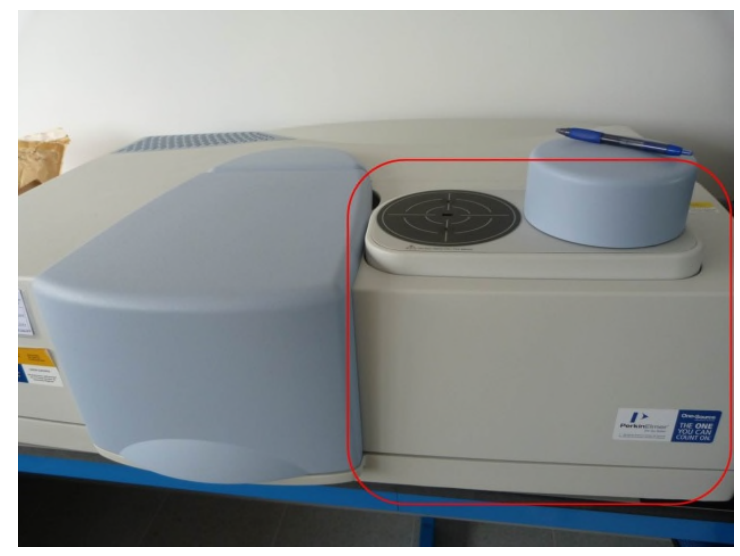

Figure 5. Picture of the spectrophotometer Lambda 1050 by PE with the URA. The red square indicates the URA accessory, which is interchanged with the detector compartment (see Figure 2).
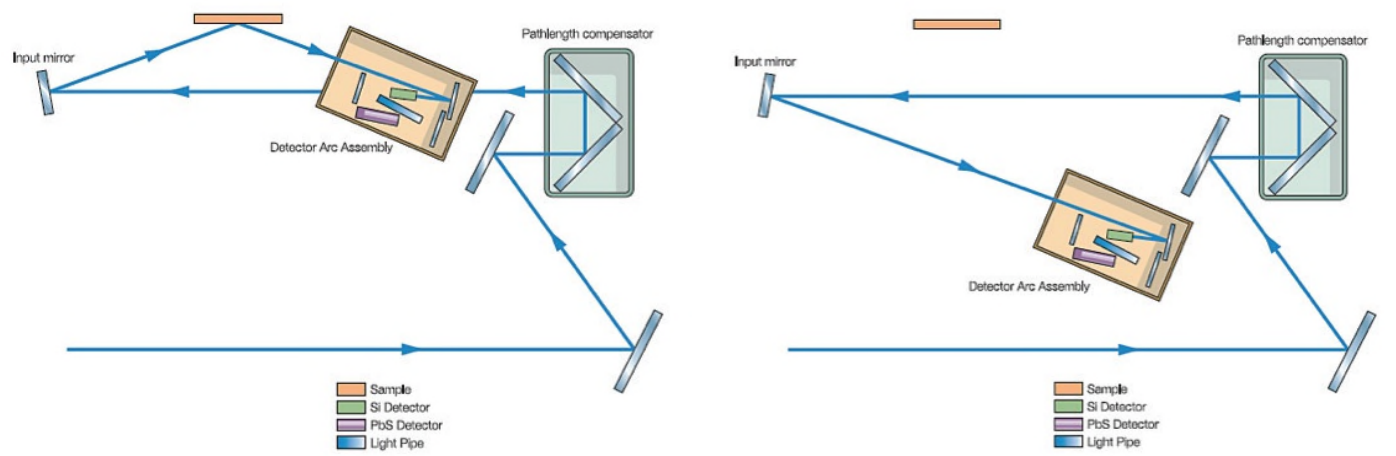

Figure 6. Scheme of the URA sample beam. Left: configuration to measure the sample.

Right: configuration to measure the baseline [47].

CIEMAT and DLR institutions, in their joint laboratory for Optical \& Aging Characterization (OPAC), made a study to compare the spectra acquired by using the same spectrophotometer (Lambda 1050 by PE) with two different accessories, the $150 \mathrm{~mm}$ diameter integrating sphere and the URA. In the URA accessory, the incidence angle selected for the measurements was the same as for the integrating sphere, that is, $\theta_{i}=8^{\circ}$. Four samples of different materials were measured: 1-mm silvered glass, 4-mm silvered glass, silvered polymer film and aluminum. The silvered film sample was measured at the initial state (that is, new) and also after some degradation had occurred. This comparison was made to check if both accessories (URA and integrating sphere) are able to detect the reflectance decrease due to the scattering caused by the sample degradation. Figure 7 toFigure $\mathbf{1 1}$ show the results obtained. As can be seen in Figure 7 
andFigure 8, highly specular reflectors, such as silvered glass (both 1 and $4 \mathrm{~mm}$ thickness) present similar spectra for the hemispherical and specular reflectance at the acceptance angle covered by the URA. The same may be concluded for the new silvered polymer film (see Figure 9), but not when this type of mirror has degraded (see Figure 10). The reason is an increase of the scattered reflectance out of the specular direction due to the front surface degradation suffered by the reflector, which is detected by the URA but not by the integrating sphere. Finally, as expected, aluminum reflectors have lower specular reflectance than hemispherical reflectance, even at the relatively high $\varphi$ covered by the URA (see Figure 11).

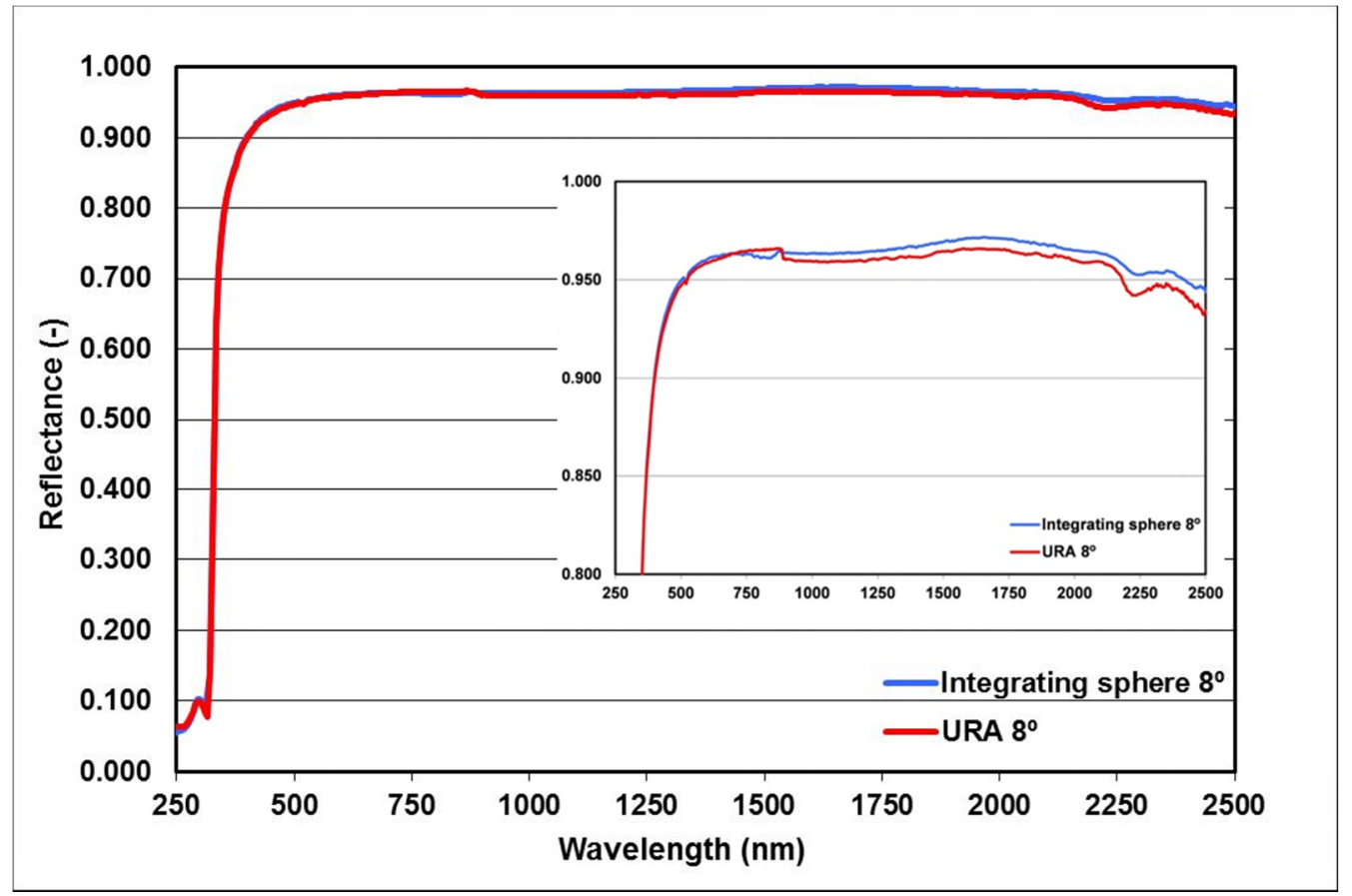

Figure 7. Reflectance measurements of 1-mm silvered glass with an integrating sphere $\left(\rho_{\lambda, h}\right)$ and the URA $\left(\rho_{\lambda, h}\right)$. 


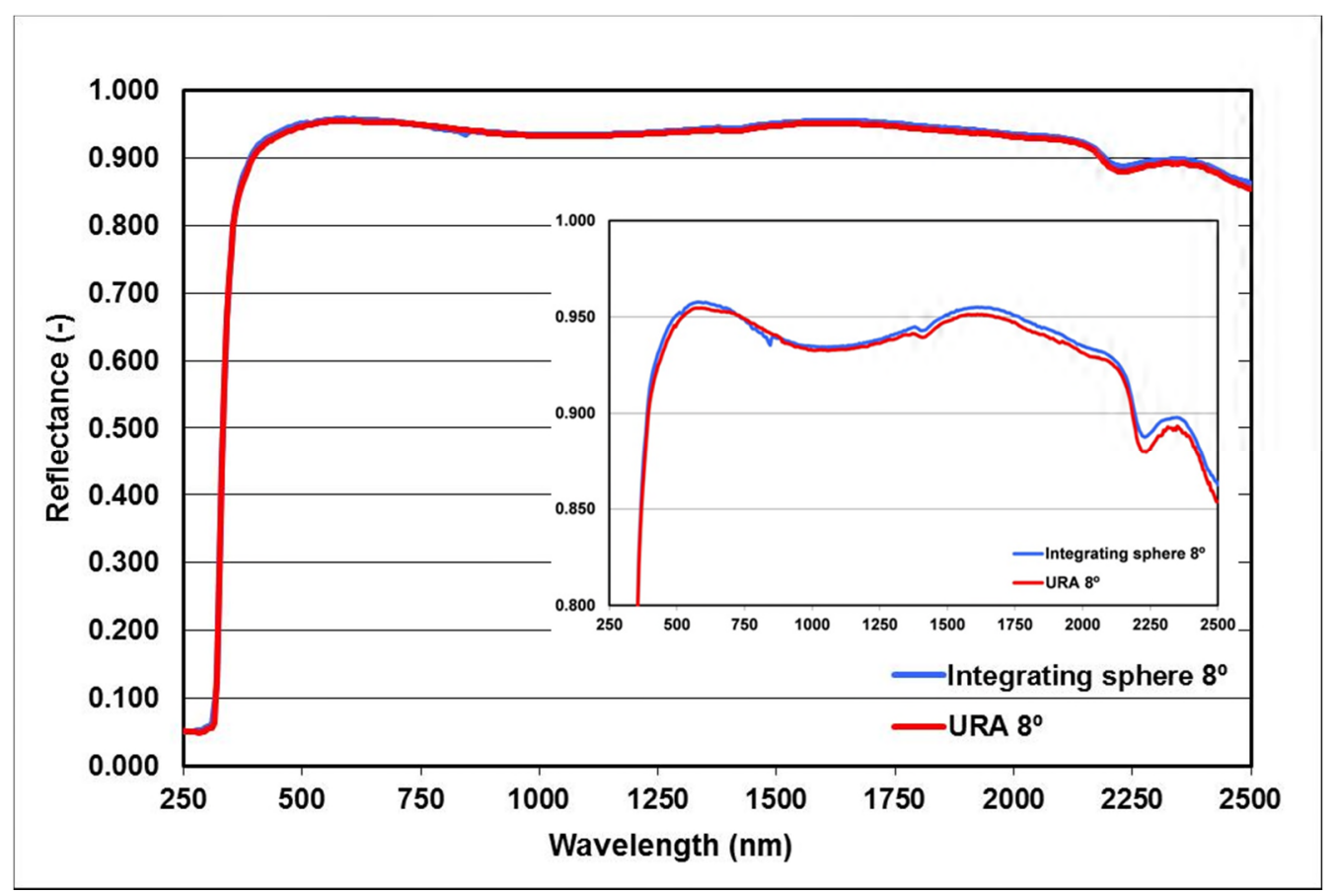

Figure 8. Reflectance measurements of 4-mm silvered glass with an integrating sphere $\left(\rho_{\lambda, h}\right)$ and the URA $\left(\rho_{\lambda, \varphi}\right)$.

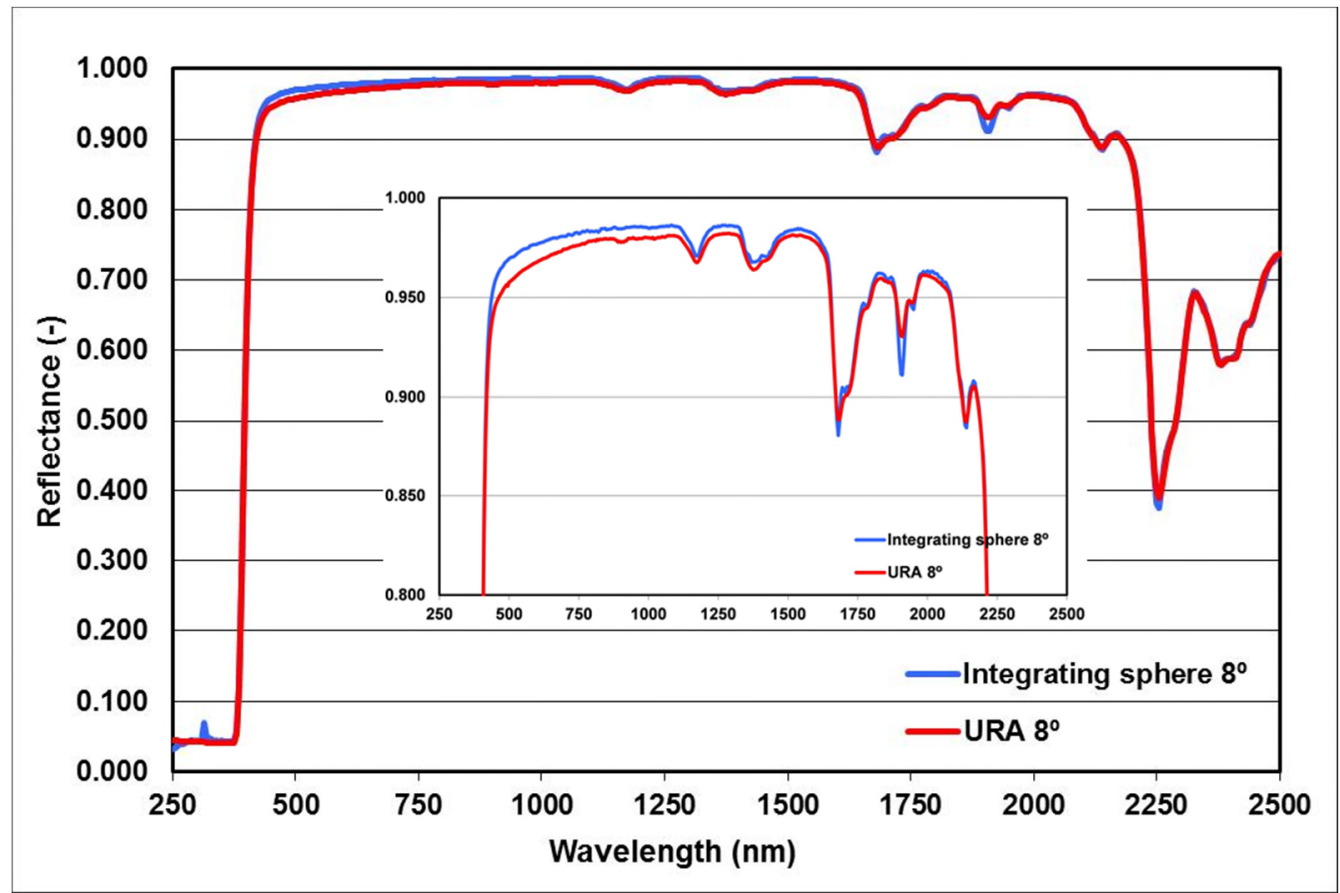

Figure 9. Reflectance measurements of a new silvered polymer film with an integrating sphere $\left(\rho_{\lambda, h}\right)$ and the URA $\left(\rho_{\lambda, \varphi}\right)$. 


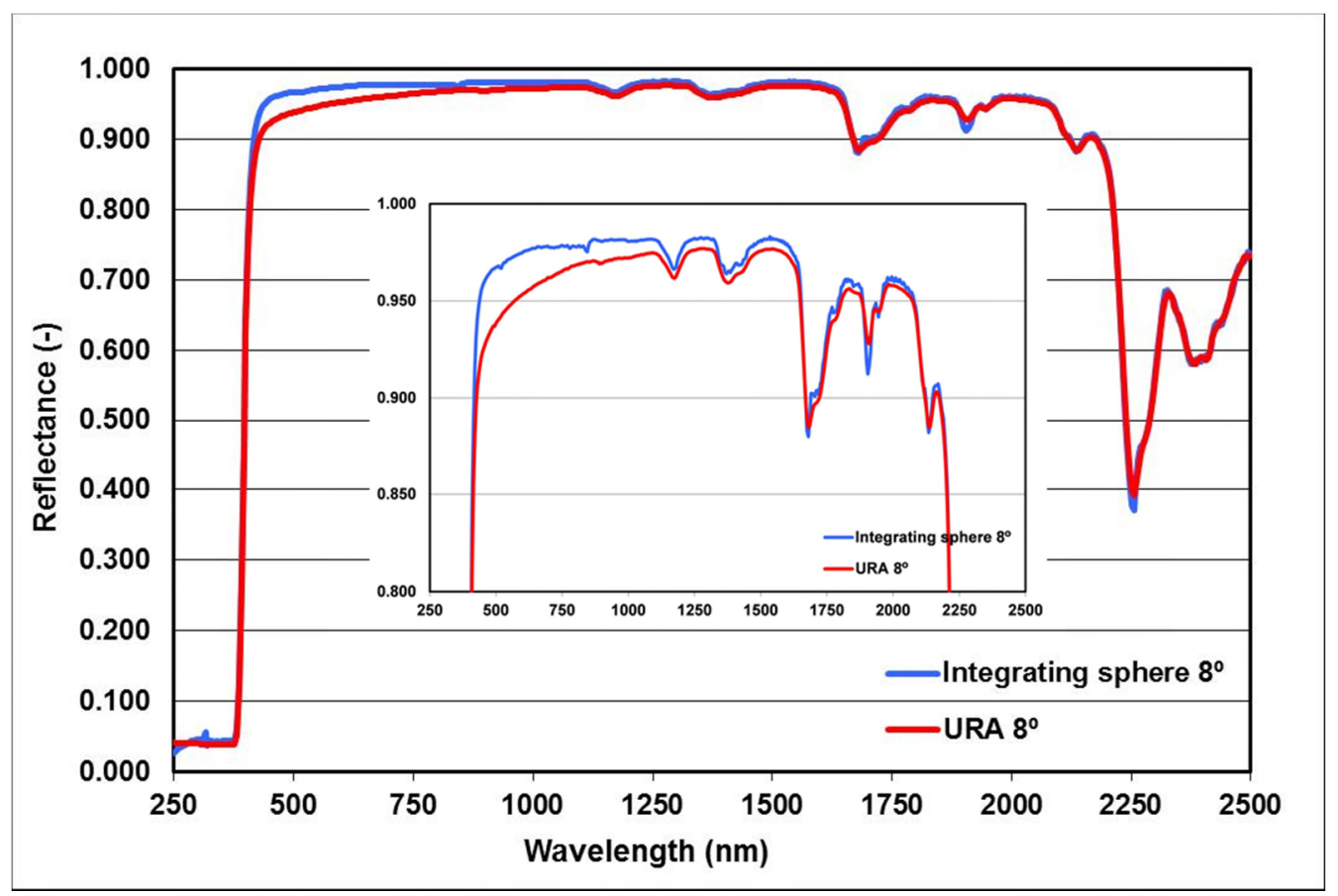

Figure 10. Reflectance measurements of degraded silvered polymer film with an integrating sphere $\left(\rho_{\lambda, h}\right)$ and the URA $\left(\rho_{\lambda, \varphi}\right)$.

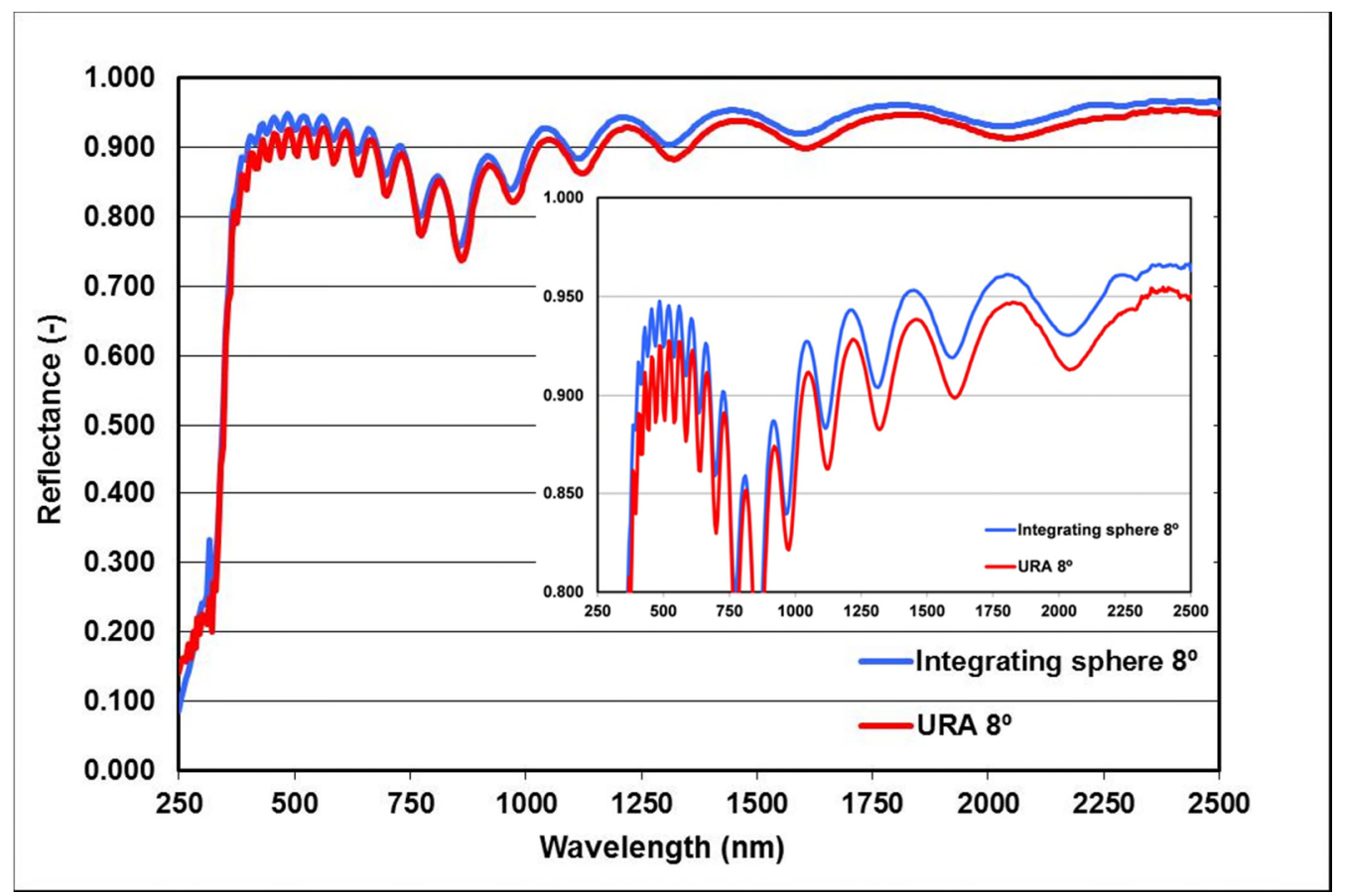

Figure 11. Reflectance measurements of an aluminum reflector with an integrating sphere $\left(\rho_{\lambda, h}\right)$ and the URA $\left(\rho_{\lambda, \varphi}\right)$.

\section{c) Absolute Reflectance and Transmittance Analyzer (ARTA)}

The ARTA is a stepper motor driven goniometer tool that uses an integrating sphere as detector, which is $60 \mathrm{~mm}$ in diameter, with photomultiplier (PMT) and InGaAs detectors 
[49], [50]. As with the two previously described accessories, this module loads directly into the detector compartment of the high performance Lambda spectrometers from PE (see Figure 12).

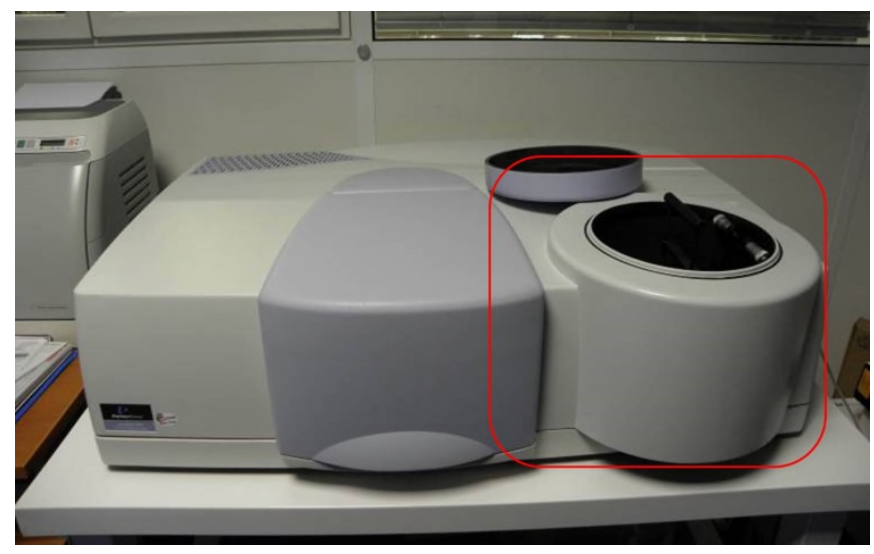

Figure 12. Picture of the spectrophotometer Lambda 950 by PE equipped with the ARTA accessory. The red square indicates the ARTA accessory, which is interchanged with the detector compartment (see Figure 2).

The ARTA can be used to collect absolute transmittance or reflectance measurements utilizing $\lambda=[220,2500] \mathrm{nm}$. The sample is placed in the center of a rotation stage and can rotate through $360^{\circ}$. The integrating sphere detector is placed either behind the sample at $180^{\circ}$ for transmittance measurements, or in front of the sample at twice the $\theta_{i}$ for reflectance measurements. The $\theta_{i}$ range is $5^{\circ}$ to $85^{\circ}$ for reflectance measurement of specular samples and $0^{\circ}$ to $85^{\circ}$ for transmittance measurement. The sample holder can receive square samples up to $10 \mathrm{~cm}$ wide.

An important improvement over other commercial instruments is the possibility to measure at "positive" and "negative" incidence angles to compensate for systematic errors by taking the average of the two measurements. The systematic errors are due to the offset in the zero position of the sample angle and the angular distribution of rays in the beam. Therefore, the correct result is obtained by taking the average of the positive and the negative measurement [51].

The ARTA is also equipped with a variable detector aperture to control the $\varphi$. The maximum aperture corresponds to an $\varphi=15^{\circ}$ approximately (about $263 \mathrm{mrad}$ ). Varying the detector aperture is an option to qualify diffuse materials but is not necessary for specular materials such as mirrors. Nevertheless, this equipment can be used to 
characterize the angular scattering of mirrors after degradation. It is being used by some research institutes for specular reflectance measurements [52], [53].

\subsubsection{Cary 5000 by Agilent (formerly Varian)}

The Cary 5000 is a dual beam UV, Vis light and NIR spectrophotometer [54]. This instrument records data in the $\lambda$ range from 175 to $3300 \mathrm{~nm}$. The extension of the NIR range up to $3300 \mathrm{~nm}$ is obtained by using a PbSmart detector. The large sample compartment can be expanded to hold large accessories and integrating spheres. For optimum analytical performance, it is recommended that the ambient temperature of the laboratory be between 20 and $25^{\circ} \mathrm{C}$. The maximum operating temperature is $50^{\circ} \mathrm{C}$.

The experimental setup for opaque samples and surface coatings include reflection measurements at fixed $\left(12.5^{\circ}\right)$ and variable incidence angles, thanks to the VASRA accessory able to measure in a range from 20 to $70^{\circ}$. Also, among other accessories, an internal integrating sphere for hemispherical reflectance measurements is available for $\lambda=[200,2500] \mathrm{nm}$.

\subsubsection{OL 750 by Gooch and Housego (formerly Optronic laboratories)}

The OL Series 750 is spectroradiometric measurement system from Gooch and Housego (formerly Optronic Laboratories) capable of performing a variety of highly accurate optical radiation measurements under computer control in the UV, Vis and IR ranges [55] (see picture and scheme in Figure 13). Both single (OL750S) and double (OL750D) grating monochromator versions are available. In this case, $\theta_{i}=10^{\circ}$. Both for OL750S and OL750D versions, the wavelength accuracy is $\pm 0.05 \%$, the wavelength precision is $\pm 0.01 \%$ and the operating temperature is from 5 to $40^{\circ} \mathrm{C}$. The bandwidth is from 0.5 to $20 \mathrm{~nm}$ in the case of OL750S and from 0.25 to $10 \mathrm{~nm}$ for the OL750D version. The integrating sphere has a diameter of $152.4 \mathrm{~mm}$ and a specular opening port (or light-trap) of $\varphi \approx 84 \mathrm{mrad}$, with a spectral range of $\lambda=[320,2500] \mathrm{nm}$. The measurement diameter may be selected at 3, 6 or $10 \mathrm{~mm}$. In reflectance measurements, the precision is $0.25 \%$ and the accuracy is $1 \%$. To calibrate the instrument, the first step is to position the standard reference sample in the sample port and measure both the signal with the beam focused on the comparison sample and the signal with the beam focused on the standard reference sample. The second step consists on positioning the test sample in the sample port and measuring both the signal with the beam focused on the comparison sample and the signal with the beam focused on the test sample [56]. 


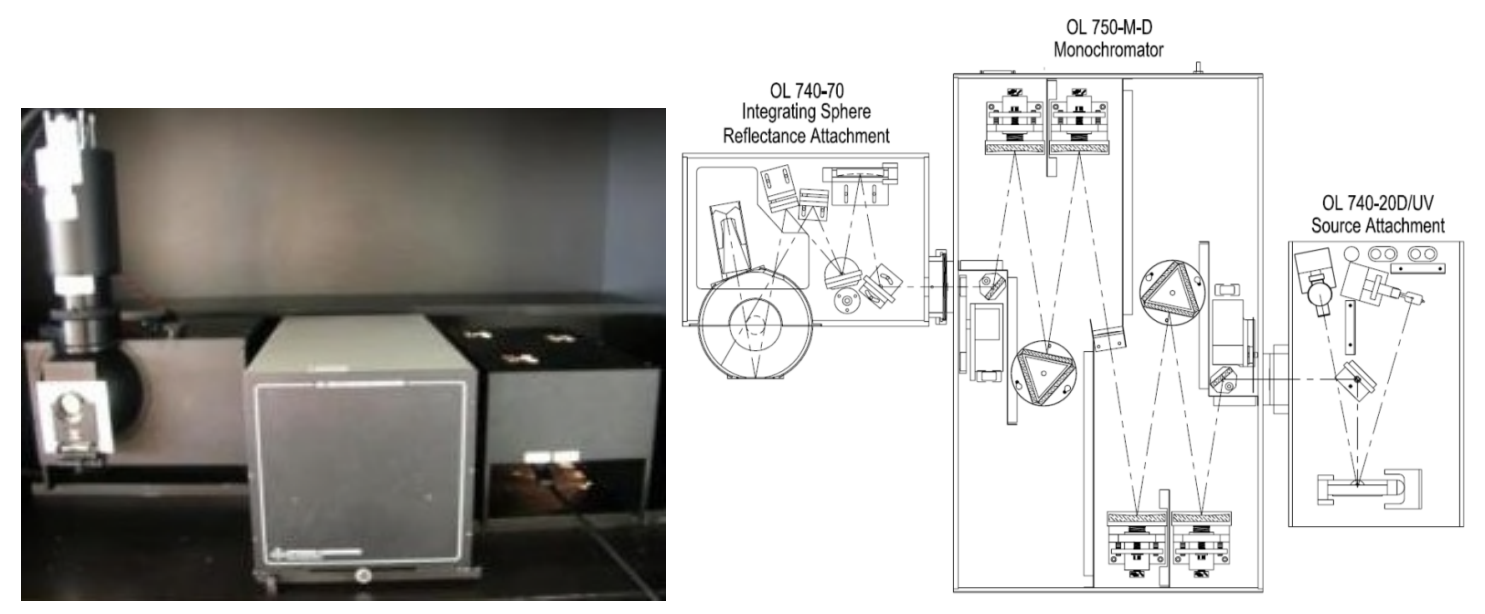

Figure 13. Left: picture of the spectrophotometer OL 750 by Gooch and Housego [21]. Right: Scheme of the spectrophotometer OL 750 by Gooch and Housego [56].

The basic system, along with an extensive selection of optical items and accessories, enables the OL Series 750 to measure over all or part of the entire $200 \mathrm{~nm}$ to $30 \mu \mathrm{m}$ wavelength range. An automated system can be configured for source spectral analysis, detector spectral response, diffuse spectral reflectance, specular spectral reflectance and spectral transmittance. The OL Series 750 can be configured with the OL 750-75MA Goniospectro-reflectance attachment to measure the specular reflectance of polished materials or mirrors as a function of both $\lambda$ and $\theta_{i}$. This type of spectrophotometer is being used by some prestigious research institutions [15].

\subsubsection{V670 by Jasco}

The JascoV-670 (see Figure 14 left) is a double-beam single monochromator type optical spectrometer covering a wide spectral range from $\lambda=190 \mathrm{~nm}$ to $\lambda=2700 \mathrm{~nm}$ which relies on dispersive mode to measure light intensity at each $\lambda$ allowing incident light passing through a monochromator and diffraction grating [57]. The UV range $(\lambda=[190,350] \mathrm{nm})$ is obtained with a deuterium lamp while the Vis and NIR ranges are generated with a Halogen lamp (see Figure 14 right). With respect to detectors, the UV and Vis ranges are covered with a PMT one and the NIR range is registered with a Peltier cooled PbS detector. The measurements are undertaken based on calibration standards and the spectral output is evaluated directly as a calibrated spectrum. The V670 is designed to measure transmission and both types of reflection, specular and diffuse, from a sample surface by mounting various types of optical accessories into the optical chamber. 
The total reflectance is estimated using an integrating sphere of $60 \mathrm{~mm}$ (inner walls covered with Barium sulphate) and fluoropolymer-based spectralon (from Labsphere) as calibration standards. Model V670 has wavelength bandwidth of $0.1 \mathrm{~nm}$ minimum and accuracy of $\pm 0.3 \mathrm{~nm}$ in UV-vis ranges with $1 \%$ stray light rejection at $198 \mathrm{~nm}$ (KCL $12 \mathrm{~g} / \mathrm{L}$ aqueous solution). The beam size is $1-5 \mathrm{~mm}$ typically and the standard sample size is $20 \times 20 \mathrm{~mm}^{2}$.
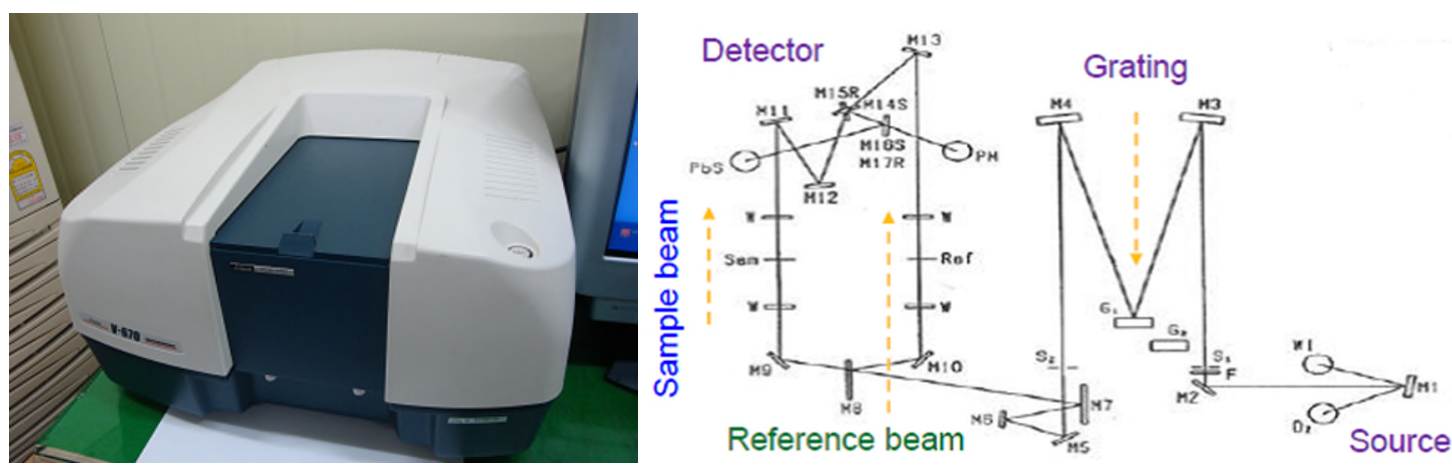

Figure 14. Left: Picture of the Jasco V670 spectrophotometer. Right: Optical scheme; WI, D2: light source; M: mirror; S: Slit; F: Filter; G: Grating; M8: sector mirror; PM: UV/Vis detector; PbS: NIR detector; Sam: sample beam; Ref:

Reference beam; W: Window.

Briefly, the optical sources used are a deuterium lamp $(187-350 \mathrm{~nm})$ for the UV range and a halogen lamp (330-2700 $\mathrm{nm})$ for the VIS-NIR bands. The light from the optical source is focused onto the monochromator which is dispersed by the grating and finally traversed through the exit slit. The wavelength-dispersed light output is split into two beams by a sector mirror of which one is incident on the sample under test and the other on the reference sample for relative spectral analysis. The two beams that pass through the test sample and reference sample are alternately collected by the detector. Both PMT and Peltier-cooled PbS photoconductive cell (NIR detection) are used as output detectors. The embedded Spectra-Manager software is used for spectral analysis. This type of spectrophotometer is being used in research activities conducted on this topic [58], [59].

\subsection{Reflectometers}

Reflectometers are devices that measure the intensity of the light source after reflection on a sample without wide spectral information, that is, they are equipped with light sources that radiate only one or a few narrow wavelength lines or bands. These lines or 
bands should at least be near the solar energy peak between $\lambda=500 \mathrm{~nm}$ and $\lambda=660 \mathrm{~nm}$. After calibration with a known reflectance reference standard, the measured intensity is automatically transformed into a reflectance reading by correlating the measured flux intensities of reference standard and sample. Reflectometers are typically prepared to measure specular reflectance. However, reflectometers that are equipped with integrating spheres may be also suitable for hemispherical reflectance measurements if their sphere is large enough. Portable instruments of this kind are also useful for relative measurements in quality control or cleanliness measurements in the field, even with a small sphere, depending on the level of precision that is required. Since these portable devices are principally destined to measure solar reflectors exposed outdoors (typically in dusty environment [23]), the influence of the soiling deposited on the material surfaces must be considered in the measurement process. In this sense, it is important to highlight that the dust accumulation produces wavelength dependent scattering [24]. As a consequence, portable reflectometers should include as maximum wavelength range as possible in their optical principle.

Reflectometers used for qualification of solar mirrors should fulfil as much as possible of the list of requirements for the ideal instrument stated in [10]. The minimal requirement for an instrument measuring specular reflection for solar applications is a selection of defined $\varphi$ of at least $12.5 \mathrm{mrad}$. Preferable are additional apertures in both smaller and larger cone angles. The reflected beam should be focused into the $\varphi$. The instrument should offer the possibility of adjusting the length of the beam path according to the reflector front-layer thickness to measure different glass thicknesses of second-surface reflectors. In addition, as it needs to perform reliably and precisely in the field, the following aspects should be considered:

- The beam alignment for each measurement should be adjustable to compensate for any surface curvatures. The positioning adjustment should be stable without damaging the mirror. The mechanism for beam adjustment and positioning needs to be easily accessible and controllable.

- Easy handling and use, and high robustness. Size and weight should allow a single operator to use it, even at above head height. 
- The time required to take a measurement should be as short as possible, to reduce the interference with plant operation. It should be possible to use the instrument at night, when the plant is not operating.

- High autonomy, i.e. battery and data storage capacity, along with indication of battery status. Low battery status should not influence the measurement results.

- The possibility of storing the digital data in addition to a display reading is recommended.

- The instrument performance must be stable in the typical operating environment of a CSP plant. This includes high, low, and variable ambient temperatures, relative humidity, wind, and dust. The instrument must be able to work in strong sunlight without stray light problems.

- Cross contamination of standards and mirrors must be minimized when characterizing mirror soiling rates.

- Operation should be possible while a cable is connected to a power source or computer (if needed), which means that the connection should not interfere with the positioning of the instrument on the sample.

\subsubsection{R-USB by Devices and Services (D\&S)}

D\&S company has manufactured optical instrumentations for solar applications since 1977. The company developed the first version of the $15 \mathrm{R}$ reflectometer at the beginning of the eighties of last century, under contract to Sandia National Laboratories (USA) [12].

\section{a) 15R-USB model by $D \& S$}

The portable specular reflectometer model 15R-USB manufactured by D\&S (see Figure 15) has a light-emitting diode (LED) source of $\lambda=[635,685] \mathrm{nm}$, with a peak at $\lambda=660 \mathrm{~nm}$ [60], [61]. $\varphi$ selected for measuring can be $\varphi=\{3.5,7.5,12.5,23.0\} \mathrm{mrad}$, and the $\theta_{i}=15^{\circ}$. First and second surface mirrors can be measured with this device. The distance between the reflective surface of the mirror and the optical components of the 15R-USB vary when measuring reflectors with different glass thicknesses. A screw located centrally on the bottom of the instrument corrects for this such that the optics are the same for all reflectors. In addition, this instrument allows the measuring of curved mirrors by using two adjusting screws situated on its base. With these two screws the 
optical measuring system is aligned and adapted to the curved surface. The battery autonomy is $25-30 \mathrm{~h}$ and the weight is $1.1 \mathrm{~kg}$.

The calibration process of the instrument may be done with the own reference standard that come with it, or with an external reference standard. The second option is recommended to assure a good quality of the reference, which may be replaced when deterioration is noticed. To calibrate the instrument, the first step consists of selecting the aperture to be used in the measurement and rotate it into place. With the reference standard in place, the gain adjustment must be set to the corresponding value of the calibration. It is recommended that the calibration process is repeated periodically while making measurements, mainly if ambient temperature changes are suffered. After calibration with the known reflectance reference standard, the measured intensity is automatically transformed into a reflectance reading by correlating the measured flux intensities from the sample to the signal from the reference standard.

An aperture in front of the lens restricts the collimated beam to a diameter of $10 \mathrm{~mm}$ so that all of the reflected beam can be collected by the $22 \mathrm{~mm}$ diameter receiver lens. The instrument resolution is 0.001 and, according to the manufacturer, the repeatability is \pm 0.002 . Operating temperature is from 0 to $50^{\circ} \mathrm{C}$. This instrument has been widely used by research institutes [40], [62]-[68] and also commercial CSP plants.
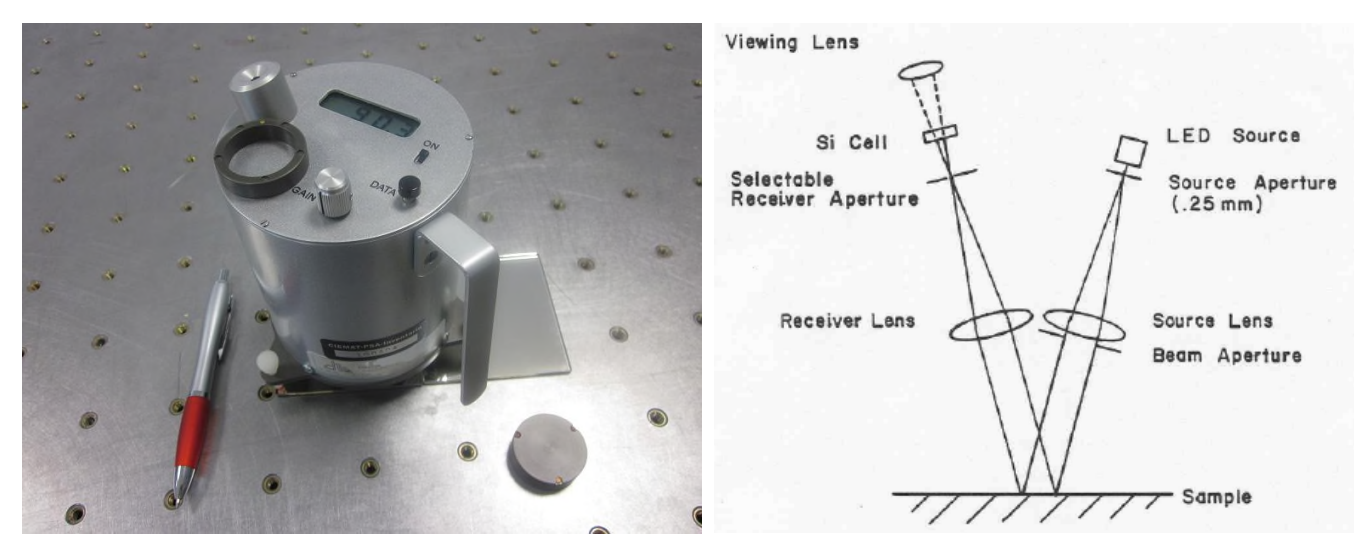

Figure 15. Left: Picture of the portable specular reflectometer 15R-USB by D\&S. Right: Principle sketch of the optical alignment of the 15R-USB by D\&S [60].

The comparability of three portable specular reflectometers, all models 15R-USB manufactured by D\&S (instrument serial numbers SN 119, 117 and 060) was investigated 
in the OPAC laboratory at the Plataforma Solar de Almeria (PSA). Different silveredglass, silvered polymer film and aluminum reflectors were used for the tests, all of them $10 \times 10 \mathrm{~cm}^{2}$. The specular reflectance was measured with the three instruments using $\varphi=12.5 \mathrm{mrad}$. The instruments were calibrated with an external working standard. Five values were measured for all material types. The average of the measurements was used as the result for the specular reflectance. The results are presented in Figure 16.

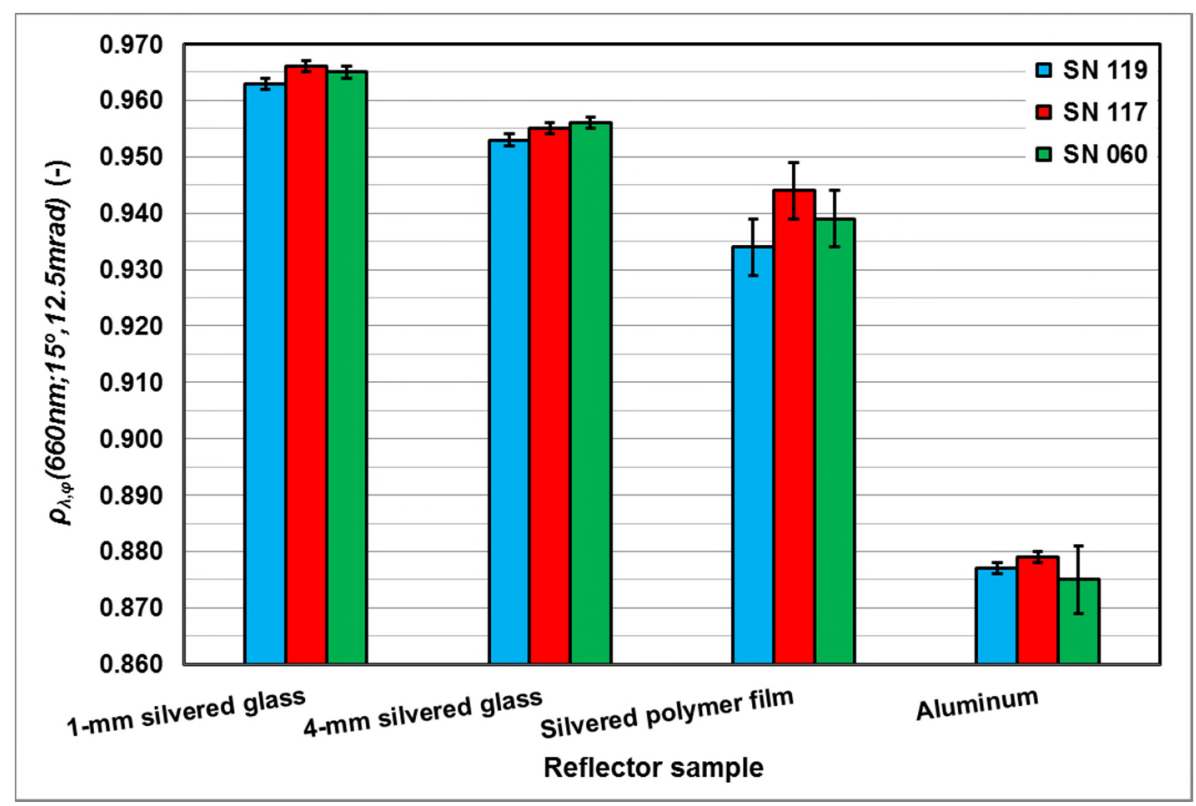

Figure 16. Specular reflectance measurements with the three 15R-USB reflectometers.

As can be observed in Figure 16, the reflectance measurements for the silvered-glass reflectors are very similar, for both glass thicknesses, with average difference of $0.002 \pm 0.002$ and maximum difference of $0.003 \pm 0.002$. This is due to the high stability and homogeneity of the glass based reflectors. The small differences can largely be due to the instruments' resolution, which in this case is 0.001 . However, due to the heterogeneity and lower rigidity of silvered polymer film and aluminum reflectors, the differences in the reflectance measurements are quite significant, with average difference of $0.007 \pm 0.005$ for polymer films and $0.003 \pm 0.002$ for aluminum and maximum difference of $0.010 \pm 0.010$ for polymer films and $0.004 \pm 0.007$ for aluminum.

\section{b) 15R-RGB (MWR) model by $D \& S$}

The 15R-RGW Multiple Wavelength Reflectometer (MWR), manufactured by D\&S, builds on the functionality of the previous model 15R-USB and was marked on 2012 (see Figure 17) [69]. It incorporates a white light source and the use of different filters makes 
it possible to measure the reflectance at $\lambda=\{460,550,650,720\} \mathrm{nm}$. Furthermore, the instrument has five different $\varphi$, which are $\varphi=\{2.3,3.5,7.5,12.5,23.0\} \mathrm{mrad}$, and the $\theta_{i}=15^{\circ}$. The rest of the features, properties and calibration methods are the same as for the model 15R-USB.

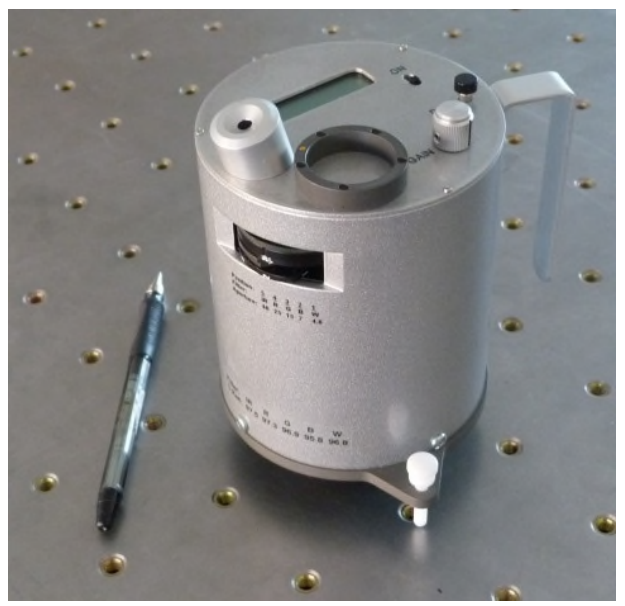

Figure 17. Picture of the multiple wavelength reflectometer 15R-RGB by D\&S.

The comparability between two types of instrument by D\&S, a 15R-RGB MWR and a standard 15R-USB, was investigated [70]. Different silvered-glass, silvered polymer film and aluminum reflectors were used in the study. The specular reflectance was measured with both instruments, using $\varphi=\{3.5,7.5,12.5,23.0\}$ mrad. As the $\lambda$ of the 15R-USB is $660 \mathrm{~nm}$, the value chosen in the MWR was $650 \mathrm{~nm}$. The instruments were calibrated with an external working standard (a second-surface silvered-glass reflector), to eliminate the influence of the calibration process in the instrument comparison. As in the previous section, three values were measured for the silvered-glass mirrors and five for the silvered polymer film and aluminum reflectors. The average of the measurements was used as the result for the specular reflectance. For comparing the instruments, the difference in the monochromatic specular reflectance $\Delta \rho_{\lambda, \varphi}$ was calculated as the value of 15R-USB minus the value of 15R-RGB. Figure 18 represents the differences between the two instruments. 


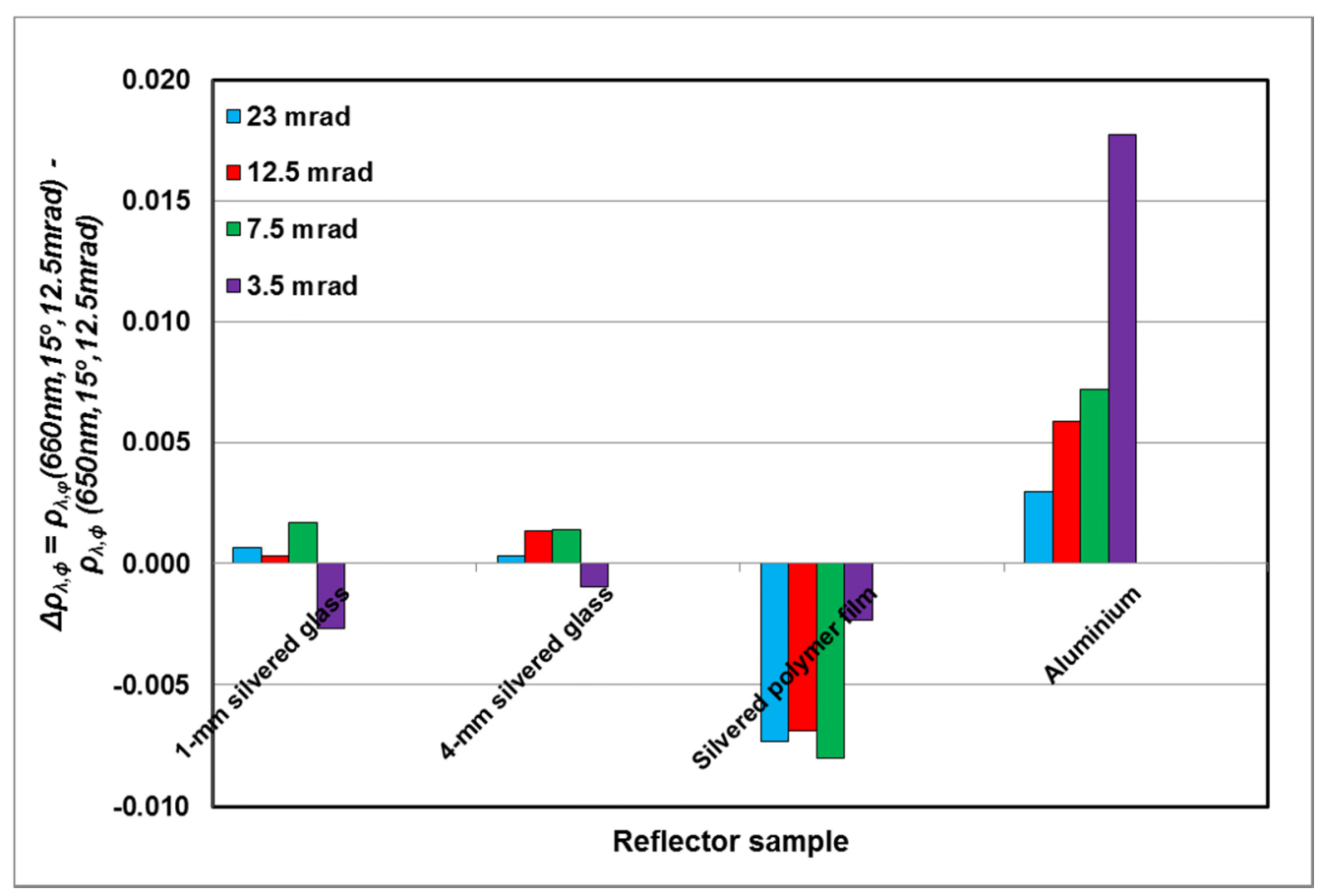

Figure 18. Reflectance difference $\Delta \rho_{\lambda, \varphi}$ of the two reflectometers by D\&S. The value of the difference is created using the measured reflectance and subtracting the value of 15R-RGB MWR from the value of 15R-USB.

As can be seen in Figure 18, in general the reflectance measured with the 15R-USB is higher than the one measured with MWR. An exception is the silvered polymer film reflector, where the reflectance measured with MWR is higher than with 15R-USB. The reflectance differences for the silvered glass reflectors are very small (0.001 in average and 0.003 as maximum). This is due to the stability and homogeneity of the silvered glass reflectors. However, due to the heterogeneity and flexibility of silvered polymer film and aluminum reflectors, the reflectance differences are more significant $(0.007$ in average and 0.018 as maximum). In addition, it should be mentioned that the calibration with the $3.5 \mathrm{mrad}$ setting is quite difficult and consequently the results for this $\varphi$ are not consistent with the ones obtained for the rest of the $\varphi$.

A test to compare the specular reflectance and the hemispherical reflectance for several types of reflectors (silvered-glass, silvered polymer film and aluminum reflectors) was done. The specular reflectance was measured with the 15R-RGB MWR by D\&S for every $\lambda$ and with every $\varphi$, and the results were compared with the hemispherical reflectance measured with a PE Lambda 1050 spectrophotometer, with the integrating sphere. The results are presented in the following 4 figures. 


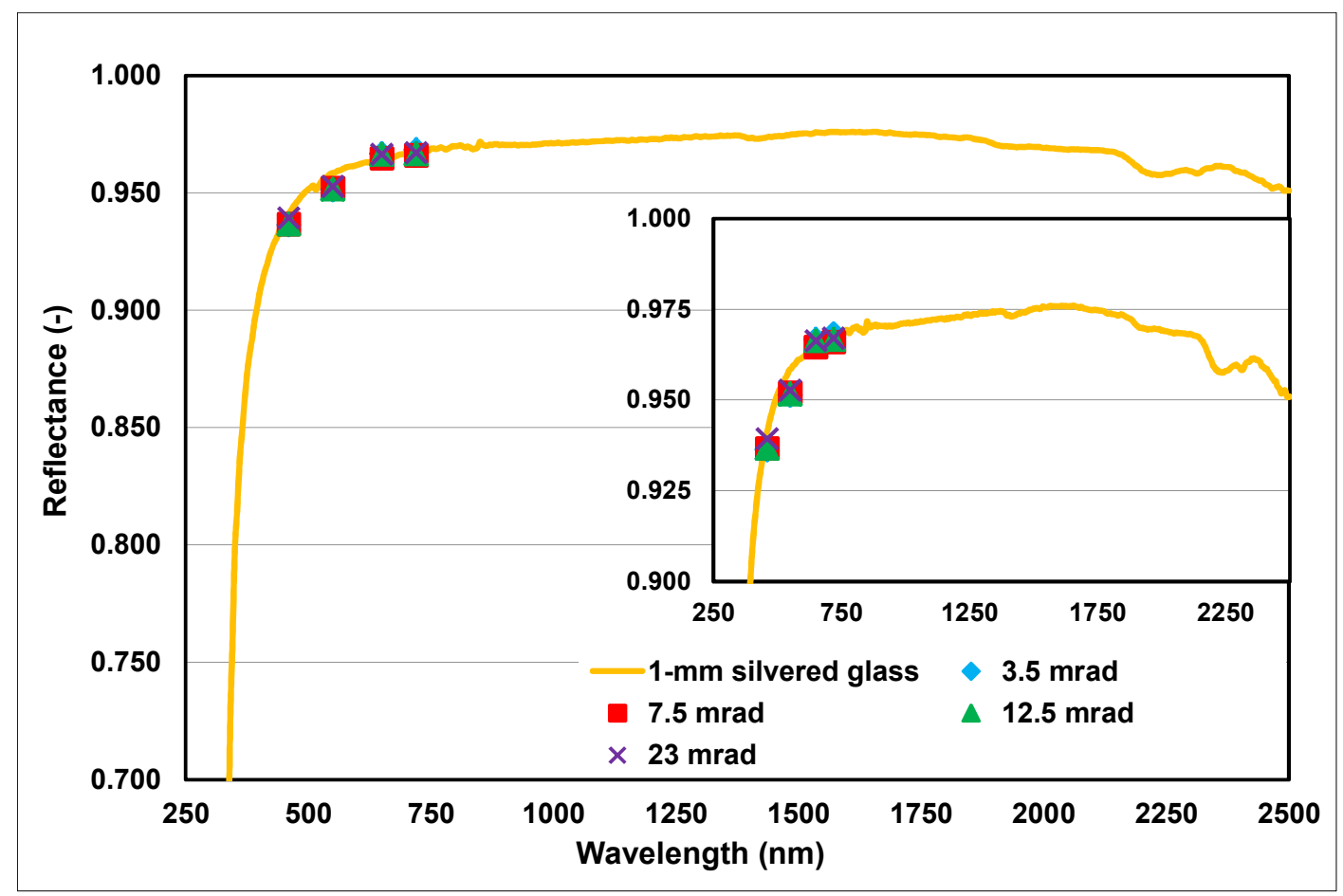

Figure 19. Reflectance measurements of 1-mm silvered glass with the PE Lambda 1050 spectrophotometer with an integrating sphere and the D\&S 15R-RGB reflectometer.

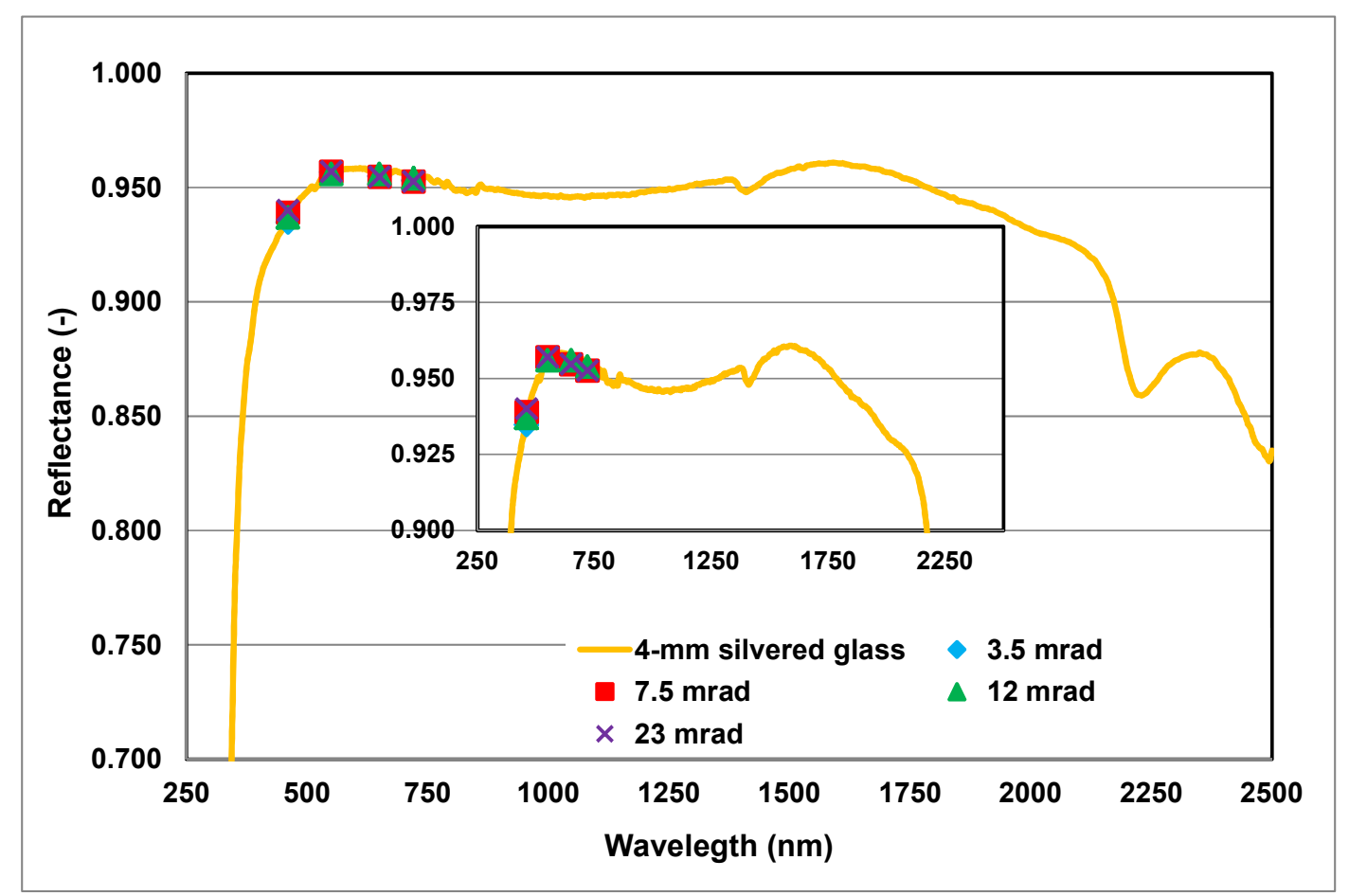

Figure 20. Reflectance measurements of 4-mm silvered glass with the PE Lambda 1050 spectrophotometer with an integrating sphere and the D\&S 15R-RGB reflectometer. 


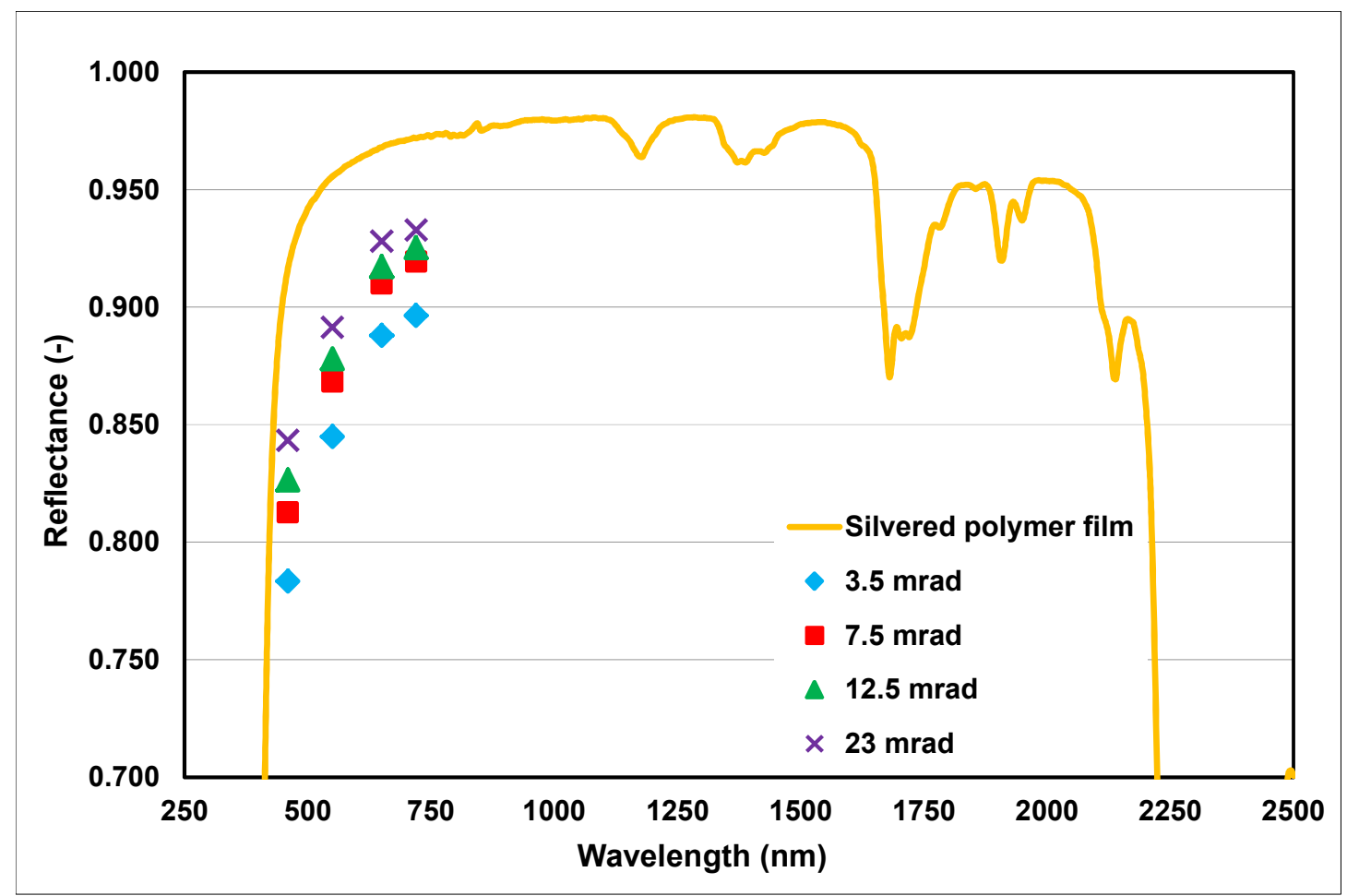

Figure 21. Reflectance measurements of silvered polymer film with the PE Lambda 1050 spectrophotometer with an integrating sphere and the D\&S 15R-RGB reflectometer.

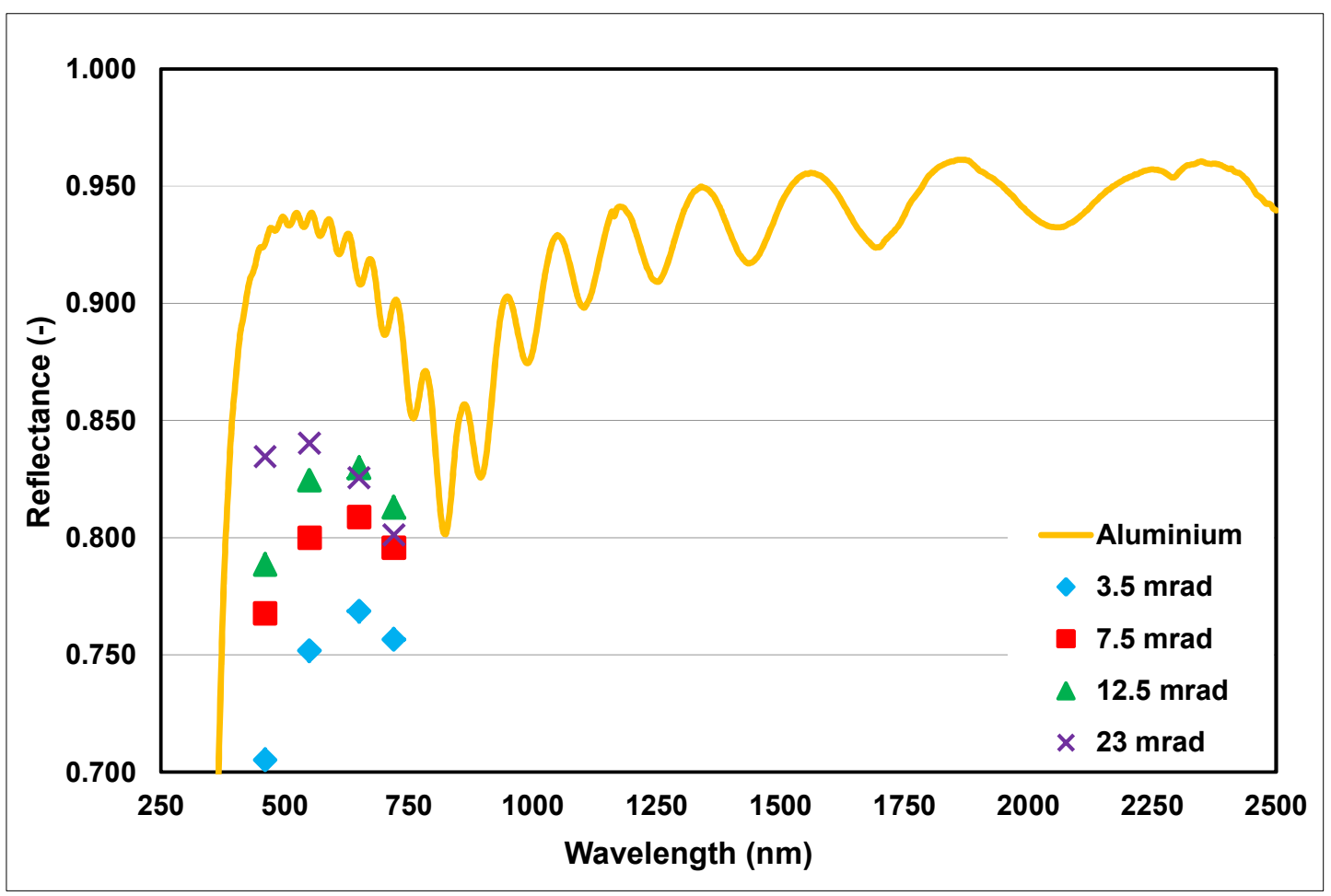


Figure 22. Reflectance measurements of aluminum with the PE Lambda 1050 spectrophotometer with an integrating sphere and the D\&S 15R-RGB reflectometer.

As can be seen in Figure 19 andFigure 20 for the silvered-glass reflectors, the specular and the hemispherical reflectance are nearly equal and the specular reflectance using different $\varphi$ is almost constant for each $\lambda$. This indicates small scattering and a high specularity for all the $\lambda$ under analysis. For the silvered polymer film and aluminum reflectors (see Figure 21 and Figure 22), the specular reflectance increases with the $\varphi$ and it is noticeably lower than the hemispherical reflectance. This indicates more scattering on these samples and that the scattering is wavelength dependent, with more scattering for small $\lambda$.

\subsubsection{Condor by Abengoa Solar}

The Condor reflectometer, marketed by Abengoa Solar since 2012 and developed in cooperation with the Zaragoza University (see Figure 23 left), is an accurate, precise, robust and easy to use portable instrument. It is designed for measurements in actual solar fields in working CSP plants [71], [72]. It can make specular reflectance measurements at different $\lambda=\{435,525,650,780,940,1050\} \mathrm{nm}$, and $\theta_{i}=12^{\circ}$. The source of these different $\lambda$ lights are six LEDs, and six corresponding detectors are included (see the optical scheme in Figure 23 right). As each LED is separated from the next by $19 \mathrm{~mm}$, the measurements for the different $\lambda$ are not done at the same position of the sample. Since there are six LEDs the distance from the first to the last is $95 \mathrm{~mm}$. The reflectometer determines the specular reflectance for both second and first surface reflectors due to the optical arrangements. The battery autonomy is 1200 measurements and the weight is $1.4 \mathrm{~kg}$. This reflectometer has a $1 \mathrm{~mm}$ beam diameter and $\varphi=290 \mathrm{mrad}$. According to the manufacturer, the repeatability is \pm 0.002 . The high $\varphi$ facilitates quick and reliable measurements of large reflecting areas. Operating temperature is from 0 to $55^{\circ} \mathrm{C}$. The instruments resolution is 0.001 . This instrument does not present optical alignment.

The Condor is simple to use. It is battery operated and requires charging before use. After switching on, it requires 5-10 minutes for pre-heating and stabilization before taking measurements. The instrument includes a visual display which guides the operator through the correct operating procedure. Since the instrument is a comparator it requires a calibration reflectance using the standard mirror provided. Following this, the 
instrument is then leaned against the mirror under test and the measurement system activated from the menu screen. The measurements through the six LEDS and detectors are taken sequentially, taking approximately 3-4 seconds for the full data to be collected and stored within the instrument. Then the next reading can be taken. The instrument includes an internal temperature sensor. If the predetermined temperature range is exceeded a warning message is displayed and the instrument must be re-calibrated. Data can be downloaded later using a USB port, and copied into Excel. The instrument can operate in automatic mode or manually if only selected wavelengths are required. It is being employed in research studies to characterize solar reflectors [59] [73].
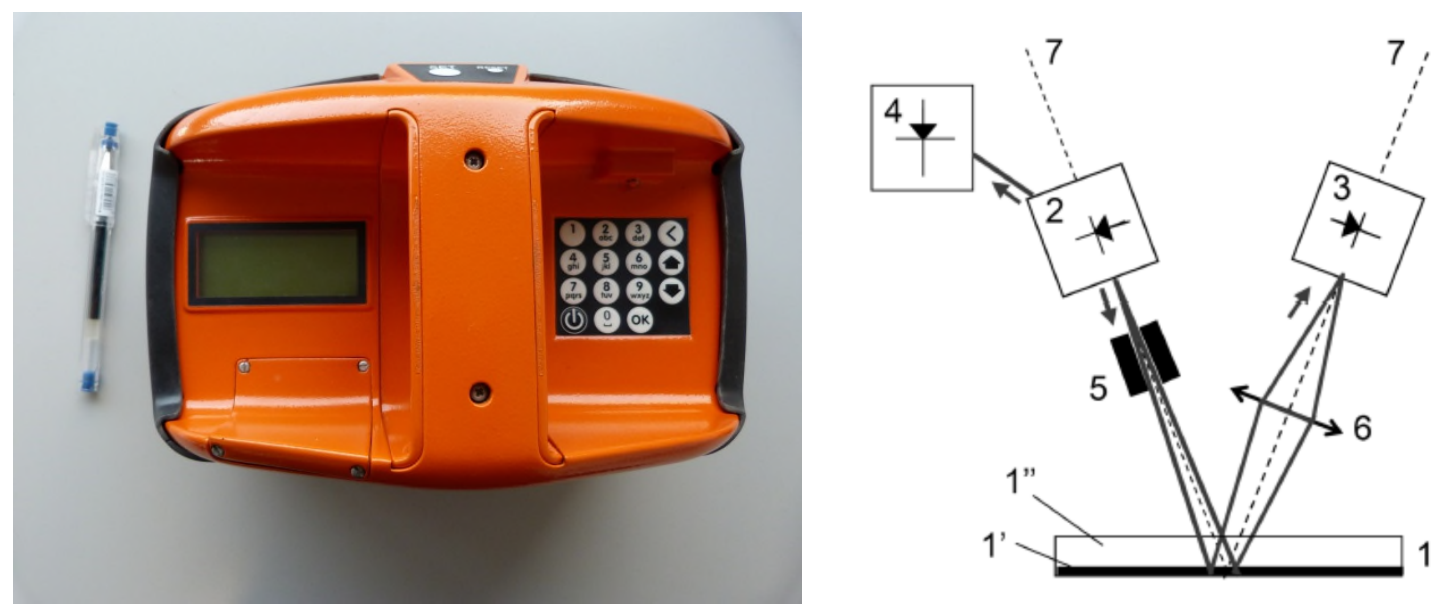

Figure 23. Left: Picture of the Condor reflectometer by Abengoa. Right: Optical scheme of the Condor reflectometer by Abengoa [71]; (1): Mirror; (1'): Reflected surface; (1')): Glass; (2): Led, emitter; (3): reflection detector; (4): Reference detector; (5): Diaphragm; (6): Lens; (7): Optic edge.

\subsubsection{SOC 410 Solar by Surface Optics}

The 410-Solar, patented (in 2007) and marketed by Surface Optics, is based on a modified integrating sphere [74][75]. It measures total reflectance at seven sub-bands between $\lambda=[330,2500] \mathrm{nm}$ spectral range with a tungsten filament source. Specifically, the wavelength bands are $\lambda_{1}=[335,380] \mathrm{nm}, \lambda_{2}=[400,540] \mathrm{nm}, \lambda_{3}=[480,600] \mathrm{nm}$, $\lambda_{4}=[590,720] \mathrm{nm}, \lambda_{5}=[700,1100] \mathrm{nm}, \lambda_{6}=[1000,1700] \mathrm{nm}$ and $\lambda_{7}=[1700,2500] \mathrm{nm}$ [76]. The signal intensity is normalized against an internal standard. Total, diffuse and specular reflectance is reported for the data at $\theta_{i}=20^{\circ}$. This reflectometer has a $6.35 \mathrm{~mm}$ 
diameter beam spot and $\varphi=52.4 \mathrm{mrad}$. A total of eight data points are produced during a single data acquisition cycle.

The device measures the diffuse portion of the total reflectance using the specular port plug which is fully automated. The port plug is lifted away from the sphere allowing the 20 degrees specular beam to escape and thus leaving the diffuse portion of the total reflectance left to measure. The specular beam portion is obtained by subtracting the diffuse reflectance from the total reflectance. For maximum accuracy it can be calibrated with a specular calibration reference standard or with a diffuse one. The maximum curvature accepted is $15.24 \mathrm{~mm}$ ratio. The battery autonomy is $2 \mathrm{~h}$ and the weight is $2.13 \mathrm{~kg}$. Operating conditions are from 0 to $40^{\circ} \mathrm{C}$, non-condensing, and storage temperature is from -25 to $70^{\circ} \mathrm{C}$. The resolution is \pm 0.001 and predicts accuracy of \pm 0.03 [76]. For the calibration, two references are needed (one with high specularity and another one highly diffuse). This instrument does not present optical alignment. Special care must be taken during the measurement to avoid moving the contact point and so modifying the diffuse reading.

A study was conducted on an LS3 sized collector (that is, $5.76 \mathrm{~m}$ aperture width and $1.71 \mathrm{~m}$ focal length) with $4 \mathrm{~mm}$ thick glass reflectors in Lakewood, Colorado, to compare three portable reflectometers: 15R-USB by D\&S, Condor by Abengoa Solar and SOC 410 Solar by Surface Optics [76]. The study compared relative reflectance measurements on naturally soiled mirrors during two months, as well as the ease of use of each instrument. According to the results obtained, the comparison between the D\&S 15RUSB and the Condor showed reasonable correlation and high agreement because they predicted the same amount of change between measurements to within $7-13 \%$. With respect to the comparisons between the SOC 410 Solar and either of the other two instruments, results achieved were inconclusive because they had low correlation. A according to the authors of the study, this could be due to the abnormally high standard deviations of the measurements done with the SOC 410 Solar reflectometer, which may be a consequence of operator errors or reflectors curvature and thickness [76].

\subsubsection{700-d by Konica Minolta}

The Konica Minolta CM-700d (marketed since 2007) is a portable spectrophotometer with vertical alignment, designed for broadband measurement with high repeatability on shaped and curved samples [77]. As in the SOC 410 Solar device, this instrument uses an 
integrating sphere to measure total hemispherical reflectance and diffuse reflectance (by opening the specular port). The difference between the two values is the specular reflection. The integrating sphere size is $40 \mathrm{~mm}$ diameter. For each measurement, data for specular components included (that is, hemispherical reflectance) and excluded (that is, diffuse reflectance) are taken simultaneously to analyse the surface conditions. The wavelength range is $\lambda=[400,700] \mathrm{nm}$ with a xenon source and $\theta_{i}=8^{\circ}$. The instrument resolution is \pm 0.001 and the repeatability is \pm 0.002 . On the $C M-700 \mathrm{~d}$, the measuring spot, i.e. the diameter of the detected beam on the reflector plane, is selectable between $3 \mathrm{~mm}$ and $8 \mathrm{~mm}$ to measure small samples. On the CM-660d, the measuring spot is $8 \mathrm{~mm}$. With a weight of $0.55 \mathrm{~kg}$, the CM-700d is quite light and thus improving portability for on-site measurement. The battery autonomy is 2000 measurements. Operating conditions are from 5 to $40^{\circ} \mathrm{C}$, and at $80 \%$ relative humidity or less with no condensation. This instrument does not present optical alignment. Special care must be taken during the measurement to avoid moving the contact point and so modifying the diffuse reading.

\subsection{5 $\mu$ Scan by Schmitt Measurement Systems (SMS)}

The SMS $\mu$ Scan System (see Figure 24 left) can calculate surface roughness, reflectance and scattered light levels on flat or curved surfaces under any lighting conditions [78]. It was firstly used for concentrating solar applications by Kramer Junction at the SEGS plants by the end of the nighties of last century. The portable system consists of an interchangeable measurement head (number 1 in Figure 24 right), a hand held control unit (number 2 in Figure 24 right) and separate charging unit (number 3 in Figure 24 right). To perform a measurement, the operator places the measurement head on the surface to be analyzed (which must be connected to the hand held control unit) and simply presses the button. The results are clearly displayed and stored in the system memory. The $\mu$ Scan measuring head has a class II laser source ${ }^{2}\left(\theta_{i}=25^{\circ}\right.$ and $\left.\lambda=670 \mathrm{~nm}\right)$, reflectance detector and two scatter detectors inside and creates a spot size on the target of $1 \mathrm{~mm}$ diameter. The instrument resolution is \pm 0.001 and the repeatability is \pm 0.005 . The curvature accepted is $114.3 \mathrm{~mm}$ diameter minimum. Operating temperature is from -10 to $45^{\circ} \mathrm{C}$. The battery autonomy is $5 \mathrm{~h}$ and the weight is $2.2 \mathrm{~kg}$ in total (control unit and measurement head). This instrument does not present optical alignment and $\varphi$ value is not

\footnotetext{
${ }^{2}$ A laser source is classified as class II when the blink reflex of the human eye (aversion response) will prevent eye damage, unless the person deliberately stares into the beam for an extended period.
} 
available. The calibration process consist on measuring a reference mirror of known specular reflectance at $\lambda=670 \mathrm{~nm}$ (reference value) and introducing the obtained datum (current value) in the software, which automatically compensate the instrument according to the relation between the true and current value. The reference mirror must be of the same type (glass thickness, reflective metal and curvature) of the mirror sample to be measured. In a research work performed at the PSA, it was detected that the accuracy of this instrument is not sufficient for high quality CSP reflector characterization [79].
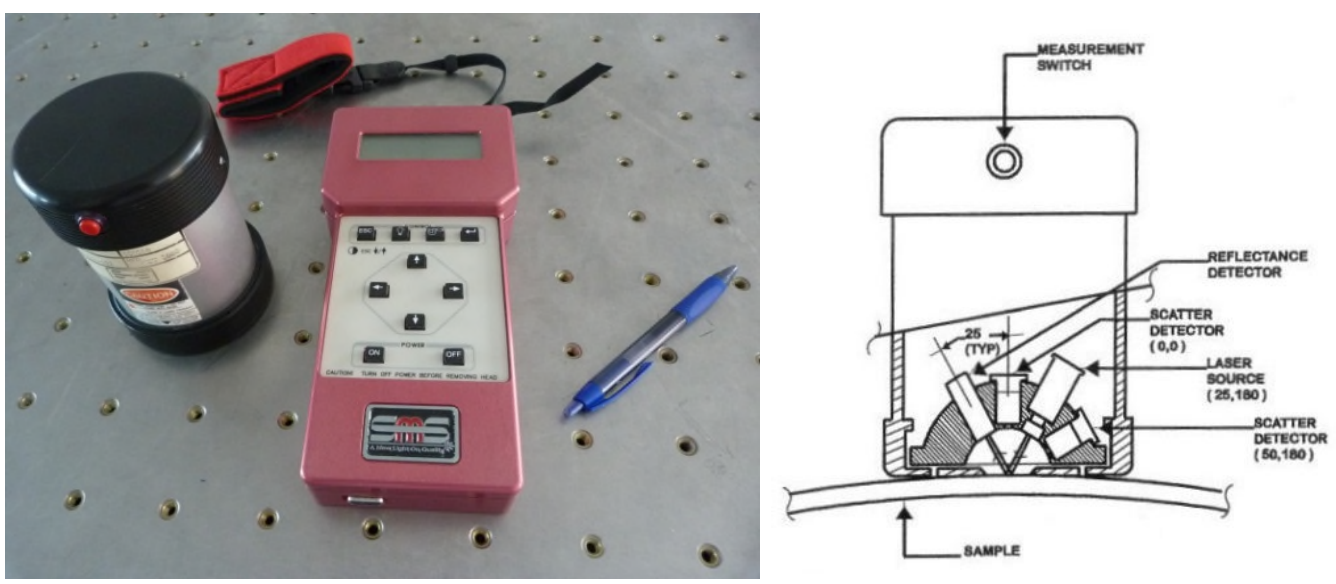

Figure 24. Left: Picture of the $\mu$ Scan portable reflectometer by SMS; (1): interchangeable measurement head; (2): hand held control unit; (3): charging unit. Right: Principle sketch of the measurement head of the $\mu$ Scan by SMS.

\subsubsection{Pflex by PSE AG / Fraunhofer ISE}

The new marketed Pflex instrument of PSE AG was developed in collaboration with Fraunhofer ISE (see Figure 25) [80]. It measures specular reflectance of both flat and curved reflectors and is operated via a user interface on a mobile phone. The measurement spot is $10 \mathrm{~mm}$ diameter size, with $\theta_{i}=8^{\circ}$ and $\lambda=631 \mathrm{~nm}$ (optionally 455, 533 or $660 \mathrm{~nm}$ ). According to the manufacturer, the repeatability is \pm 0.005 and the operating temperature is from -15 to $60^{\circ} \mathrm{C}$. The battery autonomy is more than $24 \mathrm{~h}$. The calibration is done by measuring a reference mirror and the offset is stablished with a black reference. This instrument has already been proved by the developing institution, Fraunhofer ISE [81]. 


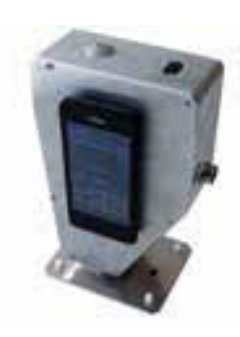

Figure 25. Picture of the PFlex reflectometer by PSE AG/Fraunhofer ISE [80].

\subsubsection{Tracking Cleanliness Sensor (TraCS) by CSP Services / DLR}

The TraCS device, developed by DLR and marketed by CSP Services since 2016 [82], is an accurate measurement system to study the cleanliness of solar mirrors by using already well-established measurement equipment [83], [84]. It differs from the above mentioned reflectometers in that it is stationary and measures reflectance with the actual sun spectrum although not spectrally resolved as in a spectrophotometer. The measurement can be taken automatically and continuously at remote sites using the available data acquisition system.

A precise meteorological station, as frequently used in resource assessment or in a running power plant, consists of a solar tracker with a pyrheliometer for measuring the direct normal irradiance (DNI) (see Figure 26). As accessory on the same tracker, a second pyrheliometer is mounted looking backwards into a mirror that reflects the direct solar irradiance into it. The measuring spot is $16 \mathrm{~mm}$ in diameter. A motor turns the mirror in its plane to increase the measurement area to approximately $30 \mathrm{~cm}^{2}$.

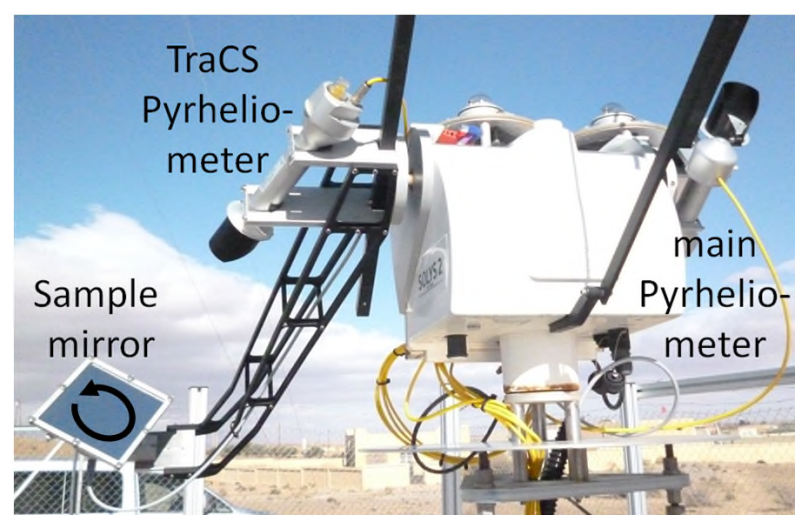

Figure 26. Picture of the TraCS accessory by CSP Services / DLR at a remote meteorological station in Morocco. 
It can be adapted to target power plant conditions regarding $\theta_{i}$ and $\varphi$. By default $\theta_{i}=15^{\circ}$ and $\varphi=13.6 \mathrm{mrad}$. The mirror surface covers the complete imaginary area defined by the opening angle of the pyrheliometer and the working distance. Therefore the portion of the detected light originating behind the sample mirror is negligible.

The specular reflectance integrated over the current solar spectrum, i.e. the solar weighted specular reflectance is obtained according to equation (10).

$$
\rho_{s, \varphi}(t)=\frac{D N I_{\text {reflected }}(t)}{D N I_{\text {sun }}(t)},
$$

where $t$ is the time, $D N I_{\text {reflected }}$ is the DNI measured by the TraCS pyrheliometer and $D N I_{\text {sun }}$ is the directly measured DNI. It has to be noted that the solar weighting is not performed with the standard spectrum, but the specific solar spectrum present at the location and time of measurement as each wavelength contributes equally to the pyrheliometer irradiance measurement signal.

A calibration constant $C_{\text {clean }}$ can be determined to give the cleanliness of the mirror according to equation (11)

$$
\begin{aligned}
& \underset{\text { Tclean }}{\operatorname{mean}}\left(\frac{D N I_{\text {reflected, clean }}(t)}{D N I_{\text {sun }}(t)}\right)=C_{\text {clean }}=\text { const, } \\
& \text { cleanliness }(t)=\frac{D N I_{\text {reflected, soiled }}(t)}{C_{\text {clean }} * D N I_{\text {sun }}(t)}
\end{aligned}
$$

where Tclean denotes a time span of approximately one hour directly after cleaning the sample mirror which is recommended every one to two weeks noting the time of cleaning for calibration. Both pyrheliometers shall be cleaned daily, which is the standard requirement for pyrheliometer measurements [85]. Thus no additional maintenance visits are required for TraCS.

The calibration of the cleanliness measurement is performed during data processing. Therefore the mirror is considered as the clean reference right after a mirror cleaning event. The accuracy of solar-weighted reflectance measurement depends on the measurement accuracy of the pyrheliometers. The solar weighting is a result of the 
measurement principle. The TraCS instrument operates at temperatures between - 20 and $+50{ }^{\circ} \mathrm{C}$.

The time derivative of the continuous cleanliness measurement is the soiling-rate. In daily time resolution it is a convenient parameter for application in optimization of cleaning cycles, plant yield analysis and research on the causes of soiling as it is independent of the cleaning cycles of the TraCS sample mirror. An example measurement curve for a soiled mirror is shown in Figure 27. This also illustrates the effect of the mirror rotation: each red dot in the graph represents the cleanliness for a spot of $2 \mathrm{~cm}^{2}$ on the mirror. These spots are located along the circular arrow shown in Figure 26. The blue dots represent the average cleanliness over one full rotation of the mirror that is completed every 10 minutes. The variation of the high time resolution measurement is an indicator for the homogeneity of the soiling pattern.

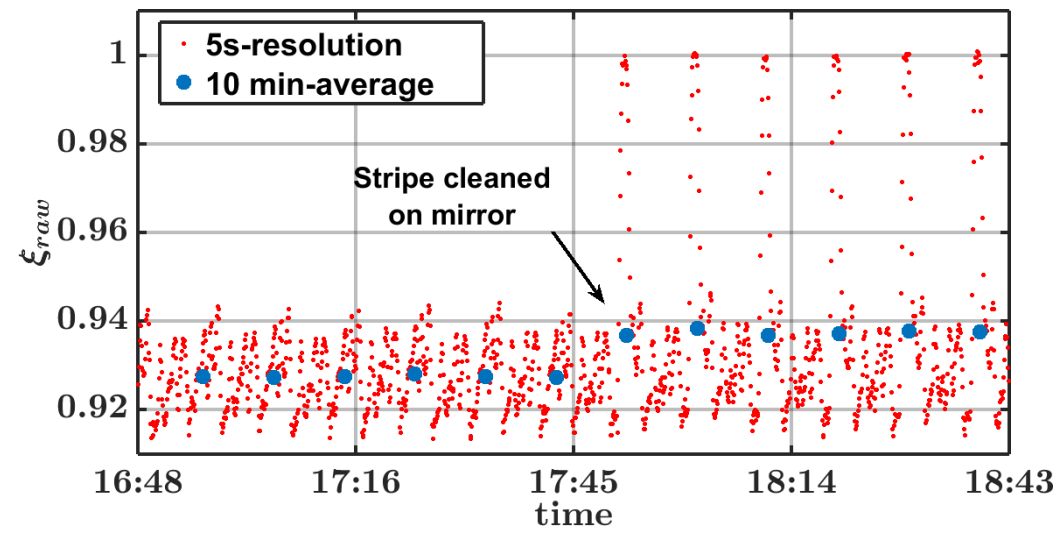

Figure 27. Measurement curve of the TraCS for cleanliness, $\xi$, over time. A stripe on the mirror has been cleaned at 17:50h. After that, the 5s-values rise regularly to 1 during the rotation of the mirror, slightly increasing the $10 \mathrm{~min}$ average and reproducing the mirror's soiling profile.

It was checked that changing $\varphi$ from 19 to $46 \mathrm{mrad}$ does not systematically affect the measurement results in accordance with the results in [18]. The TraCS has shown good accordance with the D\&S 15R-USB and same reproducibility. The accuracy for a 10 minute average cleanliness value is $1.8 \%$, for daily soiling rate $0.19 \%$ / day [86].

\subsubsection{Summary of reflectometers}

The main characteristics of the reflectometers are summarized in Table 2. The information was taken from manuals or manufacturer's data sheets, and also from the 
experience of the authors as users of those instruments.

\section{Table 2}

Main features of the commercial reflectometers. *: information not available. 


\begin{tabular}{|c|c|c|c|c|c|c|c|}
\hline Manufacturer & Surface Optics & Device \& Services Co & $\begin{array}{c}\text { Schmitt Measurement } \\
\text { Systems }\end{array}$ & Abengoa & Konica Minolta & CSP Services GmbH & PSE AG \\
\hline Model & 410 Solar & $\begin{array}{l}15 R-U S B \\
15 R-R G B\end{array}$ & $\mu \operatorname{Scan}{ }^{T M}$ & Condor & $C M-700 d / 600 d$ & $\operatorname{TraCS}$ & PFlex \\
\hline Measurement principle & $\begin{array}{c}\text { Integrating sphere unit } \\
\text { where the specular port } \\
\text { can be opened }\end{array}$ & $\begin{array}{c}\text { A source lamp and a } \\
\text { detector positioned in } \\
\text { incidence and outgoing } \\
\text { angles }\end{array}$ & $\begin{array}{c}\text { A source lamp and a } \\
\text { detector positioned in } \\
\text { incidence and outgoing } \\
\text { angles }\end{array}$ & \begin{tabular}{|c|} 
Six optical channels \\
composed by a source \\
lamp and two \\
detectors \\
\end{tabular} & $\begin{array}{c}\text { Integrating sphere unit } \\
\text { where the specular port } \\
\text { can be opened }\end{array}$ & $\begin{array}{l}\text { One pyrheliometer for } \\
\text { measuring DNI and } \\
\text { another looking at the } \\
\text { mirror sample }\end{array}$ & $\begin{array}{c}\text { A source lamp and a } \\
\text { detector positioned in } \\
\text { incidence and outgoing } \\
\text { angles }\end{array}$ \\
\hline Measurement type & $\begin{array}{l}\text { Hemispherical and } \\
\text { diffuse reflectance } \\
\text { (specular calculated) }\end{array}$ & $\begin{array}{c}\text { Specular reflectance at } \\
\text { selected } \varphi\end{array}$ & $\begin{array}{c}\text { Bidirectional scatter } \\
\text { function, roughness and } \\
\text { specular reflectance }\end{array}$ & Specular reflectance & $\begin{array}{c}\text { Hemispherical and } \\
\text { diffuse reflectance and } \\
\text { colour }\end{array}$ & Specular reflectance & Specular reflectance \\
\hline Light source & Tungsten & $\begin{array}{c}\text { LED (USB), white } \\
\text { light with filters (RGB) }\end{array}$ & Class II Laser & Six LED & Xenon & Sun & $*$ \\
\hline Incidence angle, $\theta_{i}\left({ }^{\circ}\right)$ & 20 & 15 & 25 & 12 & 8 & 15 & 8 \\
\hline $\begin{array}{c}\text { Beam spot size } \\
\text { (diameter in } \mathrm{mm} \text { ) }\end{array}$ & 6.35 & 10.00 & 1.00 & 1.00 & $\begin{array}{c}3 \text { to } 8(700 \mathrm{~d} \text { model }) \\
8(600 \mathrm{~d} \text { model })\end{array}$ & 16 & 10.00 \\
\hline $\begin{array}{l}\text { Wavelength range, } \lambda \\
(\mathrm{nm})\end{array}$ & $\begin{array}{l}\text { Seven bands between } \\
300 \text { and } 2500\end{array}$ & $\begin{array}{c}\text { Peak at } 660(15 \mathrm{R}- \\
\text { USB) } \\
460,550,650720 \\
(15 \mathrm{R}-\mathrm{RGB})\end{array}$ & Peak at 670 & $\begin{array}{l}435,525,650 \\
780,940,1050\end{array}$ & $400-700$ & $\begin{array}{l}\text { Integrated full solar } \\
\text { spectrum }\end{array}$ & $\begin{array}{c}631 \text { (optional } 455,533, \\
660)\end{array}$ \\
\hline $\begin{array}{c}\text { Acceptance angle, } \varphi \\
(\mathrm{mrad})\end{array}$ & 52.4 & $\begin{array}{c}2.3 \text { (15R-RGB only), } \\
3.5,7.5,12.5,23.0\end{array}$ & $*$ & 290 & $*$ & 13.6 & $*$ \\
\hline $\begin{array}{c}\text { Accuracy (reflectance } \\
\text { units) }\end{array}$ & \pm 0.020 & 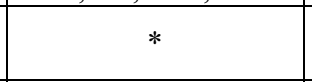 & \pm 0.020 & \pm 0.002 & * & \pm 0.018 & $*$ \\
\hline $\begin{array}{c}\text { Repeatability } \\
\text { (reflectance units) } \\
\end{array}$ & $\pm 0.002-0.005$ & \pm 0.002 & \pm 0.005 & \pm 0.002 & \pm 0.002 & $*$ & \pm 0.001 \\
\hline $\begin{array}{c}\text { Resolution (reflectance } \\
\text { units) }\end{array}$ & $*$ & \pm 0.001 & \pm 0.001 & \pm 0.001 & \pm 0.001 & $*$ & \pm 0.005 \\
\hline $\begin{array}{c}\text { Adaptable to mirror } \\
\text { curvature }\end{array}$ & $\begin{array}{c}\text { Yes, } 15.24 \mathrm{~mm} \text { ratio } \\
\text { minimum }\end{array}$ & Yes & $\begin{array}{c}\text { Yes, } 114.3 \mathrm{~mm} \text { ratio } \\
\text { minimum }\end{array}$ & No & No & limited & Yes \\
\hline $\begin{array}{c}\text { Suitable for } 1^{\text {st }} \text { and } 2^{\text {nd }} \\
\text { surface mirrors }\end{array}$ & 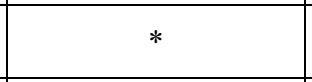 & Yes & No & Yes & No & Yes & Yes \\
\hline $\begin{array}{c}\text { Influence of external } \\
\text { light }\end{array}$ & $*$ & $\begin{array}{l}\text { No (chopped light } \\
\text { source) }\end{array}$ & Yes & $\begin{array}{c}\text { No (synchronous } \\
\text { detection at modulated } \\
\text { frequency) }\end{array}$ & $\begin{array}{l}\text { No (pulsed light } \\
\text { source) }\end{array}$ & $\begin{array}{l}\text { Requires DNI }>200 \mathrm{~W} / \mathrm{m}^{2} \\
\text { for measurement }\end{array}$ & No \\
\hline Weight $(\mathrm{kg})$ & 2.13 & 1.10 & 2.2 & 1.40 & 0.55 & $*$ & $*$ \\
\hline Operating temp. $\left({ }^{\circ} \mathrm{C}\right)$ & $0-40$ & $0-50$ & $-10-45$ & $0-55$ & $5-40$ & $-20-50$ & $-15-60$ \\
\hline Autonomy & $2 \mathrm{~h}$ & $49-52 \mathrm{~h}$ & $5 \mathrm{~h}$ & 1200 measurements & 2000 measurements & $*$ & $>24 \mathrm{~h}$ \\
\hline
\end{tabular}




\begin{tabular}{|c|c|c|c|c|c|c|c|}
\hline $\begin{array}{l}\text { Average time needed } \\
\text { for a measurement (s) }\end{array}$ & $10 \mathrm{~s}$ & $10 \mathrm{~s}$ & $7 \mathrm{~s}$ & $8 \mathrm{~s}$ & $*$ & $10 \mathrm{~m}$ & 8 \\
\hline $\begin{array}{l}\text { Level of required } \\
\text { experience of the } \\
\text { operator }\end{array}$ & $\begin{array}{c}\text { On site: high } \\
\text { (maintaining the seal } \\
\text { with the mirror is } \\
\text { highly prone to } \\
\text { operator error } \\
\text { Data evaluation: } \\
\text { medium } \\
\end{array}$ & $\begin{array}{l}\text { On site: high (optical } \\
\text { alignment require an } \\
\text { experienced operator) } \\
\text { Data evaluation: low }\end{array}$ & $\begin{array}{l}\text { On-site: low } \\
\text { Data evaluation: } \\
\text { medium }\end{array}$ & \begin{tabular}{|c|} 
On-site: low (very \\
little room for operator \\
error) \\
Data evaluation: \\
medium
\end{tabular} & * & $\begin{array}{c}\text { On site: low } \\
\text { Data evaluation: high }\end{array}$ & $\begin{array}{c}\text { On site: low } \\
\text { (insensitive and robust } \\
\text { against slight tilt or } \\
\text { twist of the instrument) } \\
\text { Data evaluation: } \\
\text { medium }\end{array}$ \\
\hline Type of calibration & $\begin{array}{c}\text { Two external reference } \\
\text { mirrors }\end{array}$ & $\begin{array}{c}\text { One external reference } \\
\text { mirror }\end{array}$ & $\begin{array}{c}\text { One external reference } \\
\text { mirror }\end{array}$ & $\begin{array}{c}\text { One external reference } \\
\text { mirror }\end{array}$ & * & $\begin{array}{c}\text { Cleanliness: sample } \\
\text { mirror in clean state } \\
\text { Reflectance: reference } \\
\text { mirror } \\
\end{array}$ & $\begin{array}{c}\text { Black reference } \\
\text { (offset) and one } \\
\text { external reference } \\
\text { mirror }\end{array}$ \\
\hline Beam aligment & No & Yes & No & No & No & $\begin{array}{c}\text { Optical, using } \\
\text { pyrheliometer pinholes }\end{array}$ & No \\
\hline References & {$[74][76]$} & {$[60],[61]$} & [78] & {$[71][76]$} & [77] & {$[82]$} & [81] \\
\hline
\end{tabular}




\section{Prototypes}

In the last decade, and thanks to the great evolution and increasing interest in CSP technologies, a significant research effort has been dedicated to developing more appropriate instrumentation to characterize the CSP components. In particular, several prestigious research institutes and related industrial companies have been working on the development of prototypes to characterize the optical properties of concentrating solar reflectors in an adequate manner. This section includes a summary of the most advanced ones.

\subsection{Space Resolved Specular Reflectometer (SR) ${ }^{2}$ by DLR}

$(\mathrm{SR})^{2}$ is a laboratory scale reflectometer developed by DLR in 2010 to improve the existing specular reflectance measurement capabilities (see Figure 28 left) [16]. It makes possible to measure specular reflectance on an extended measuring spot of $53.5 \mathrm{~mm}$ diameter. It has a spatial resolution of $37 \mathrm{pixel} / \mathrm{mm}$ and the possibility to measure at three different $\lambda, \lambda=\{410,500,656\} \mathrm{nm}$, with $\theta_{i}=15^{\circ}$. Furthermore, the $\varphi$ is defined by choosing one of the three available aperture sizes, $\varphi=\{3.5,6.0,12.5\} \mathrm{mrad}$.

Figure 28 right depicts the light path of the $(\mathrm{SR})^{2}$. The vertical sample holder has a vacuum suction mechanism for precise sample placement. This is especially advantageous for thin and flexible samples, as the measured specularity of the material depends strongly on the sample flatness. Desired $\lambda$ is set by changing the interference filters inserted in the light path coming from the source, which is a white stabilized LED. Similarly, the $\varphi$ is set making use of the aperture wheel placed in front of the detector. The light passing the aperture is detected by the complementary metal-oxidesemiconductor (CMOS) sensor of a commercial single lens reflex camera. The specular reflectance of the sample is obtained by calibrating the instrument with a reference mirror, whose reflective properties are known. The working temperature should be laboratory conditions. 

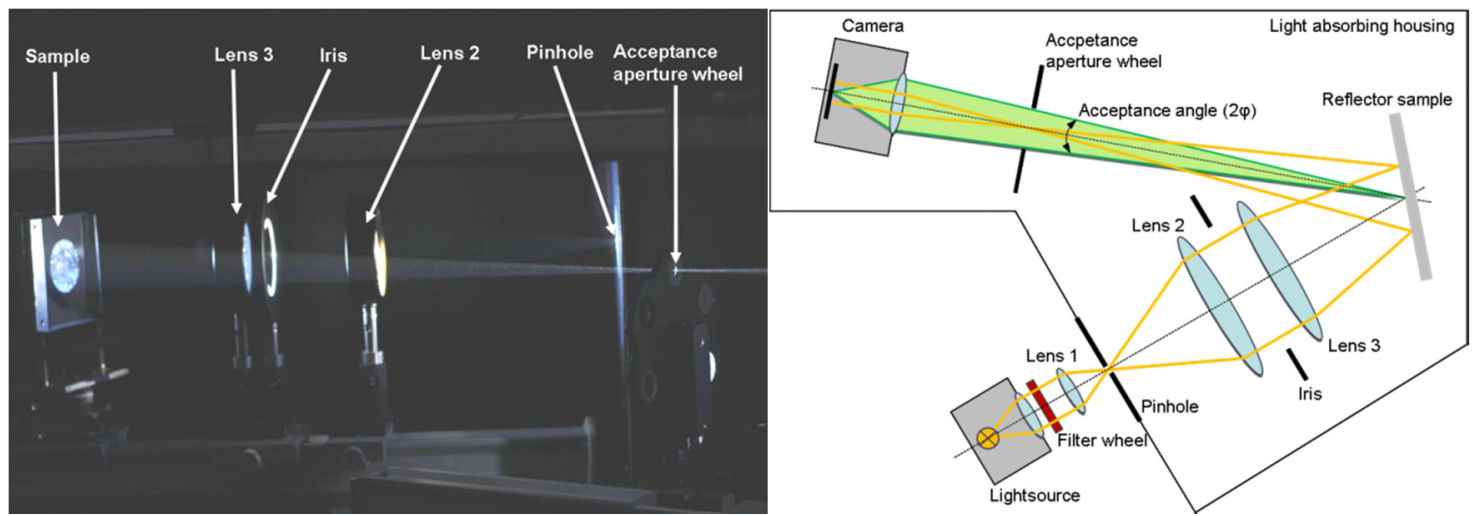

Figure 28. Left: Picture of the light path of the (SR $)^{2}$ prototype by DLR within the absorbing housing (camera was not mounted). Right: Scheme of the light path of the $(\mathrm{SR})^{2}$ prototype by DLR.

The image captured by the camera is transferred to a computer unit for processing. To obtain the measurement data, image processing is done from a graphical user interface developed with Matlab ${ }^{\circledR}$. Primarily, average specular reflectance and a reflectance map of the measured region are shown as the output. In the reflectance map, every pixel is displayed on a color scale from $0 \%$ to $100 \%$, where blue pixels mean low specular reflectance and red pixels mean high specular reflectance. The features for degradation analysis include information such as automatic counting of detected degradation spots, percentage of degraded area and specular reflectance values of corroded and noncorroded areas in order to determine the influence of corrosion on the overall performance of the material.

Thanks to its relatively large measuring area and spatial resolution, this device is helpful to characterize the effect of localized degradation on specular reflectance of degraded reflectors and to monitor gradual changes such as the growth of degradation on the surfaces. Another interesting application of the instrument is the characterization of the spatial distribution of reflectance loss due to soiling found on mirrors after exposure. A research study to analyze the effect of localized corrosion on the specular reflectance of enhanced aluminum reflectors and to monitor corrosion growth was conducted using the $(\mathrm{SR})^{2}$ [87] - [89]. The study consisted on the one hand of the outdoor exposing of several samples at the following weathering sites: Phoenix (Arizona), Golden (Colorado), and Miami (Florida) in the United States, plus Cologne (Germany) and Tabernas (Spain) in Europe (see Figure 29). In addition, accelerated aging tests were conducted (sand erosion, 
salt spray and humidity/temperature combination) and a model to estimate the specular reflectance as a function of exposure conditions at different weathering sites was developed [89].

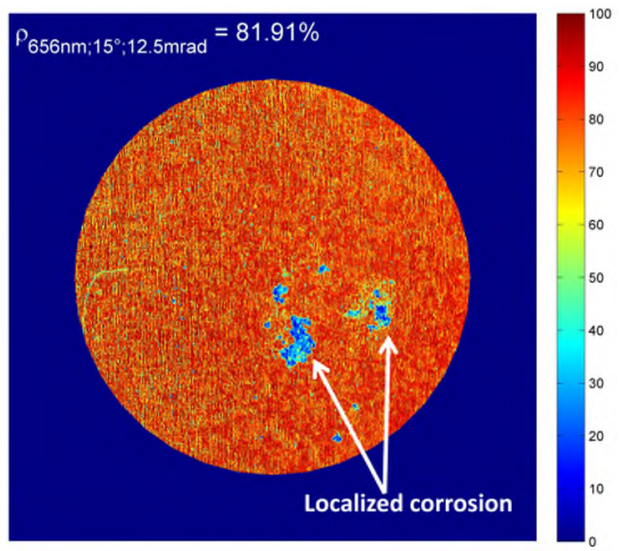

Figure 29. Example of localized corrosion monitoring with the (SR $)^{2}$ of an enhanced aluminum reflector sample after 64 months of outdoor exposure in Tabernas, Spain.

In order to validate the measurements of the prototype (SR $)^{2}$, several different solar reflector materials were measured [16]. The results were compared to the measurements performed with the D\&S 15R-USB reflectometer during a Round Robin testing campaign, for 5 reflector types [9]. The results are shown in Table 3, being the differences inserted in the last column the reflectance of the D\&S 15R-USB reflectometer minus the reflectance of the $(\mathrm{SR})^{2}$ prototype. According to these data, only the $1.60-\mathrm{mm}$ silvered glass reflector showed higher reflectance with the prototype (negative difference), while the rest of the reflector materials presented lower values with the prototype (positive differences). The mean value of absolute reflectance differences is 0.011 , which means that an acceptable agreement was found. The prototype (SR) ${ }^{2}$ has a good repeatability of the specular reflectance. For $\varphi=12.5 \mathrm{mrad}$, the repeatability represented by the standard deviation lies in the range of $\sigma=0.005$. For smaller acceptance angles $(\varphi=3.5 \mathrm{mrad})$ the measurement uncertainty increased up to $\sigma=0.008$.

Table 3 
Differences of $\rho_{s, \varphi}\left(656 \mathrm{~nm} ; 15^{\circ}, 12.5 \mathrm{mrad}\right)$ obtained with the $(\mathrm{SR})^{2}$ and the $\rho_{\lambda, \varphi}\left(660 \mathrm{~nm} ; 15^{\circ}, 12.5 \mathrm{mrad}\right)$ measured with the 15R-USB D\&S reflectometer, for different solar reflector materials.

\begin{tabular}{|c|c|c|c|}
\hline Sample & $\begin{array}{c}\rho_{\lambda, \varphi}\left(660 \mathrm{~nm} ; 1^{\circ}, 12.5 \mathrm{mrad}\right) \\
\text { with } 15 \mathrm{R}-\mathrm{USB} \text { by D\&S }\end{array}$ & $\begin{array}{c}\rho_{s, \varphi}\left(656 \mathrm{~nm} ; 15^{\circ}, 12.5 \mathrm{mrad}\right) \\
\text { with }(\mathrm{SR})^{2} \text { by DLR }\end{array}$ & $\begin{array}{l}\text { Reflectance } \\
\text { difference }\end{array}$ \\
\hline $\begin{array}{l}1.60 \text {-mm silvered } \\
\text { glass }\end{array}$ & $0.963 \pm 0.004$ & $0.952 \pm 0.005$ & -0.011 \\
\hline Aluminum & $0.877 \pm 0.010$ & $0.887 \pm 0.002$ & +0.010 \\
\hline $\begin{array}{l}0.95 \mathrm{~mm} \text { silvered } \\
\text { glass }\end{array}$ & $0.961 \pm 0.003$ & $0.974 \pm 0.001$ & +0.013 \\
\hline $\begin{array}{l}4 \mathrm{~mm} \text { silvered } \\
\text { glass }\end{array}$ & $0.955 \pm 0.004$ & $0.962 \pm 0.003$ & +0.007 \\
\hline $\begin{array}{l}\text { First surface } \\
\text { aluminum }\end{array}$ & $0.930 \pm 0.004$ & $0.946 \pm 0.005$ & +0.016 \\
\hline
\end{tabular}

\subsection{Solar Mirror Qualification (SMQ) by ENEA}

ENEA has developed in 2011 a new and promising method based on measuring hemispherical reflectance and near-specular reflectance at near-normal incidence $\left(\theta_{i}=2.9^{\circ}\right)$ for several $\varphi[17]$ (see Figure 30). This experimental apparatus adopts three lasers of different wavelengths $\lambda=\{405.5,543.5,632.8\} \mathrm{nm}$. The switching from one to another is achieved by shifting the mirror.

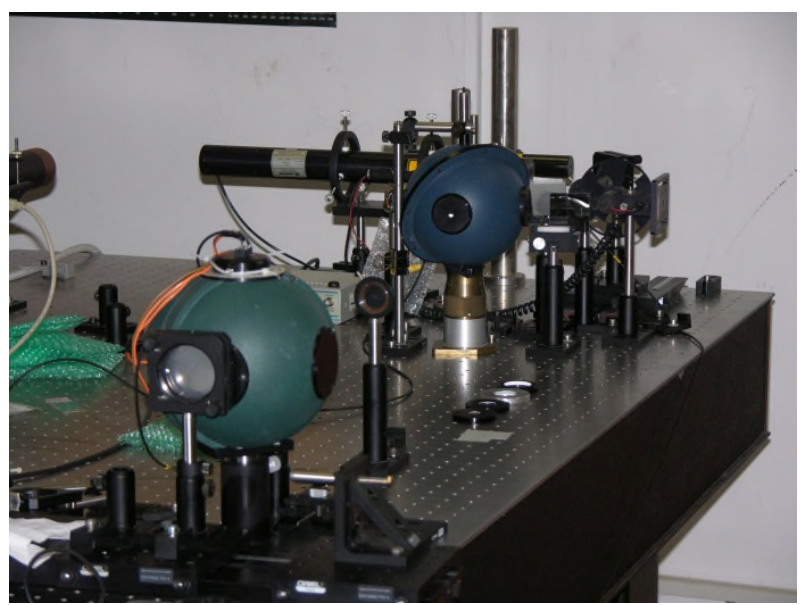

Figure 30. Picture of the SMQ prototype by ENEA.

In the specular reflectance configuration, the laser beam hits the specimen at near-normal incidence and the reflected beam crosses the entrance-port of a $150 \mathrm{~mm}$ integrating sphere (IS-1), aligned on the specular direction (see Figure 31). The measurement can be realized for a set of six entrance-ports, the diameter of which is sized to capture all the radiation 
reflected in the $\varphi=\{3.39,6.56,9.84,13.97,16.83,19.95\} \mathrm{mrad}$. In order to ensure that both near-specular and hemispherical reflectance values refer to the same area of the specimen surface, for radiation with same coherence length, the experimental-apparatus was equipped with a second integrating sphere (IS-2, diameter $150 \mathrm{~mm}$ ) dedicated to the hemispherical measurement. The calibration is done via the reference sample $\mathrm{R}$, that is a high quality first surface aluminium mirror (glass substrate). Each measurement is repeated twice, one for the sample $\mathrm{S}$ and another for the reference $\mathrm{R}$. Because the reflectance of $\mathrm{R}$ is known, one can evaluate both hemispherical and near-specular reflectance of the unknown specimen $\mathrm{S}$. The instrument is a laboratory setup, working at room temperature.
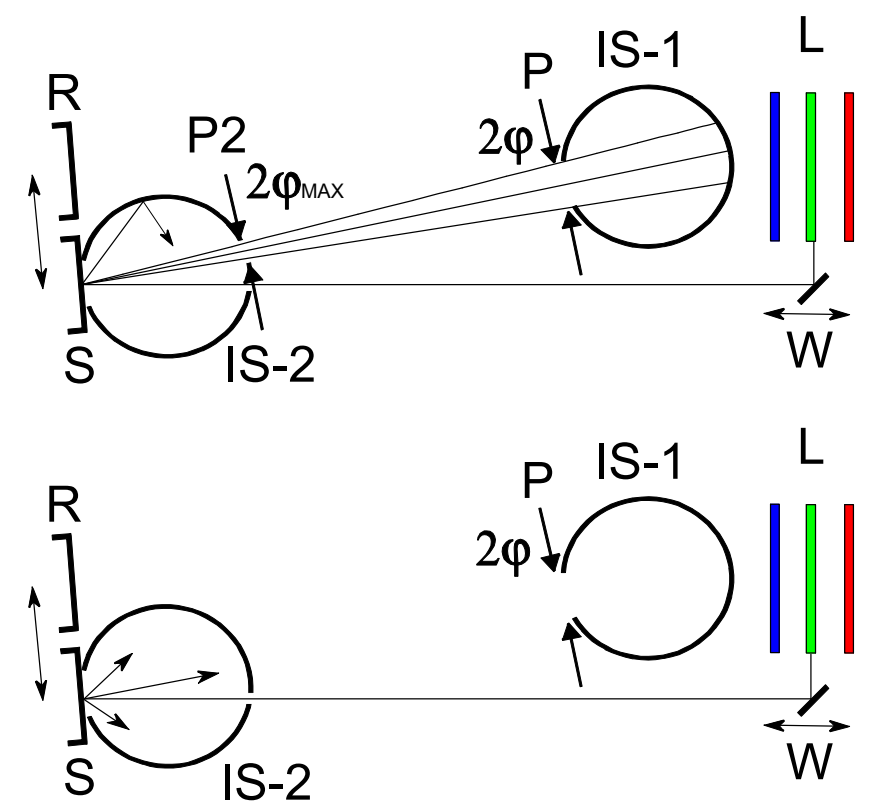

Figure 31. Scheme of the SMQ prototype by ENEA.

This instrument was used in a research study to model the near-specular reflectance in the whole solar spectrum of two laminated mirrors and one traditional [17]. The mirrors were analyzed with the experimental set-up to obtain near-normal incidence reflectance measurements of the hemispherical spectrum, and near-specular at $\lambda=\{405.5,543.5$, $632.8 \mathrm{~nm}$, for $\varphi$. For a given $\varphi$, the wavelength-behaviour of the ratio nearspecular/hemispherical is found to be well modelled by the well-known Total Integrated Scattering (TIS) relationship. The angular-behaviour of the hemispherical reflectance was predicted by a simplified optical model of the mirror [90]. As final result, the behaviour of near-specular solar reflectance versus the $\theta_{i}$ over the investigated $\varphi$ range was obtained. 
The instrument set-up was updated, in view of its forthcoming commercialization in 2012. The most relevant modifications are as follows: direct measurement of diffuse reflectance beyond 20 mrad; adoption of cheaper, more compact, and less coherent lasers; and a new procedure of data processing to get more reliable coherent-free assessments [90].

\subsection{New reflectometer developed by Malaysia University of Science and Technology}

A new method of reflectance measurement was presented in 2003, which employs a fast rotating reference mirror and a geometry configuration to alternatively deliver the light via a sample mirror or by passing it to a photo detector [91]. The instrument incorporates four optical components (see Figure 32): a sample mirror, a reference mirror, a flatsurfaced photo detector and a laser source. In the measurement, the reference mirror rotates (except during short stops for data reading). At a certain moment, the laser beam impinges on the reference mirror with an incident angle $\beta$ and is then reflected to a photo detector at an incident angle $\theta$. The signal received by the photo detector is the reference signal. At the next moment when the reference mirror continues rotation, the reflected laser beam is directed to the sample mirror. The sample mirror then bounces the laser beam to the photo detector. The signal detected is now the sample signal. The reflectance of the sample mirror is thus simply the quotient of the sample signal and reference signal. If the rotation is fast, the measurement can take place within such a short period that the environmental conditions, such as the fluctuation of the laser intensity, do not change much. However, because of the strong dependence of the reflectivity with incident angles, it is necessary in this proposed method to have the same incident angles to reference mirror and to photo detector in these two cases. This is possible if in the sample case, the data reading is taking place at the moment that the rotation angle of the reference mirror has further rotated $2 \beta$ and the normal of the sample mirror is so arranged that the reflected beam from the sample mirror is incident into the photo detector with the same incident angle of $\theta$ although from the opposite side. 

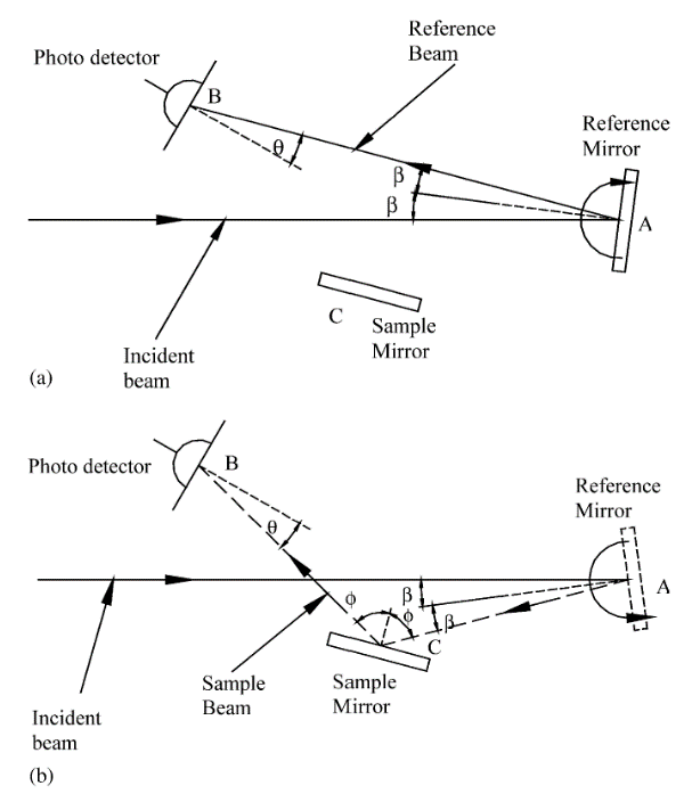

Figure 32. Basic principle of the new reflectometer by Malaysia University. (a):

Measurement of the reference signal; (b): measurement of the sample signal [91].

To prove the precision, reflectance measurements have been conducted for a front-coated silver mirror. The measurement uncertainty achieved is better than 0.0001 (with a standard deviation of 0.00006 reflectance unit). In the experimental setup, the incident angle was $\beta=\theta=22.5^{\circ}$ and a single-frequency laser beam $(633 \mathrm{~nm})$ as the optical source is used.

\subsection{Mirror Reflectance Function Analyzer (MIRA) by DLR}

MIRA is a new prototype instrument which has been developed by DLR at the OPAC Laboratory at the PSA in 2012 to measure near specular scatter and evaluate its impact on specular reflectance [92], [93] (see Figure 33). The prototype design is based on the appealing idea of a parallel imaging goniophotometer. The main components are a mirrored spheroid to create an angular-to-spatial mapping of the bidirectional reflectance distribution function (BRDF) coming from a mirror sample, and a camera with a fisheye lens to capture the reflected light in one image. This way the complete light distribution is captured simultaneously. A $180^{\circ}$ Sigma circular fisheye lens with $f=4.5 \mathrm{~mm}$ focal length is used. This lens produces a circular image on the 4/3 CCD detector array with 3296 x 2472 pixels. Therefore an angular resolution of around $1.3 \mathrm{mrad}$ can be expected if the lens produces linear mapping over the whole hemisphere. 
The instrument allows the distinction of the high intensity specular peak and the low intensity scatter by taking two measurements with different sensitivity settings for the CCD chip. In order to prevent blooming on the CCD chip, the specular peak can be shadowed by a movable band. The evaluation method creates the specular reflection as a function of the offset angle from the specular direction. The concept is well suited for the analysis of near specular scatter angles, although less suited for the analysis of rough surfaces that require high accuracy at full $180^{\circ}$ view angle.

The sample holder uses precision screws to position the sample, which can be a first or second surface mirror. The measurement spot has a diameter of $3.5 \mathrm{~mm}$. The instrument features a movable light source that can be set to varying incidence angles and a filter system to create monochromatic illumination at variable wavelength bands in the range of $\lambda=[500,700] \mathrm{nm}$.
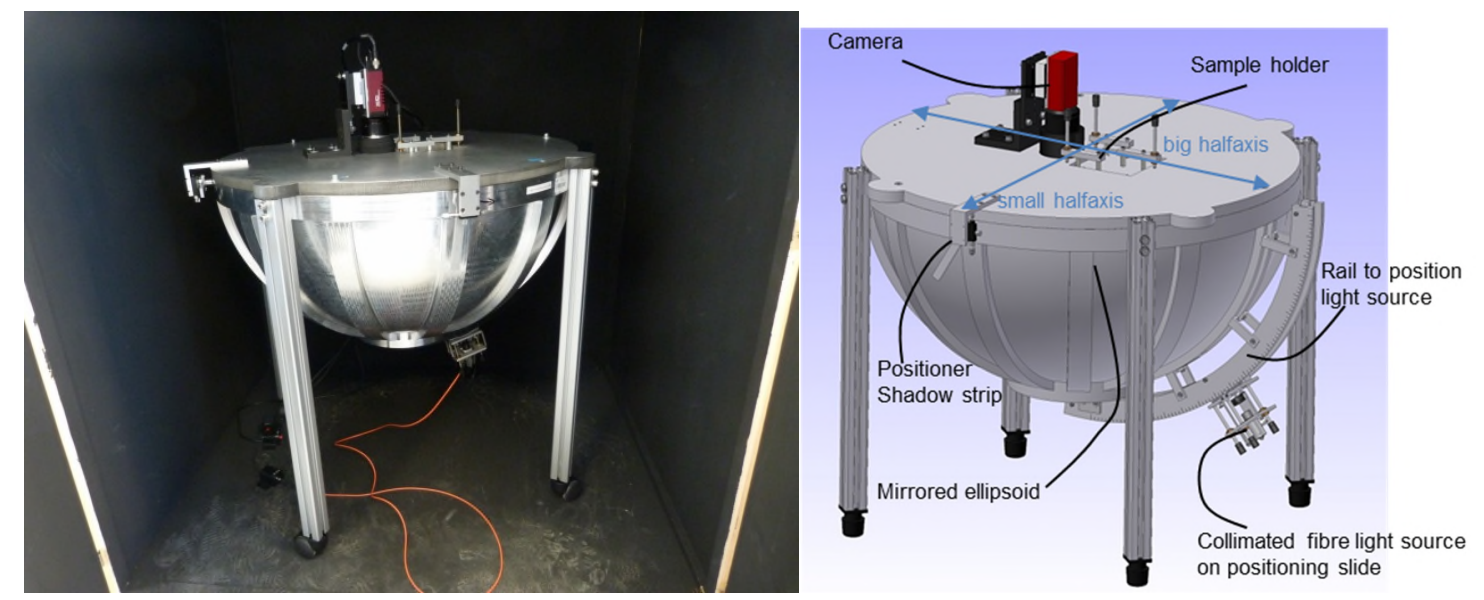

Figure 33. Left: picture of the MIRA prototype by DLR. Right: draw of the MIRA prototype by DLR with components.

This parallel catadioptric imaging goniophotometer features as main component a mirrored ellipsoid (catoptric part). The two dimensional counterpart of an ellipsoid is the ellipse, which is defined by its two focal points $F 1$ and $F 2$. The focal points are located on one axis defined by the major half axis, $a$. The minor half axis, $c$, continues perpendicular to $a$. The ellipsoid is created by rotating the ellipse around the major half axis with a rotation angle $\pi$. Any light ray coming from one focal point is redirected by the ellipsoid walls towards the other focal point (see Figure 34). If the incoming light bundle is composed of parallel light, the ellipsoid creates a junction point at half the distance between the wall and F2. A camera with a $180^{\circ}$ fisheye lens (dioptric part) is 
positioned at the focal point $F 2$ and creates an image of the light distribution, where each pixel represents one scatter angle in which the light left the sample.

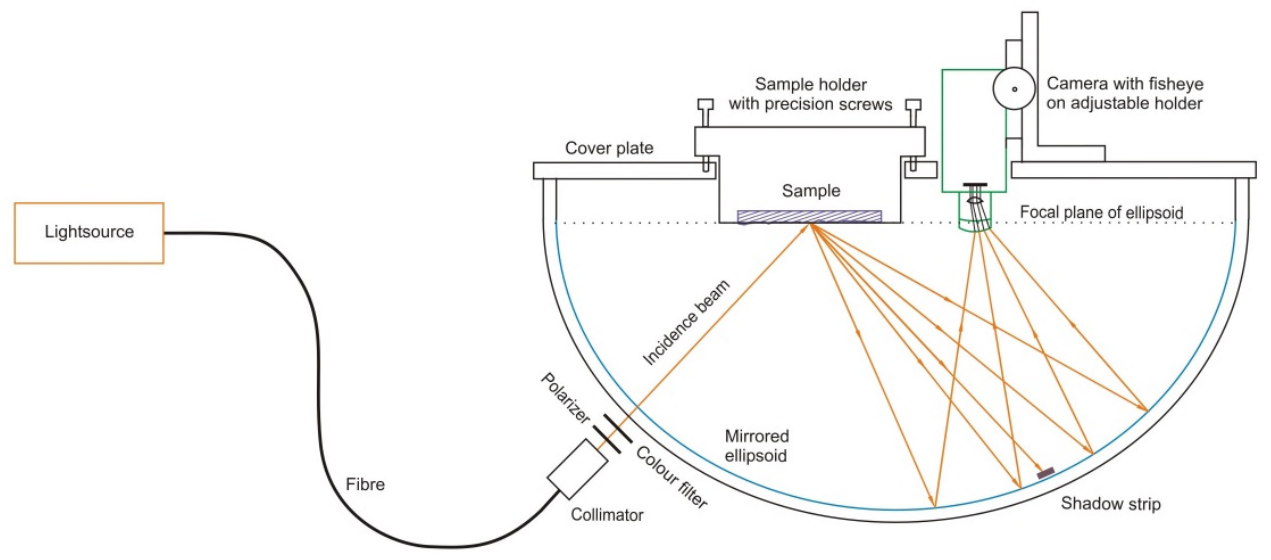

Figure 34. Scheme of the MIRA prototype by DLR.

The MIRA measures relative reflectance. If the hemispherical reflectance of the sample is known, absolute reflectance values can be obtained by relating the hemispherical reflectance with the integrated intensity of all pixels of the measurement image. The working temperature should be laboratory conditions. Two reflector materials (silvered polymer film material and enhanced aluminum sheet with a protective top coat) were sent to Pab advanced technologies Ltd (pab) for a measurement of the BRDF with their GonioPhotometer at $\lambda=633 \mathrm{~nm}$ for reference. The measurement results were compared with the data generated by pab. The results showed good agreement for both materials, having the BRDF surface plots comparable shapes, with a difference of $<5$ percentage points at $\varphi>10 \mathrm{mrad}$. However, for smaller $\varphi$ there are significant deviations. The MIRA measurement of a highly specular thin glass mirror already showed a much broader peak than the pab measurements of reflectors with less specularity, although this is not expected for this kind of mirror. This indicates that the instrument signature in itself does not allow distinguishing the distribution at small $\varphi$. Reasons for this are being investigated at the moment. The problem might be due to manufacturing errors of the ellipsoid like imperfections in the shape of the ellipsoid wall or scattering effects at the surface. Deviations might also be induced by the imperfectly collimated light source or an erroneous sample holder position with respect to the camera so that no exact match with the focal points of the ellipsoid is achieved. These effects will be studied and improved in the future in order to achieve a higher measurement precision in the small acceptance angle range. 


\subsection{Soiling sensor by IK4-Tekniker}

IK4-Tekniker developed in 2013 a new low-cost sensor based on light scattering measurements which is able to monitor the soiling level accumulated on a solar field in real time [94] (see Figure 35). Due to the low-cost involved, several units may be installed along the solar field to monitor it and, as a consequence, highly valuable information is obtained to optimize the global maintenance scheme by implementing a continuous and real-time reflectance measurement system. In addition, as reflectance measurements are continuously taken by sensors without operator intervention, a significant manpower saving is also achieved.

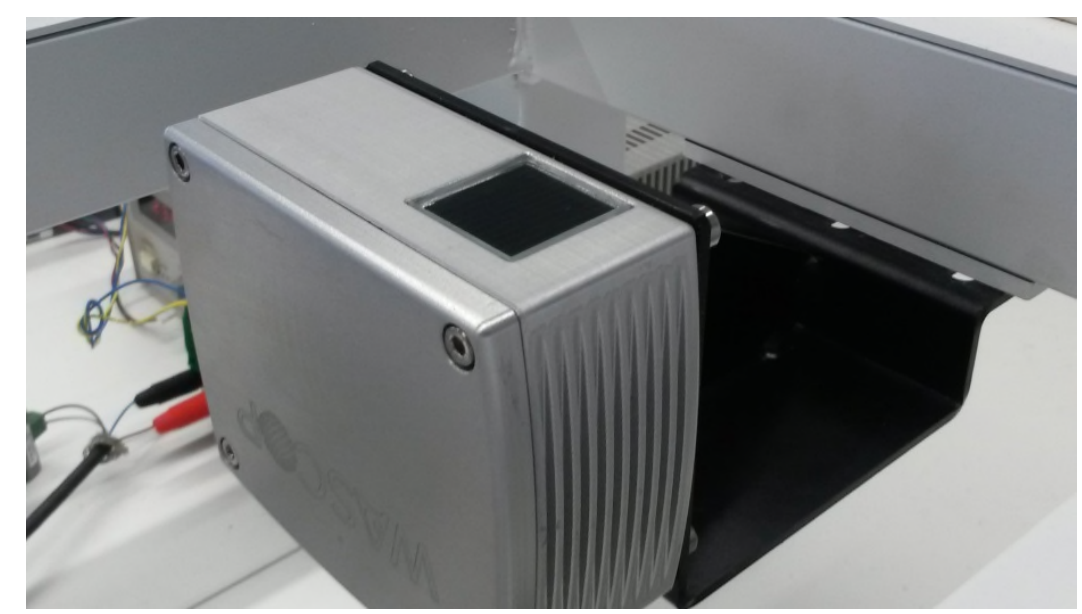

Figure 35. Picture of soiling sensor prototype by IK4-Tekniker.

It was developed under several considerations, including the need to avoid the interference of the solar surfaces and cleaning tasks, and to be able to conduct measurements during daytime while maintaining acceptable stability. The period between measurements can be programmed. The sensor was designed on the basis of a transparent substrate that is exposed to the same environmental conditions as the solar concentrating reflector. The measuring principle is based on light scattering from the dust deposited on the substrate (see Figure 36). The system projects a beam of light onto the internal face of the substrate, and a set of photo-sensors detect the scattered light. The sensor incorporates compensation algorithms to correct gain and offset variations of the light source and of the photodetectors. Preliminary laboratory tests indicate stabilities around $0.02 \%$ of the measuring range. Within an extended working temperature range of between $-5^{\circ} \mathrm{C}$ and $45^{\circ} \mathrm{C}$ (functional temperature range from -20 to $60^{\circ} \mathrm{C}$ ), measurement stabilities close to $0.2 \%$ of relative cleanliness were achieved. 


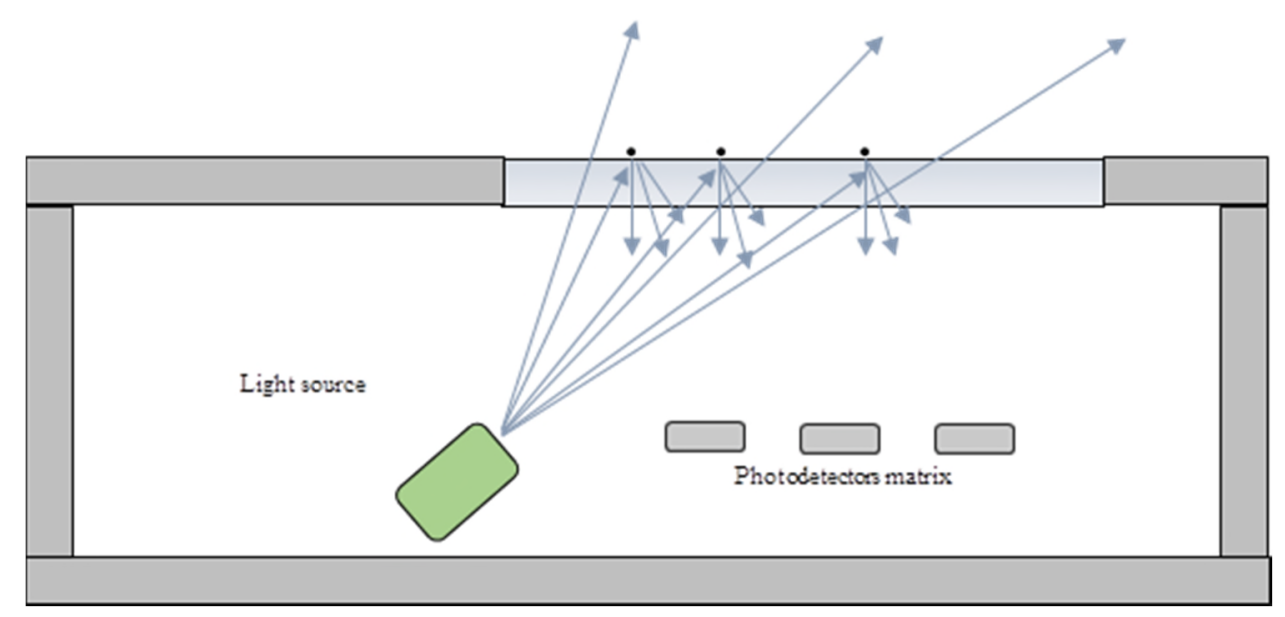

Figure 36. Scheme of the soiling sensor prototype by IK4-Tekniker.

\subsection{Very-low-angle beam spread (VLABS) by Fraunhofer ISE}

The VLABS is a laboratory instrument developed by Fraunhofer ISE to determine the absolute, angle resolved specular reflectance as a function of $\varphi$ with an angular resolution of $0.03 \mathrm{mrad}$ (see Figure 37) [18], [31]. The first results with this prototype were presented in SolarPACES Conference in 2010 [31]. It has LED irradiation as light source at $\lambda=\{455,533,631\} \mathrm{nm}$ (extendable to other $\lambda$ ). The light source is adjustable, with a beam divergence half-angle of about $1 \mathrm{mrad}$. The light source spot diameter on reflector samples ranges from $0.6 \mathrm{~mm}$ to $10 \mathrm{~mm}$. The $\theta_{i}$ can be varied in the range of $8^{\circ}<\theta_{i}<80^{\circ}$, and the maximum $\varphi$ is $33 \mathrm{mrad}$. The dynamic range of the detector covers about five orders of magnitude. It is important to highlight that with this instrument the results are not influenced by light source signature, spot size on sample, detector aperture.

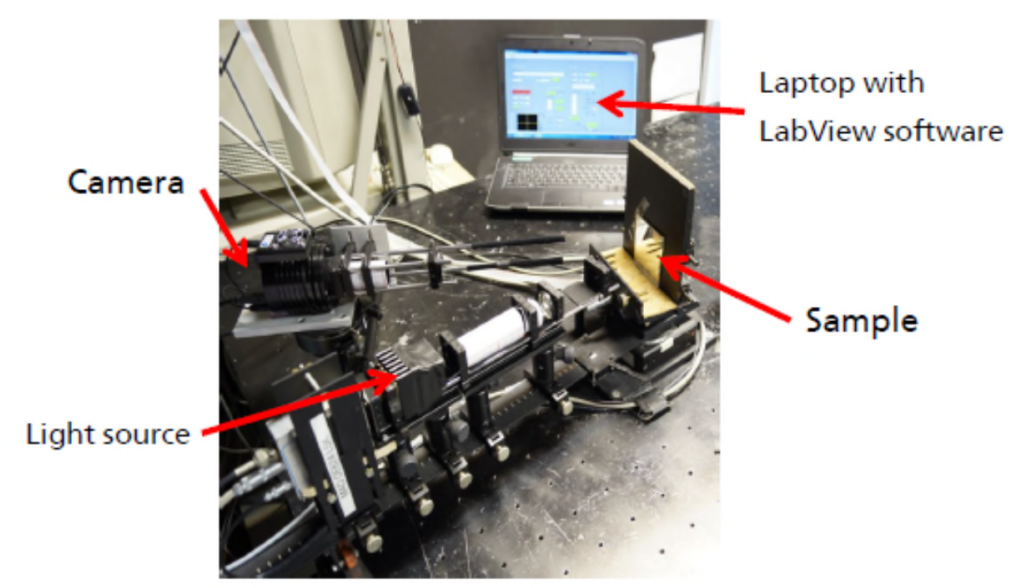

Figure 37. Picture of the VLabs prototype by Fraunhofer ISE [18].

With respect to the working principle (see Figure 38), the quasi-monochromatic light from an LED is collimated by an achromatic lens and is directed to the sample. The 
reflected light passes through a second achromatic lens and is detected by a CCD array with high resolution and high quantum efficiency. The reflected radiation (as detected by the CCD array) is the convolution of the light source, the instrument signature and the reflecting properties of the sample. To verify the absolute reflectance values a reference mirror was measured for which reflectance values were provided by the by the Dutch Organization for Applied Scientific Research (TNO). A comparison of VLABS measurement results with the mirror's reference values revealed that the basic principle of the method leads to accurate absolute results for specular reflectance within an uncertainty of 0.3 percent points for high quality glass mirrors without first surface coatings. The working temperature should be laboratory conditions.
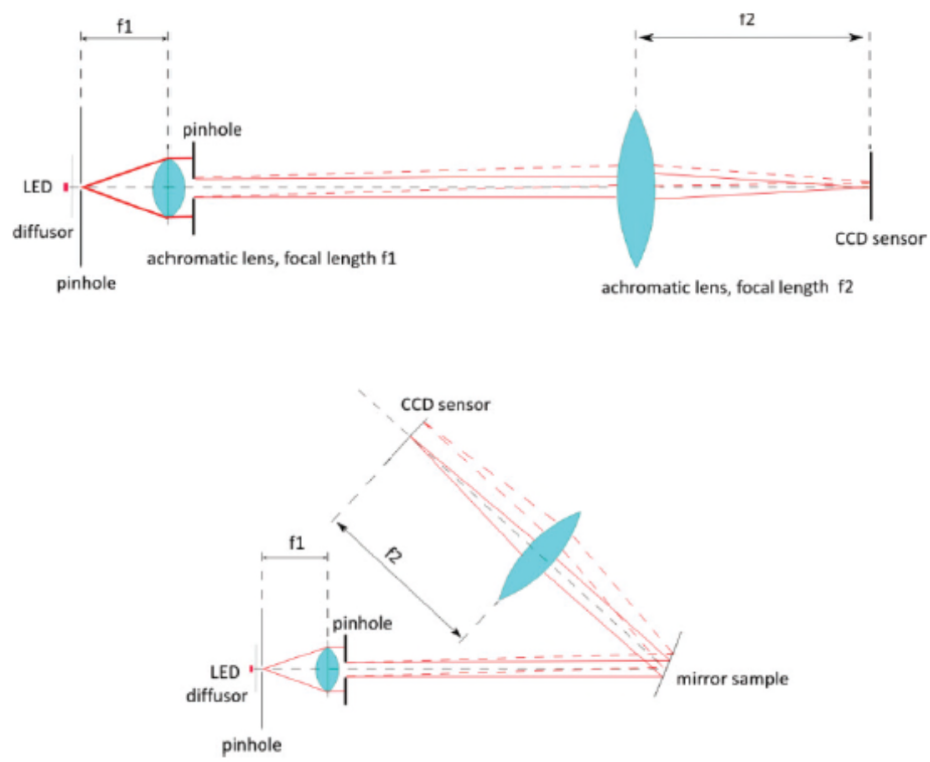

Figure 38. Scheme of the VLabs prototype by Fraunhofer ISE [18]. Top: light source and instrument signature measurement. Bottom: sample measurement.

This instrument was used to investigate the specular reflectance properties of four different mirror samples suitable for mass manufacturing of concentrating photovoltaics (CPV) primary concentrators [95]. For this purpose, measurement of specular reflectance with a very high angular resolution around the specular direction was performed, making it possible to compare different mirror materials to a high degree of accuracy for arbitrary acceptance angles. According to the results obtained, for a CPV system with $\varphi=1^{\circ}$ the loss of radiant flux due to surface scattering amounts to a maximum of $8 \%$ relative for the investigated samples. In addition, this instrument was used to study the impact of the incidence angle on the specular reflectance of soiled glass mirrors [96]. Measurements 
showed that for soiled mirrors, the specular reflectance decreases significantly for increasing angles of incidence.

\subsection{Spectral Specular Reflectometer (S2R) by DLR}

The Spectral Specular Reflectometer (S2R) was developed by DLR in 2014 to measure specular reflectance spectra and solar-weighted specular reflectance at variable $\theta_{i}$ and $\varphi$ (see Figure 39) [48]. The reflectometer was designed as an accessory for the commonly used PE Lambda UV/Vis/NIR spectrophotometers. The S2R accessory is based on the commercially available General Purpose Optical Bench (PELA1003) from PE equipped with a $60 \mathrm{~mm}$ integrating sphere and can be employed in the Lambda 950 or Lambda 1050 series (see section 3.1.1).

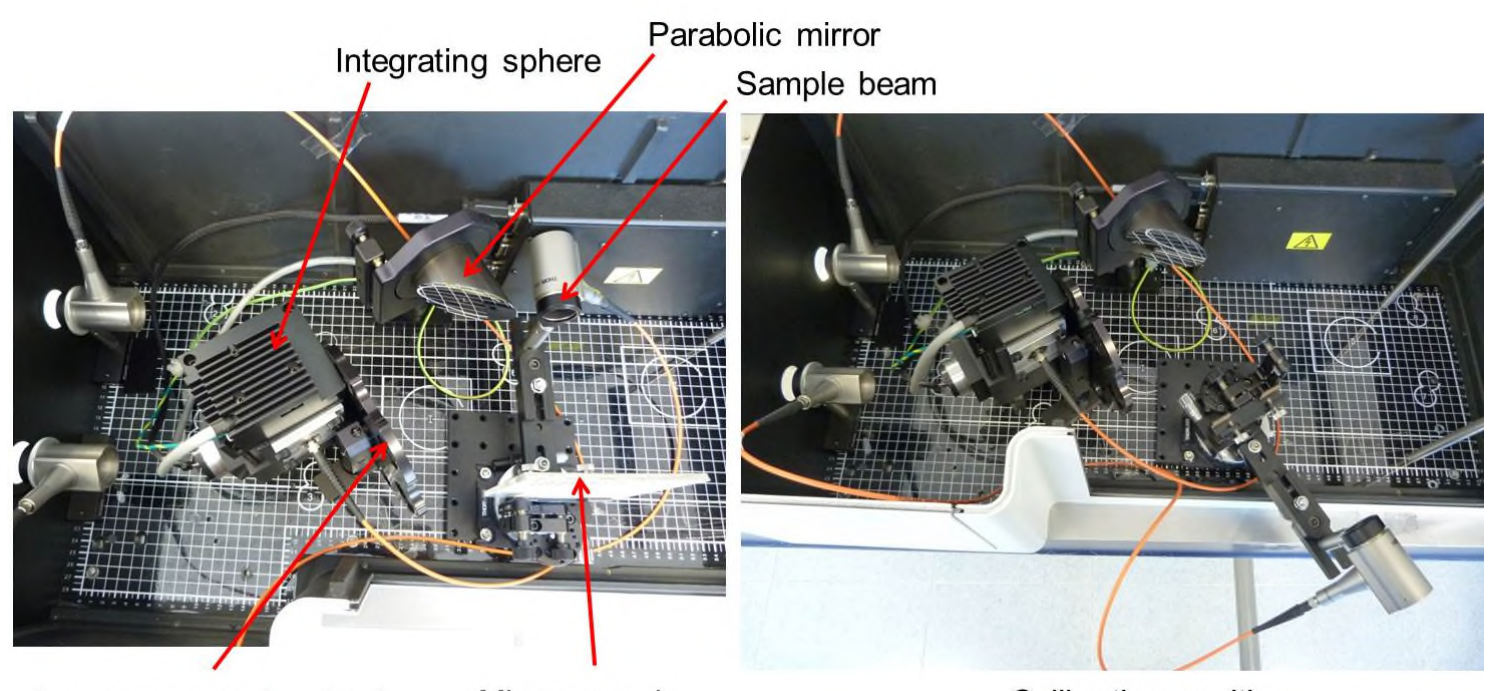

Acceptance angle wheel

Mirror sample

Calibration position

Figure 39. Pictures of the S2R prototype by DLR.

The measurement principle is shown in Figure 40. The sample and reference beam originating from the PE Lambda spectrophotometer are coupled into optical fibers using UV-enhanced aluminum coated reflective collimators. The reference beam is directly coupled into the integrating sphere using a custom-made adapter plate. The sphere contains two detectors: a PMT for UV/VIS spectral measurements and an InGaAs photodiode detector for NIR applications. The sample beam is coupled to another reflective collimator which outputs a homogeneous collimated beam of $22 \mathrm{~mm}$ in diameter. The sample and the reflective fiber collimator are mounted on independent rotating platforms, allowing one to change the $\theta_{i}$ by adjusting two micrometer screws. The parallel light hits the reflector sample and its reflected light is collected by a $90^{\circ}$ off 
axis parabolic mirror with low scattering, which focuses the reflected light from the sample. The reflected light is focused into an aperture stop of variable diameter which is placed directly before the entrance port of the integrating sphere. The calibration is done by moving the light source and measuring a 100\% reference baseline in air. The absolute calibration of the S2R has the advantage of not having to rely on reference mirrors. The working temperature should be laboratory conditions.

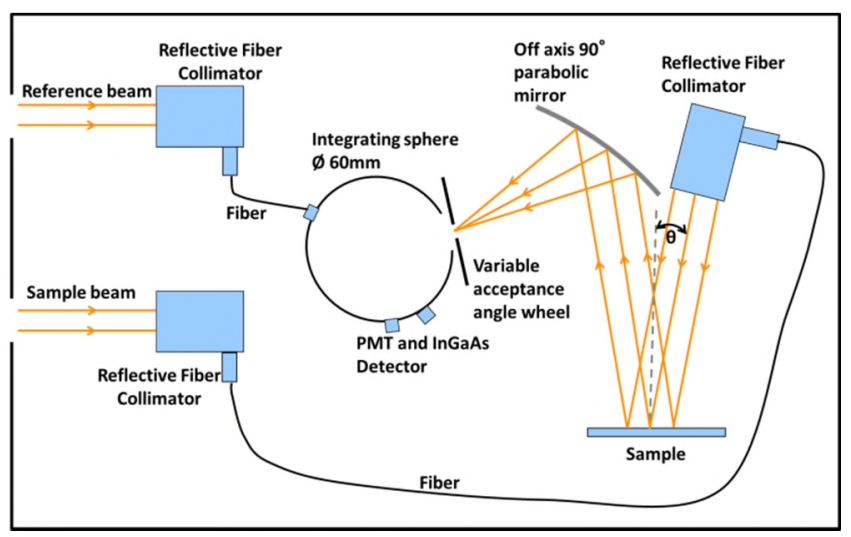

Figure 40. Scheme of the working principle of the S2R prototype by DLR.

The range of the main parameters are $\lambda=[250,2500] \mathrm{nm}, \varphi=\{9.8,12.3,14.8,20.2,35.9$, $107.4 \mathrm{mrad}$ and $\theta_{i}=[8,70]^{\circ}$. The maximum sample size is $150 \times 150 \mathrm{~mm}^{2}$ and the spot size is $12 \mathrm{~mm}$. The S2R measurements were validated by measuring a first surface silver reference master mirror which was calibrated by the National Research Council Canada (NRC). The S2R instrument has a precision in the range of 0.1 percentage points. Direct measurement of spectral specular reflectance with the S2R has been shown to be especially advantageous for innovative mirror materials like polymer films or aluminum mirrors, which show scattering effects.

\subsection{Summary of prototypes}

The main characteristics of the prototypes are summarized in Table 4.

\section{Table 4}

Main features of the prototypes. *: information not available. 


\begin{tabular}{|c|c|c|c|c|c|c|c|}
\hline Manufacturer & DLR & ENEA & Malaysia UST & DLR & IK4-Tekniker & Fraunhofer ISE & DLR \\
\hline Model & $(\mathrm{SR})^{2}$ & SMQ & $*$ & MIRA & Soiling sensor & VLABS & $\mathrm{S} 2 \mathrm{R}$ \\
\hline Described in section & 4.1 & 4.2 & 4.3 & 4.4 & 4.5 & 4.6 & 4.7 \\
\hline Measurement principle & $\begin{array}{l}\text { White light source, } \\
\text { lens focussing, } \\
\text { wavelength filter, } \\
\text { aperture wheel with } \\
\text { CMOS detector behind }\end{array}$ & $\begin{array}{l}\text { Triple wavelength } \\
\text { source with movable } \\
\text { sample and two } \\
\text { integrating spheres }\end{array}$ & $\begin{array}{l}\text { Single laser source, } \\
\text { rotating reference } \\
\text { mirror, sample mirror, } \\
\text { and detector }\end{array}$ & $\begin{array}{l}\text { Based on the concept } \\
\text { of a parallel } \\
\text { catadioptric imaging } \\
\text { goniophotometer }\end{array}$ & \begin{tabular}{|} 
Soiling sensor based on \\
light scattered from \\
soiling particles on \\
mirror surface
\end{tabular} & $\begin{array}{l}\text { Measurement of absolute } \\
\text { reflectance with reference } \\
\text { mirror }\end{array}$ & $\begin{array}{l}\text { Accessory for the } \\
\text { commonly used PE } \\
\text { Lambda UV/Vis/NIR } \\
\text { spectrophotometers }\end{array}$ \\
\hline Measurement type & $\begin{array}{c}\text { Specular reflectance } \\
\text { compared to known } \\
\text { reference mirror }\end{array}$ & \begin{tabular}{|c|} 
Hemispherical \\
reflectance and near- \\
specular reflectance
\end{tabular} & $\begin{array}{l}\text { Specular reflectance } \\
\text { compared to known } \\
\text { reference mirror }\end{array}$ & $\begin{array}{c}\text { Specular reflectance } \\
\text { and near-specular } \\
\text { scatter }\end{array}$ & $\begin{array}{c}\text { Real-time measurement } \\
\text { of partial reflectance, } \\
\text { with reference glass }\end{array}$ & $\begin{array}{c}\text { Angular resolved specular } \\
\text { reflectance (absolute } \\
\text { measurement) }\end{array}$ & $\begin{array}{c}\text { Specular reflectance at } \\
\text { variable } \theta_{i} \text { and } \varphi\end{array}$ \\
\hline Light source & White light LED & \begin{tabular}{|c|} 
Three Source lasers \\
$405.5,543.5,632.8 \mathrm{~nm}$ \\
\end{tabular} & $633 \mathrm{~nm}$ laser & $\begin{array}{l}\text { Fibre light source in } \\
\text { range } 500-700 \mathrm{~nm}\end{array}$ & Low cost light source & $\begin{array}{c}\text { LED sources at } 455,533, \\
631 \mathrm{~nm}\end{array}$ & $\begin{array}{c}250-2500 \mathrm{~nm} \text { from two } \\
\text { lamp sources }\end{array}$ \\
\hline Incidence angle, $\theta_{i}\left({ }^{\circ}\right)$ & 15 & 2.9 & 22.5 & Near normal & Variable & Adjustable 8-80 & $8-70$ \\
\hline $\begin{array}{c}\text { Beam spot size } \\
\text { (diameter in } \mathrm{mm} \text { ) }\end{array}$ & 53.5 & $*$ & $*$ & 3.5 & $*$ & Adjustable $0.6-10.0$ & 12 \\
\hline $\begin{array}{l}\text { Wavelength range, } \lambda \\
(\mathrm{nm})\end{array}$ & $410,500,656$ & $405.5,543.5,632.8$ & 633 & $500-700$ & $*$ & $455-631$ & $250-2500$ \\
\hline $\begin{array}{c}\text { Acceptance angle, } \varphi \\
(\mathrm{mrad})\end{array}$ & $3.5,6.0,12.5$ & $\begin{array}{c}3.39,6.56,9.84,13.97 \\
16.83,19.95\end{array}$ & $*$ & $>10 \mathrm{mrad}$ & $*$ & $<33$ & $\begin{array}{c}9.8,12.3,14.8,20.2 \\
35.9,107.4\end{array}$ \\
\hline Operating temp. $\left({ }^{\circ} \mathrm{C}\right)$ & Room temperature & Room temperature & $*$ & Room temperature & $-20 \mathrm{C}$ to +60 & Room temperature & $\begin{array}{c}\text { Room } \\
\text { temperature }\end{array}$ \\
\hline References & {$[16][87][88][89]$} & {$[17][90]$} & [91] & {$[92][93]$} & [94] & {$[18][31][95][96]$} & {$[48]$} \\
\hline
\end{tabular}




\section{Conclusions}

According to the results of the revision performed in this review regarding the instruments and methods to measure the reflectance of solar mirrors, it may be concluded that a huge effort has been carried out by research centers and companies during the last two decades to characterize this solar component, both theoretically and experimentally.

The requirements for measuring the solar reflectance of concentrating mirrors are challenging. Measurements should cover the complete solar wavelength range, at least from 280 to $2500 \mathrm{~nm}$, with angles of incidence from near normal to $70^{\circ}$, with acceptance angles $\leq 20 \mathrm{mrad}$. These requirements are principally driven by the geometries found in parabolic-trough solar fields with absorbers along the line focus, with high quality backsilvered mirrors as the solar collectors. However, the measurements, procedures, and standards that are discussed in this review paper have wider applicability in the field of concentrating solar technologies, and within other applications that demand high precision optical reflectance measurements. For CSP applications, we require instruments that can test small laboratory samples, and also large solar collectors in real solar fields. The mirror surface can vary from as-manufactured and pristine, naturally or artificially soiled, contact or non-contact cleaned, and either naturally or artificially aged (through erosion, abrasion, corrosion, and chemical effects (including pollution)). The solar mirrors may be front or back silvered glass, polished or coated metal (mainly aluminum), polymer-based, and with a variety of backside coatings and sub-structures. Some techniques to measure reflectance require calibration standards, which should be durable, stable and traceable. Depending on its application and location an instrument may need to be durable, portable, easy to set up and operate, capable of remote operation, automatic, and self-calibrating. This review is testament to the fact that there is no single instrument that meets all of these criteria, and the instruments reviewed all have their merits and deficiencies. Some assumptions and approximations are sometimes required in order to post-process the actual measurements made. One example of this is the Pettit assumption [12] of a wavelength independent ratio of specular to hemispherical reflectance.

In the laboratory, spectrophotometers are routinely used to measure wavelength dependent light intensity, not only for solar applications. They are accurate but not portable, and require a number of accessories to be adapted to carry out the measurements needed to characterize a concentrating solar mirror. In this review we have described 
instruments manufactured by Perkin-Elmer, Agilent, Gooch and Housego, and Jasco, together with some of the most useful accessories for solar reflectance measurements.

Reflectometers measure reflected light intensity over a narrow wavelength band (or series of bands). For solar applications this should include the solar energy peak wavelengths between 500-660 $\mathrm{nm}$. The commercial reflectometers are collectively summarized in Table 2. Despite being developed for similar purposes, the instruments contain a number of different design features. The standard laboratory-based instrument is the Devices \& Services 15R. It can also be used outdoors in solar fields, although the best results require an experienced operator. The standard instrument is a single wavelength $(\lambda=660 \mathrm{~nm})$ unit, whereas the more sophisticated 15R-RGB device can cover four wavelengths in the range of $\lambda=[460,720] \mathrm{nm}$. The Abengoa and Surface Optics reflectometers are designed for rapid measurements of reflectance in solar fields and do not require experienced operators. Both have larger acceptance angles than the D\&S instrument, considerably larger in the case of the Abengoa Condor. The Surface Optics and the Konica Minolta CM 700d instruments are actually sphere-type spectrophotometers which do not measure specular reflectance directly, but subtracts the diffuse reflectance from the hemispherical reflectance. They are designed for both portability and for broadband measurements $(\lambda=[400,700] \mathrm{nm}$ for the Konica Minolta instrument and the Surface Optics one measure 7 bands between 300 and $2500 \mathrm{~nm}$ ). The final two instruments classed as commercial reflectometers are the SMS $\mu$ Scan and the Pflex from PSE/Fraunhofer ISE. The $\mu$ Scan, whilst portable, actually comprises separate control unit, measurement head, and charging unit. According to work performed at CIEMAT-PSA [79] it is not suitable for high quality CSP reflector characterization. The Pflex, according to Fraunhofer ISE [81], is capable of high quality reflector characterization and can be operated from a mobile phone app. A totally different approach is demonstrated by the DLR/CSP Services TraCS cleanliness sensor. This stationary installation is designed to be permanently installed outdoors and measures reflectance using the actual solar spectrum. It can take measurements automatically and remotely, if required.

Since CSP reflectance measurement is such an active area of research, the authors have also taken the opportunity to describe some new prototype instruments which are under development but not yet commercially available. The (SR $)^{2}$ from DLR is a laboratoryscale instrument. With its characteristic feature of large measurement spot size $(53.5 \mathrm{~mm}$ diameter) and good spatial resolution it is ideal for tracking the degradation of mirrors 
over time [16], [89]. DLR also has developed two other instruments. The MIRA uses the principle of a parallel imaging goniophotometer to measure near specular scatter, mapping the BRDF by means of a $180^{\circ}$ circular fisheye lens and a CCD detector array [92], [93]. DLR has also designed an accessory for the PE Lambda spectrophotometer. The (S2R) is intended to measure the solar-weighted specular reflectance at variable angles of incidence and acceptance angles [48]. The ENEA SMQ was primarily labbased, but is now being developed as a commercial product [90]. Using three lasers as light sources $(\lambda=\{405.5,543.5,632.8\} \mathrm{nm})$ the set-up is capable of qualifying solar mirrors by measuring hemispherical reflectance and near-specular reflectance at nearnormal incidence for a selected number of acceptance angles. Malaysia University of Science and Technology has reported [91] a system to achieve a reflectance measurement uncertainty of better than 0.0001 . Using a $633 \mathrm{~nm}$ laser source, a fast rotating reference mirror and a photo-detector, the sample mirror reflectance was measured with a standard deviation of 0.00006 reflectance units. The Fraunhofer ISE VLABS instrument has been tested on solar PV concentrators [95]. Using three LED sources and a CCD detector array it is capable of measuring absolute specular reflectance for a variety of acceptance angles with an angular resolution of $0.03 \mathrm{mrad}$. Finally amongst the prototype instruments, IK4Tekniker has developed a low-cost sensor to monitor soiling on mirrors within the solar field in real time [94]. These new developments therefore have different aims ranging from measurements at different incidence and acceptance angles, long term, cost efficient and practical soiling measurement in solar fields or more accurate specular measurements regarding the BRDF or the direct measurement of spectral specular reflectance.

It deserves to be remarked the advances found in the soiling monitoring, a research topic recently focusing a great interest [66][81][83]. Two promising devices were identified to real time monitoring of soiling (the TraCS by DLR/CSP Services [84] and the instrument by IK4-Tekniker [94]), which are capable of providing on-line information about the state of soiling of solar reflectors under real outdoor conditions. The data are recorded in high time resolution and thus pave the way to understanding the mechanisms for particle adhesion.

\section{Acknowledgments}


The research work leading to this article received funding from the European Union Seventh Framework Programme (FP7/2007-2013) under grant agreement n 609837 (Scientific and Technological Alliance for Guaranteeing the European Excellence in Concentrating Solar Thermal Energy, STAGE-STE). It also received funding from the Spanish government in the framework of the DETECSOL project (Ref. ENE2014-56079R), Programa Estatal de Investigación, Desarrollo e Innovación orientada a los Retos de la Sociedad (National Program of Research, Development and Innovation oriented to Society's Challenges) of the Ministerio de Economía y Competitividad (Spanish Ministry of Economy and Competitiveness) with ERDF funds.

\section{References}

[1] Hernández-Escobedo Q, Rodríguez-García E, Saldaña-Flores R, Fernández-García A, Manzano-Agugliaro F. Solar energy resource assessment in Mexican states along the Gulf of Mexico. Renew Sustain Energy Rev 2015;43:216-23.

[2] Cruz-Peragon F, Palomar J M, Casanova P J, Dorado M P, Manzano-Agugliaro F. Characterization of solar flat plate collectors. Renew Sustain Energy Rev 2012;16:1709-20.

[3] Manzano-Agugliaro F, Alcayde A, Montoya FG, Zapata-Sierra A, Gil C. Scientific production of renewable energies worldwide: An overview. Renew Sust Energy Rev 2013;18:134-43.

[4] Mills D. Advances in solar thermal electricity technology. Sol Energy 2004;76:1931.

[5] Price H, Lüpfert E, Kearney D, Zarza E, Cohen G, Gee R, et al. Advances in parabolic trough solar power technology. J Sol Energy Eng Trans ASME 2002;124(2):109-25.

[6] Fernández-García A, Zarza E, Valenzuela L, Pérez M. Parabolic-trough solar collectors and their applications. Renew Sust Energy Rev 2010;14:1695-1721.

[7] García-Segura A, Fernández-García A, Ariza MJ, Sutter F, Valenzuela L. Durability studies of solar reflectors: A review. Renew Sust Energy Rev 2016;62:453-467.

[8] Gee R, Brost R, Zhu G, Jorgensen G. An improved method for characterizing 
reflector specularity for parabolic trough concentrators. In: Proceedings of SolarPACES 2010 International Conference on Concentrating Solar Power and Chemical Energy Systems, Perpignan; 2010.

[9] Montecchi M, Delord C, Raccurt O, Disdier A, Sallaberry F, García de Jalón A, Fernández-García A, Meyen S, Happich C, Heimsath A, Platzer W. Hemispherical Reflectance Results of the SolarPACES Reflectance Round Robin. Energy Procedia 2015;69:1904-7.

[10] Meyen S et al. Parameters and method to evaluate the solar reflectance properties of reflector materials for concentrating solar power technology. SolarPACES guideline V2.5. http://www.solarpaces.org/tasks/task-iii-solar-technology-andadvanced-applications/reflectance-measurement-guideline.

[11] ASTM standard G173-03. Terrestrial Reference Spectra for Photovoltaic Performance Evaluation. West Conshohocken: American Society for Testing and Materials (ASTM); 2003.

[12] Pettit RB. Characterizing Solar Mirror Materials Using Portable Reflectometers. Tech Report SAND82-1714. Albuquerque: Sandia National Laboratories; 1982.

[13] Meyen S, Lüpfert E, Pernpeintner J, Fend J. 2009 Optical Characterization of Reflector Material for Concentrating Solar Power Technology. In: Proceedings of SolarPACES 2009 International Conference on Electricity, fuels and clean water powered by the Sun, Berlin; 2009.

[14] Heimsath A, Kutscheidt G, Nitz P. Measuring reflectance-Overview and influence on optical performance. In: Proceedings of SolarPACES 2011 International Conference on Concentrating Solar Power and Chemical Energy Systems, Granada; 2011.

[15] Fernández-García A, Sutter F, Heimsath A, Montecchi M, Sallaberry F, PeñaLapuente A, Delord C, Martínez-Arcos L, Reche-Navarro TJ, Schmid T, Heras C. Simplified Analysis of Solar-Weighted Specular Reflectance for Mirrors with High Specularity. In: Proceedings of SolarPACES 2015 International Conference on Concentrating Solar Power and Chemical Energy Systems, Cape Town; 2015.

[16] Sutter F, Meyen S, Heller P, Pitz-Paal R. Development of a spatially resolved reflectometer to monitor corrosion of solar reflectors. Optical Materials 
2013;35:1600-9.

[17] Montecchi M. Approximated method for modelling hemispherical reflectance and evaluating near-specular reflectance of CSP mirrors. Solar Energy 2013;92:280-8.

[18] Heimsath A, Schmid T, Nitz P. Angle resolved specular reflectance measured with VLABS. Energy Procedia 2015;69:1895-9.

[19] Sallaberry F, Bello A, Burgaleta JI, Fernández-García A, Fernandez-Reche J, Gomez JA, Herrero S, Lüpfert E, Morillo R, San Vicente G, Sanchez M, Santamaria P, Ubach J, Terradillos J, Valenzuela L. Standards for components in concentrating solar thermal power plants - status of the Spanish working group. In: Proceedings of SolarPACES 2015 International Conference on Concentrating Solar Power and Chemical Energy Systems, Cape Town; 2015.

[20] Sanchez M, Burgaleta Ordoñez JI, Fernández-García A, Fernández J, Gomez JA, Luepfert E, Sallaberry F, Santamaria P, San Vicente Domingo MG, Sutter F, Valenzuela L. Standards For Components In Concentrating Solar Thermal Power Plants - Status Of The Spanish Standardization Committee. In: Proceedings of First EERA Conference 2016, Birmingham; 2016.

[21] Sallaberry F, Fernández-García A, Lüpfert E, Morales A, San Vicente G, Sutter F. Towards standardized testing methodologies for optical properties of components in concentrating solar thermal power plants. In: Proceedings of SolarPACES 2016 International Conference on Concentrating Solar Power and Chemical Energy Systems, Abu Dhabi; 2016.

[22] Sarver T, Al-Qaraghuli A, Kazmerski L. A comprehensive review of the impact of dust on the use of solar energy: History, investigations, results, literature, and mitigation approaches. Renew Sust Energy Rev 2013;22:698-733.

[23] http://www.nrel.gov/csp/solarpaces/by_project.cfm.

[24] Pettit RB, Freese JM. Wavelength dependent scattering caused by dust accumulation on solar mirrors. Sol Energy Mat 1980;3:1-20.

[25] UNE 206009. Solar thermal electric plants. Terminology. (In Spanish: Centrales termo solares. Terminología). Madrid: Spanish Committee for Standardization (AENOR); 2013.

[26] EN ISO 9488. Solar Energy - Vocabulary. Brussels: European Committee for 
Standardization (CEN); 1999.

[27] ASTM E903-12. Standard Test Method for Solar Absorptance, Reflectance, and Transmittance of Materials Using Integrating Spheres. West Conshohocken: American Society for Testing and Materials (ASTM); 2012.

[28] ISO 9050. Glass in building, Determination of light transmittance, solar direct transmittance, total solar energy transmittance, ultraviolet transmittance and related glazing factors. Geneva: International Organization for Standardization (ISO); 2003.

[29] Pettit RB. Characterization of the Reflected Beam Profile of Solar Mirror Materials. Solar Energy 1977;19:733-9.

[30] Petitt RB, Vittitoe CN, Biggs F. Simplified Calculational Procedure for Determining the Amount of Intercepted Sunlight in an Imaging Solar Concentrator. J. Sol. Energy Eng. 1983;1:101-6.

[31] Heimsath A, Kutscheidt G and Nitz P. Detailed optical characterization of reflector materials for CSP applications. In: Proceedings of SolarPACES 2010 International Conference on Concentrating Solar Power and Chemical Energy Systems, Perpignan; 2010.

[32] Beckman P, Spizzichino A. The Scattering of Electromagnetic Waves from Rough Surfaces. New York: Pergamon; 1963.

[33] Perkin Elmer. High Performance Lambda Spectrophotometers. Hardware Guide. United Kingdom: Perkin Elmer; 2007.

[34] Storm SL, Art Springsteen A. The Integrating Sphere Reflectance Accessory. Labsphere Application Note No. 03.

[35] Sphere Optics. Integrating Sphere Design and Applications. Technical information. Sphere Optics; 2007.

[36] Perkin-Elmer. Reflectance measurements of material used in the solar industry. Selecting the Appropriate Accessories for UV/Vis/NIR Measurements. Waltham: Perkin Elmer; 2009.

[37]Labsphere. A Guide to Integrating Sphere Theory and Applications. Labsphere Techguide; 2008. 
[38] Goebel DG. Generalized Integrating-Sphere Theory. Applied Optics 1967;6(1):1254.

[39] Polato P, Masetti E. Reflectance measurements of second-surface mirrors using commercial spectrophotometer accessories. Sol Energy 1998;41(5):443-452.

[40] Kennedy CE, Terwilliger K. Optical durability of candidate solar reflectors. J Sol Energy Eng Trans ASME 2005;127(2):262-9.

[41] Fernández-García A, Cantos-Soto ME, Röger M, Wieckert C, Hutter C, MartínezArcos L. Durability of solar reflector materials for secondary concentrators used in CSP systems. Sol Energy Mater Sol Cells 2014;130:51-63.

[42] Sutter F, Fernández-García A, Wette J, Heller P. Comparison and evaluation of accelerated aging tests for reflectors. Energy Procedia 2014;49:1718-27.

[43] Brogren M, Karlsson B, Roos A, Werner A. Analysis of the effects of outdoor and accelerated ageing on the optical properties of reflector materials for solar energy applications. Sol Energy Mater Sol Cells 2004;82:491-515.

[44] Taylor JL. Design Considerations of Small $(60 \mathrm{~mm})$ Vs. Large $(150 \mathrm{~mm})$ Integrating Spheres. Application Note. Shelton: Perkin Elmer; 2010.

[45] Meyen S, Fernández-García A, Kennedy C, Lüpfert E. Standardization of solar mirror reflectance measurements - Round Robin Test. In: Proceedings of SolarPACES 2010 International Conference on Electricity, Fuels and Clean Water Powered by the Sun, Perpignan; 2010.

[46] Universal Reflectance Accessory. User's Guide. Beaconsfield: Perkin Elmer; 2006.

[47] Design Considerations for a Variable Angle Absolute Reflectance Accessory For the LAMBDA 950/850/650 UV/Vis/NIR and UV/Vis Spectrophotometers. Application note. Shelton: PE; 2004.

[48] Sutter F, Meyen S, Fernández-García A, Heller P. Spectral characterization of specular reflectance of solar mirrors. Sol Energy Mater Sol Cells 2016;145:248254.

[49] OMT Solutions BV, ARTA - Technical Description, 2010.

[50] Yu Z, Holman Z, O’Neill M, Lynch C. Full-Spectrum, Angle-Resolved Reflectance and Transmittance of Optical Coatings Using the LAMBDA 950/1050 
UV/VIS/NIR Spectrophotometer with the ARTA Accessory. Tech note. Waltham: Perkin Elmer; 2015.

[51] Van Nijnatten PA. Measurement Techniques for Solar Energy Properties of Glazing. In: Proceedings of World renewable Congress VI, Brighton; 2000.

[52] Raccurt O, Delord C, Bouquet C, Couturier R. Correlation between solar mirror degradation and colorimetric measurement of protective back layer. Energy Procedia 2014;49:1700-7.

[53] Girard R, Delord C, Disdier A, Raccurt O. Critical constraints responsible to solar glass mirror degradation. Energy Procedia 2015;68:1519-1528.

[54] Agilent technologies. Agilent Cary 4000/5000/6000i series UV-VIS-NIR spectrophotometers. User's Guide. 2013.

[55] Optronic laboratories, INC. OL series 750. Automated spectroradiometric measurement system. 2001.

[56] OL 740-70 Integrating Sphere Reflectance Attachment Manual No: M000131. 2003.

[57] http://www.jasco.co.uk/UV_Visible_NIR_spectrophotometer.php.

[58] Sansom CL, Comley P, Bhattacharyya D, Macerol N. A comparison of polymer film and glass collectors for concentrating solar power. Energy Procedia 2014;49:209-19.

[59] Sansom C, Fernández-García A, Sutter F, Almond H, King P. Contact Cleaning of Polymer Film Solar Reflectors. In: Proceedings of SolarPACES 2015 International Conference on Concentrating Solar Power and Chemical Energy Systems, Cape Town; 2015.

[60]Devices and Services. Portable Specular Reflectometer Model 15R-USB. Operation and Maintenance Manual. Dallas: Devices and Services (D\&S); 2009.

[61] Devices and Services. Portable Specular Reflectometer Model 15R-USB. Operating Instructions. Dallas: Devices and Services (D\&S); 2009.

[62]Fernández-García A, Álvarez-Rodrigo L, Martínez-Arcos L, Aguiar R, MárquezPayés JM. Study of different cleaning methods for solar reflectors used in CSP plants. Energy Procedia 2014;49:80-89. 
[63] Karim M, Naamane S, Delord C, Bennouna A. Laboratory simulation of the surface erosion of solar glass mirrors. Sol Energy 2015;118:520-32.

[64] Merrouni AA, Wolfertstetter F, Mezrhab A, Wilbert S, Pitz-Paal R. Investigation of soiling effect on different solar mirror materials under Morroccan climate. Energy Procedia 2015;69:1948-1957.

[65]Bouaddi S, Ihlal A, Fernández-García A. Soiled CSP solar reflectors modelling using dynamic linear models. Solar Energy 2015;122:847-863.

[66] Bouaddi S, Ihlal A, Fernández-García A. Comparative analysis of soiling of CSP mirror materials in arid zones. Renew Energy 2017;101:437-449.

[67] Wiesinger F, Sutter F, Fernández-García A, Reinhold J, Pitz-Paal R. Sand erosion on solar reflectors: accelerated simulation and comparison with field data. Sol Energy Mater Sol Cells 2016;145:303-3013.

[68] Tahboub ZM, Bahleh B, Goebel O. Solar mirrors soiling campaign- Abu Dhabi. In: Proceedings of SolarPACES 2012, International Conference on Concentrating Solar Power and Chemical Energy Systems. Marrakech; 2012.

[69]Devices and Services. Multiple wavelength portable specular reflectometer 15RRGB specification sheet. Dallas: Devices and Services (D\&S); 2013.

[70] Maurer P, Meyen S, Fernández-García A. Comparison between Multiple Wavelength Reflectometer and Standard Reflectometer by Devices and Services. Tech. Report OPAC-OA_201211_New Instrument. Almería: OPAC; 2012.

[71] Martinez N, Navio R, Heras C, Salinas I, Mainar M. A New Portable Specular Reflectometer, Condor: Description, laboratory and field tests. Energy Procedia 2015;69:1948-1957.

[72] Salinas I, Heras C, Alcañiz C, Izquierdo D, Martínez N, Alonso R. Portable Solar Spectrum Reflectometer for planar and parabolic mirrors in solar thermal energy plants. Solar Energy 2016;135:446-454.

[73] Sansom CL, Comley P, King P, Almond HJ, Atkinson C, Endaya E. Predicting the effects of sand erosion on collector surfaces in CSP plants. Energy Procedia 2015;69:198-207.

[74] Surface Optics. 410 Solar Visible/NIR Hand-Held Reflectometer. Technical information. San Diego: Surface Optics Corporation; 2010.

[75]Beecroft MT, Szczesniak MM, Smith BJ, Fujima Matsumoto J, Ferguson JP. Handheld spectrometer. US Patent 7236243 B2. 
[76]Crawford J, Stewart J, Pérez-Ullivarri J. A Comparison of Three Portable Reflectometers for Use in Operations and Maintenance of CSP Plants. In: Proceedings of SolarPACES 2012, International Conference on Concentrating Solar Power and Chemical Energy Systems. Marrakech; 2012.

[77] Konica Minolta. Spectrophotometer 700d/600d. Instruction Manual. Konica Minolta Sensing Inc; 2007.

[78] SMS. $\mu$ ScanTM Scatterometer. User's Manual. Oregon: Schmitt Measurement Systems, Inc; 1998.

[79] Fernández-GarcíaA. Estudio de la reflectancia especular en plantas de captadores solares cilindroparabólicos. Madrid: CIEMAT; 2012. ISBN: 978-84-7834-672-1.

[80]PFlex. A new portable soiling/cleanliness handheld reflectometer. Freiburg: PSE AG; 2016.

[81] Heimsath A, Heck M, Morin G, Kiewitt W, Platzer W. Soiling of aluminum and glass mirrors under different climatic conditions and techno-economic optimization of cleaning intervals. In: Proceedings of SolarPACES 2010, International Conference on Electricity, Fuels and Clean Water Powered by the Sun. Perpignan; 2010.

[82] Solar Mirror Soiling Measurement. Refined solar resource assessment with Tracking Cleanliness Sensor (“TraCS”). Almería: CSP Services; 2016.

[83] Wolfertstetter F, Pottler K, Alami Merrouni A, Mezrhab A, Pitz-Paal R. A Novel Method for Automatic Real-Time Monitoring of Mirror Soiling Rates. In: Proceedings of SolarPACES 2012, International Conference on Concentrating Solar Power and Chemical Energy Systems. Marrakech; 2012.

[84] Wolfertstetter F, Pottler K, Geuder N, Affolter R, Merrouni AA, Mezrhab A, PitzPaal R. Monitoring of mirror and sensor soling with TraCS for improved quality of ground based irradiance measurements. Energy Procedia 2014;49:2422-2432.

[85] Sengupta M, Habte A, Kurtz S, Dobos A, Wilbert S, et al. Best Practices Handbook for the Collection and Use of Solar Resource Data for Solar Energy Applications. Technical Report Rep. NREL/TP-5D00-63112. Denver West Parkway: NREL; 2015.

[86] Wolfertstetter F. Auswirkungen von Verschmutzung auf Parabolrinnenkraftwerke. Aachen University PhD thesis; to be published in 2017. 
[87] Sutter F, Fernández-García A, Heller P, Kennedy C, Pitz-Paal R, Schmücker M. A new method to characterize degradation of first surface aluminum reflectors. In: Proceedings of SolarPACES 2010, International Conference on Electricity, Fuels and Clean Water Powered by the Sun. Perpignan; 2010.

[88] Sutter F, Heller P, Fernandez-García A, Kennedy C, López-Martín R, Meyen S, PitzPaal R. Methods for service life time estimation of aluminum reflectors. In: Proceedings of SolarPACES 2011, International Conference on Concentrating Solar Power and Chemical Energy Systems. Granada; 2011.

[89] Sutter F, Ziegler F, Schmücker M, Heller P, Pitz-Paal R. Modelling of optical durability of enhanced aluminum solar reflectors. J. Sol. Energy Mater. Sol. Cells 2012;107:37-45.

[90]Montecchi M. Upgrading the ENEA Solar Mirror Qualification Set-up. Energy Procedia 2014;49:2154-2161.

[91]Chen YT, Lim H, Lim CS, Chong KK, Tan BK. High precision (1 part in 104) reflectivity measurement for the study of reflective materials used in solar collectors. Sol Energy Mater Sol Cells 2003;80:305-314.

[92] Meyen S, Sutter S, Heller P. Near specular scatter analysis method with a new goniophotometer. In: Proceedings of the SPIE Optics and Photonics Conference. San Diego; 2014.

[93] Meyen S, Sutter S, Heller P, Oschepkov A. A new instrument for measuring the reflectance distribution function of solar reflector materials. Energy Procedia 2014;49:2145 - 2153.

[94]Calvo R, Cantero D. A new high sensitivity and low cost solution for the measurement of reflectance loss due to dust deposition in solar collectors. In: Proceedings of SolarPACES 2013, International Conference on Concentrating Solar Power and Chemical Energy Systems. Las Vegas; 2013.

[95] Schmid T, Heimsath A, Hornung T, Nitz P. Specularity of concentrator mirrors for CPV measured with VLABS. SolarPACES 2015. AIP Conference Proceedings 2016;1679:070004.

[96]Heimsath A, Lindner P, Klimm E, Schmid T, Ordonez Moreno K, Elon Y, AmShallem M, Nitz P. Specular reflectance of soiled glass mirrors - Study on the impact 
of incidence angles. SolarPACES 2015. AIP Conference Proceedings 2016;1734:130009. 
2017-04-06

\section{Equipment and methods for measuring reflectance of concentrating solar reflector materials}

Fernandez-Garcia, Aranzazu

Elsevier

Aránzazu Fernández-García, Florian Sutter, Lucía Martínez-Arcos, Christopher Sansom, Fabian Wolfertstetter, Christine Delord, Equipment and methods for measuring reflectance of concentrating solar reflector materials, Solar Energy Materials and Solar Cells, Volume 167, August 2017, Pages 28-52 http://dx.doi.org/10.1016/j.solmat.2017.03.036

Downloaded from Cranfield Library Services E-Repository 